
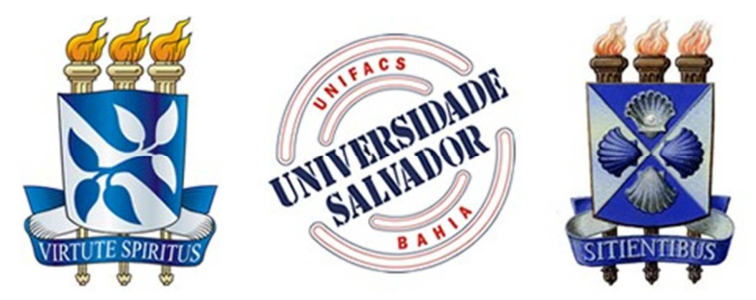

Programa Multiinstitucional de Pós-Graduação em Ciência da ComputaçãoPMCC

\title{
A METHOD TO SUPPORT THE ADOPTION OF REUSE TECHNOLOGY IN LARGE SOFTWARE ORGANIZATIONS
}

Luiz Augusto Matos de Amorim

D. Sc. Thesis 


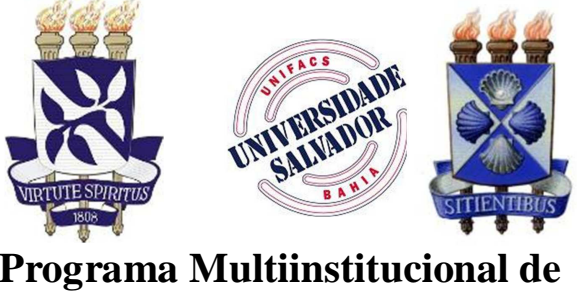

Pós-Graduação em Ciência da Computação - PMCC

PMCC-IM-UFBA, Campus de Ondina

Av. Adhemar de Barros S/N, Salvador - Bahia, CEP 40.170-110

dmcc@ufba.br

http://dmcc.dcc.ufba.br 


\section{LUIZ AUGUSTO MATOS DE AMORIM}

\section{A METHOD TO SUPPORT THE ADOPTION OF REUSE TECHNOLOGY IN LARGE SOFTWARE ORGANIZATIONS}

D.Sc. Thesis presented to the Multiinstitutional Graduate Program in Computer Science at Federal University of Bahia, Salvador University, and Feira de Santana State University in partial fulfillment of the requirements for the degree of Doctor of Science Computer.

Advisor: Prof. Manoel Gomes de Mendonça Neto

SALVADOR

May/2016 
LUIZ AUGUSTO MATOS DE AMORIM

A METHOD TO SUPPORT THE ADOPTION OF REUSE TECHNOLOGY IN LARGE SOFTWARE ORGANIZATIONS

Tese apresentada ao Programa Multiinstitucional de Pós-Graduação em Ciência da Computação da Universidade Federal da Bahia, Universidade Salvador e Universidade Estadual de Feira de Santana, como requisito parcial à obtenção do título de Doutor em Ciência da Computação.

Orientador: Prof. Dr. Manoel Gomes de Mendonça Neto

Salvador

2016 
Amorim, Luiz Augusto Matos de

A Method to support the adoption of reuse technology in large software organizations / Luiz Augusto Matos de Amorim. - - Salvador, 2016.

196 f.: il

Orientador: Manoel Gomes de Mendonça Neto

Tese (Doutorado - Doutorado Multiinstitucional em Ciência da Computação) - - Universidade Federal da Bahia, Universidade Federal da Bahia, 2016.

1. Engenharia de Software. 2. Reuso de Software. 3. Adoção de tecnologia de software. 4. Sistema de Crenças e Conhecimento. 5. Re-significação de crenças. I. Mendonça, Manoel Gomes de. II. Titulo 


\title{
LUIZ AUGUSTO MATOS DE AMORIM
}

\section{"A METHOD TO SUPPORT THE ADOPTION OF REUSE TECHNOLOGY IN LARGE SOFTWARE ORGANIZATIONS"}

\begin{abstract}
Esta tese foi julgada adequada à obtenção do título de Doutor em Ciência da Computaçáo e aprovada em sua forma final pelo Programa Multi-institucional de Pós-Graduação em Ciência da Computação da UFBA-UEFS-UNIFACS.
\end{abstract}

Salvador, 06 de maio de 2016.

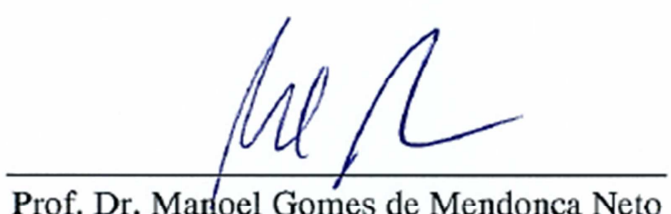

Orientador

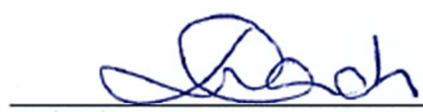

Prof. ${ }^{a}$ Dr. ${ }^{a}$ Christina von Flach Garcia Chavez

Examinadora Interna

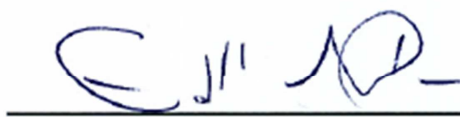

Prof. Dr. Eduardo Santana de Almeida

Examinador Interno

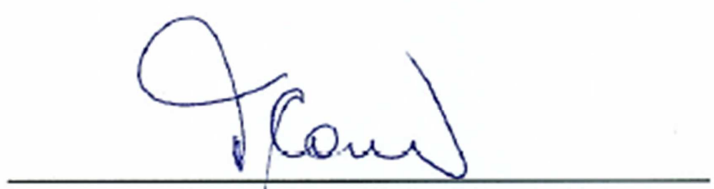

Prof. ${ }^{\text {a Dr. }}{ }^{\text {a Tayana Uchoa Conte }}$

Examinadora Externa

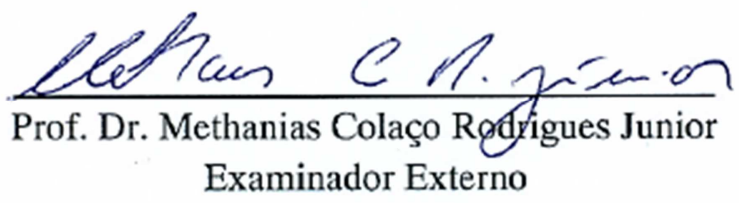

vii 


\section{RESUMO}

O processo de adoção de uma tecnologia de software em uma organização de grande porte é significativamente influenciado pela cultura organizacional e aspectos comportamentais dos profissionais envolvidos no processo. A identificação de fatores que facilitam ou dificultam este processo está fortemente correlacionada com o sistema de crenças atual e representa um elemento-chave para o planejamento desse processo. A adoção da tecnologia de reutilização de software em particular altera significativamente o processo de software da organização, bem como o modus operandi dos profissionais envolvidos. Esta tese propõe um modelo de ação baseado em classes de crenças para apoiar o processo de adoção da tecnologia de reutilização de software, fornecendo um meio para tratar as crenças que podem dificultar o processo de adoção. Um estudo de caso foi realizado em uma organização de grande porte para validar e aperfeiçoar a abordagem proposta. Como resultado deste trabalho, é proposto um método baseado na identificação de classes de crenças e re-significação daquelas que dificultam a adoção de tecnologias de reutilização de software. Também é apresentado um catalogo de crenças referentes à tecnologia de reuso de software, devidamente ponderadas quando ao impacto no processo de adoção da tecnologia, validado por um conjunto de especialistas da área de reuso de software.

Palavras chave: Adoção de tecnologia de software; Reuso de software; Cultura organizacional; Sistema de Crenças e Conhecimento; Modelo de Ação Fundamentada; Re-significação de crenças; Prática de Desenvolvimento de Software; Estudo de Caso na Indústria. 


\begin{abstract}
The process of adopting a software technology in a large organization is significantly influenced by organizational culture and behavioral aspects of the practitioners involved in the process. The identification of factors that will facilitate or hinder this process is strongly correlated with the existing system of beliefs and represents a key element to the planning of this process. The adoption of software reuse technology in particular significantly alters the software process of the organization as well as the modus operandi of the involved practitioners. This dissertation proposes an action model based on classes of beliefs that will support the process of adoption of software reuse technology, providing a means to deal with beliefs that may hinder the adoption process. A case study was conducted in a large organization to validate and refine the proposed approach. As a result of this work, we propose a method based on the identification of classes of beliefs and re-signification of those that hinders the adoption of software reuse technologies. The dissertation also provides a catalog of beliefs weighted by the impact in the technology adoption process, validated by a group of experts in the software reuse area.
\end{abstract}

Keywords: Adoption of software technology; Software reuse; Organizational Culture; Belief System and Knowledge; Reasoned Action Model; Re-signification of beliefs; Software Development Practice; Industrial Study Case. 
To my family, my advisor, professors and friends, who gave me all the necessary support to get here. 


\section{ACKNOWLEDGEMENTS}

At this time I want to express my thanks to many people who contributed in different ways to carrying out this work.

Initially, I would like to thank my advisor Professor Manoel Mendonça, for his support, dedication and encouragement.

I would like to thank Professor Eduardo Almeida who contributed with comments, suggestions and criticisms throughout this study.

My gratitude to Professor Cristina von Flach for recommending me to Professor Manoel Mendonça, to define and plan this work.

Special thanks to my boss Luciene Souza for making this work feasible and to Petrobras for allowing and supporting the development of this project.

My thanks to all professionals and experts who participated in the interviews and interacted with me during the two year case study.

Thanks to some key Researchers in the software reuse area Bill Frakes, Claudia Werner, Eduardo Almeida, Jeff Poulin and John Favaro for sharing their important time and knowledge as participants in this work.

To all my former students, during thirty-five years of teaching at the Federal University of Bahia, my thanks for the continuous learning and constant challenges.

Thanks to my wife Sandra Meneses, for her support and exchange of knowledge in various parts of this study.

I am grateful to my son Augusto Luiz and my daughters Daniele and Michele for their constant stimulus to seek new challenges.

Finally, to everyone who contributed directly or indirectly to this work, my sincere thanks. 
"Not everything that can be counted counts, and not everything that counts can be counted"

Albert Einstein

xvii 


\section{CONTENTS}

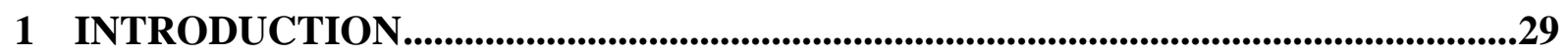

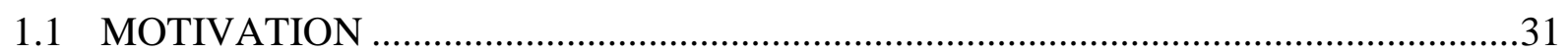

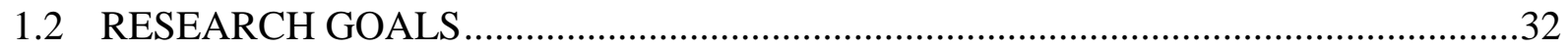

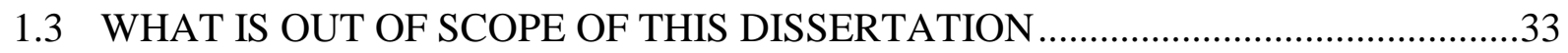

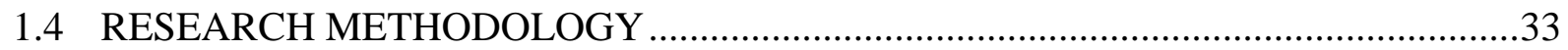

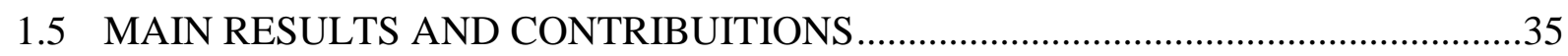

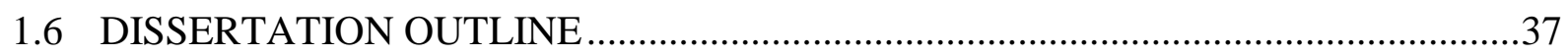

2 BACKGROUND AND RELATED WORK ................................................................39

2.1 THE ADOPTION OF NEW TECHNOLOGY IN ORGANIZATIONS .........................39

2.2 THE ADOPTION OF A SOFTWARE TECHNOLOGY ............................................43

2.3 THE ADOPTION OF SOFTWARE REUSE TECHNOLOGY ….................................46

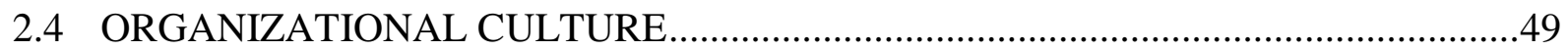

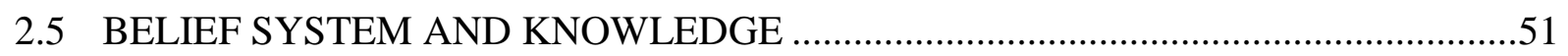

2.6 COGNITIVE MODELS THAT REPRESENT THE WAY PEOPLE ACT....................53

3 A METHOD BASED ON AN ACTION MODEL REASONED ON CLASSES OF BELIEFS TO SUPPORT THE ADOPTION OF SOFTWARE TECHNOLOGY ....61

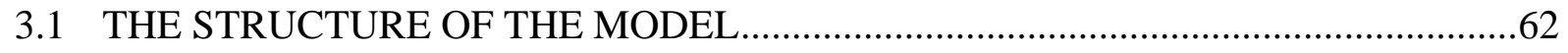

3.2 DEFINING A BASIC SET OF CLASSES OF BELIEFS ….......................................64

3.3 INSTANTIATION OF THE CLASSES OF BELIEFS FOR THE DOMAIN OF A SPECIFIC SOFTWARE TECHNOLOGY

3.4 CAPTURE OF PRACTITIONER' INTENTIONS IN A SOFTWARE ORGANIZATION

3.5 RE-SIGNIFICATION OF BELIEFS

4 INSTANTIATING A BELIEFS CATALOG FOR SOFTWARE REUSE TECHNOLOGY ADOPTION IN A LARGE ORGANIZATION .......................................77

4.1 IDENTIFICATION OF BELIEFS TO REUSE ADOPTION ........................................78

4.2 MAPPING THE BELIEFS SYSTEM OF THE PRACTITIONERS INVOLVED IN A REUSE PROCESS ADOPTION 
4.3 APPLICATION PROCESS OF THE METHOD PROPOSED TO SUPPORT THE ADOPTION OF SOFTWARE REUSE TECHNOLOGY

5 APPLICATION OF THE METHOD FOR THE PROCESS OF ADOPTION OF REUSE TECHNOLOGY IN A LARGE ORGANIZATION - A CASE STUDY WITH ETHNOGRAPHY .94

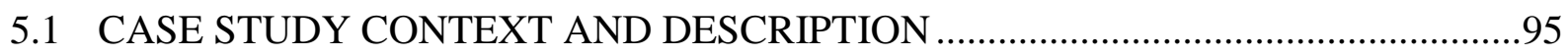

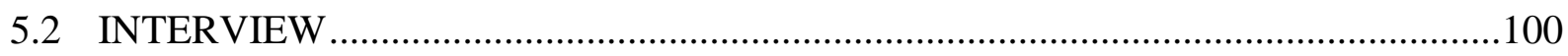

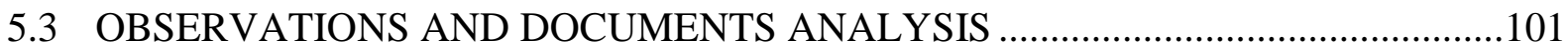

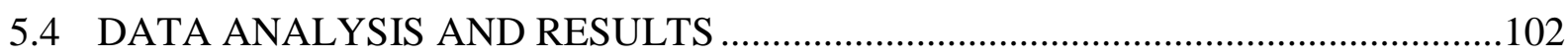

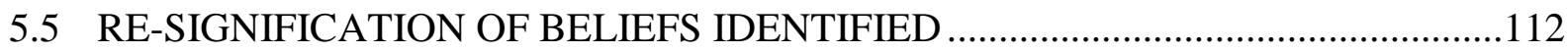

5.6 SIGNIFICANT OBSERVATIONS RECORDED DURING THE ADOPTION

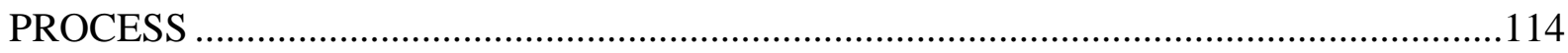

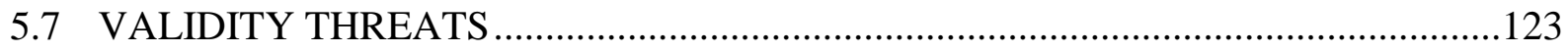

6 A STANDARD CATALOG OF BELIEFS TO SUPPORT SOFTWARE REUSE

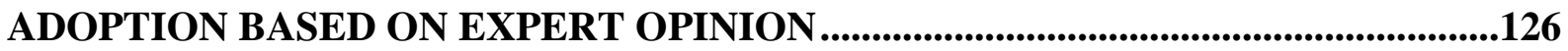

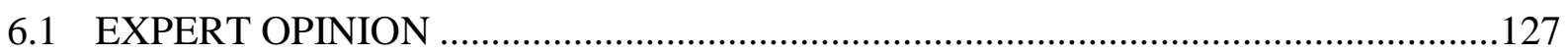

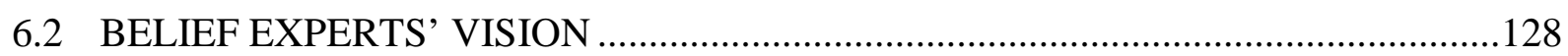

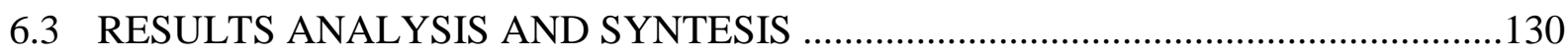

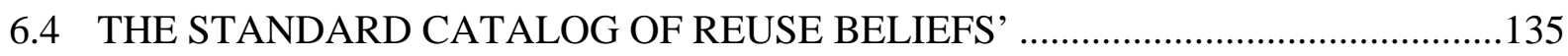

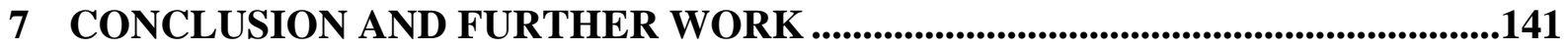

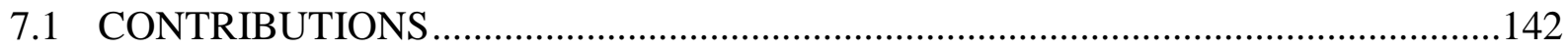

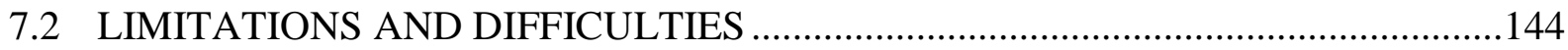

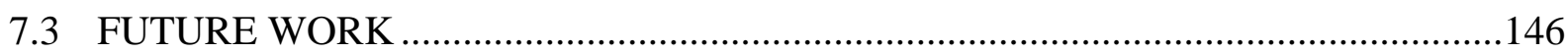

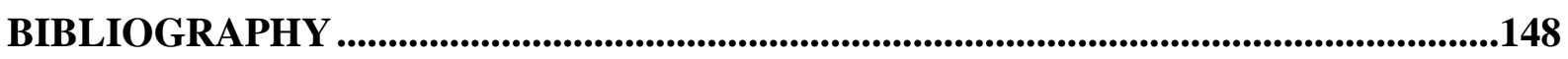

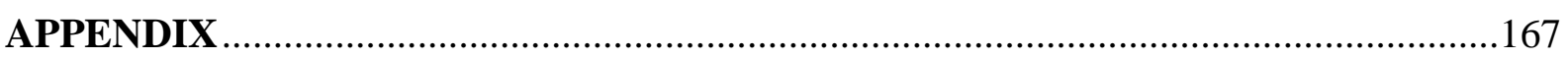

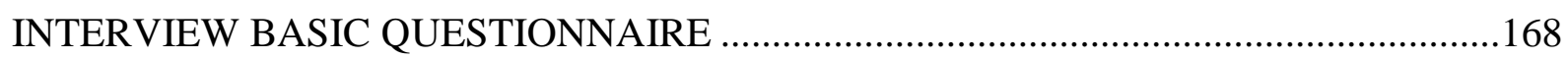

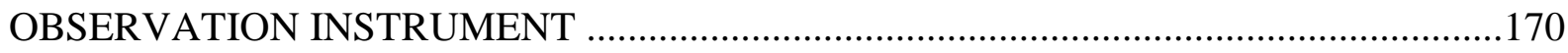

EXPERT OPNIONS OF THE CLASSES OF BELIEFS AND BELIEFS ...........................171

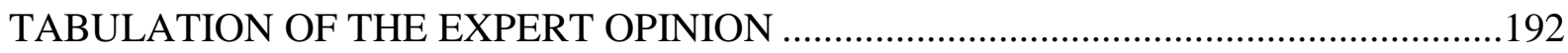




\section{LIST OF FIGURES}

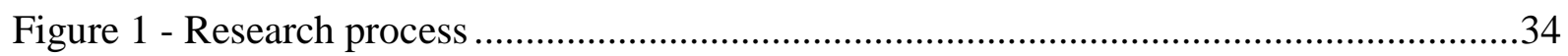

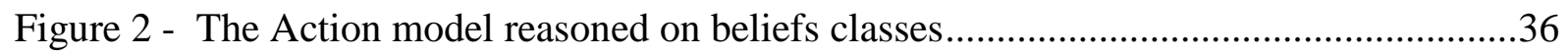

Figure 3 - A Conceptual Framework for Technology Transition ...........................................40

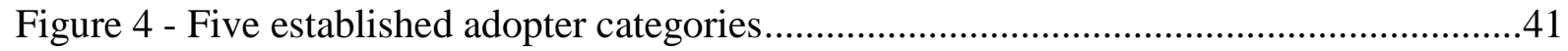

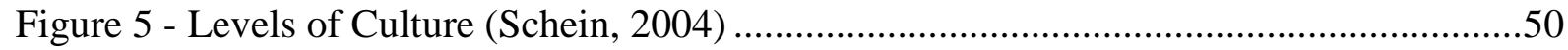

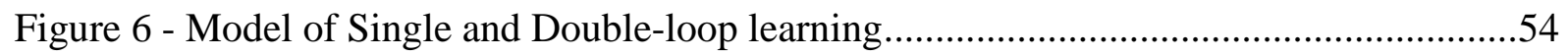

Figure 7 - Conceptual framework of TRA - (Fishbein \& Ajzen, 1975) ..................................55

Figure 8 - Schematic presentation of the model Reasoned..................................................57

Figure 9 - Basic structure of our Action model ..................................................................62

Figure 10 - Refined action model to support the adoption of software technology ................64

Figure 11 - Action model reasoned on beliefs classes.........................................................67

Figure 12 - Treatment of identified beliefs refer to adoption .............................................. 71

Figure 13 - The complete Action model reasoned on beliefs classes ....................................75

Figure 14 - Form to support the structured interview ...........................................................90

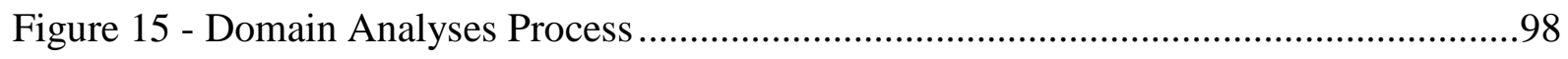

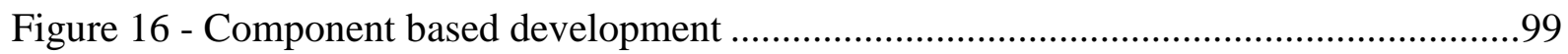




\section{LIST OF TABLES}

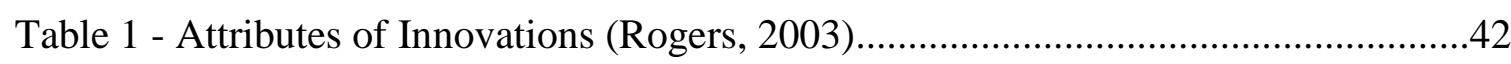

Table 2 - Types of beliefs from models..........................................63

Table 3 - Intention Determinants from Models and Theories presented...........................66

Table 4 - Example reuse beliefs identification from the literature...................................79

Table 5- Beliefs identification from experts interviews analysis.....................................82

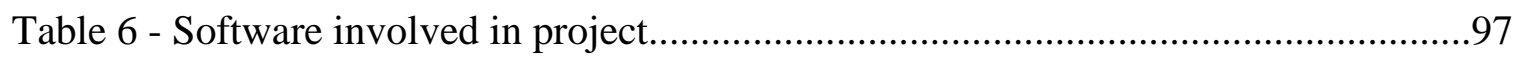

Table 7- Fragment of the Interview's transcription and analysis......................103

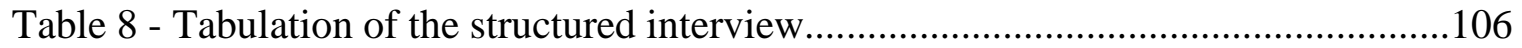

Table 9 - Quality attributes for components certification........................................120

Table 10 - List of experts that participate in the study.............................. 130

Table 11 - Standard catalog of weighted beliefs...................................136 


\section{GLOSSARY OF TERMS}

Software technology Methods, techniques, and tools used in software development and software evolution.

Software reuse The process of creating software systems from existing software rather than building them from scratch

Technology adoption Insertion of a new technology in most organizations that perform similar task. 
xxvi 


\section{ACRONYMS}

CFRP

CMM

CMMI

IEC

IEEE

ISO

OC

RISE

RiSE-CBD

RiSE-DA

SE

SEI

SPC

SPI

SPICE

SWEBOK

TAM

TBP

TPB

TRA
Conceptual Framework for Reuse Processes

Capability Maturity Mode

Capability Maturity Model Integration

International Electrotechnical Commission

Institute of Electrical and Electronics Engineers

International Organization for Standardization

Organizational Culture

Reuse in Software Engineering Labs

RiSE Component Based Development

RiSE Domain Analyses

Software Engineering

Software Engineering Institute

Software Productivity Consortium

Software Process Improvement

Software Process Improvement and Capability Determination

Software Engineering Body of Knowledge

Technology Acceptance Model

Theory of Behavioral Prediction

Theory of Planned Behavior

Theory of Reasoned Action

xxvii 
xxviii 


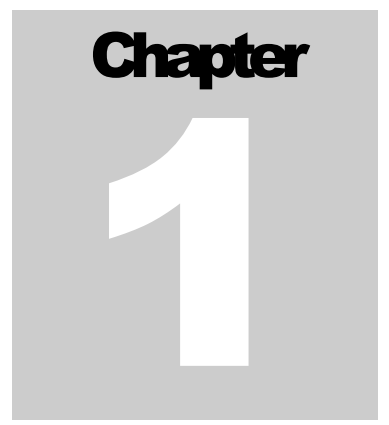

This chapter presents the motivation of this work, including key aspects from the literature, the research problem goals and approach. It ends by introducing the main research results highlighting the contributions of this thesis.

\section{INTRODUCTION}

The adoption of a new technology is an innovation process for the organization and is strongly related to organizational learning and directly interferes with its human resources. Organizational learning that integrates individual learning is a vital factor to increase the practice of innovation in organizations (Song \& Chermack, 2008).

Technology adoption within software organizations involves cognitive and social aspects that permeate the engineers, team leaders, practitioners and users involved in the software engineering activities.

Beliefs are propositions or premises - or even a formed opinion or conviction - that an individual holds as true (Schwitzgebel, 2006). The basis of models referring to mental processes that affect people's behavior is their belief system. This beliefs system also significantly influences their position facing a change in an organizational process (Passos at al., 2013) (Wernick \& Hall, 2004). Understanding belief system can significantly help to influence technology acceptance.

The adoption of reuse technology in a large organization significantly changes the software process of the organization as well as the modus operandi of the technicians involved. Thus, human and organizational obstacles often outweigh the 
technical obstacles in this context (Sametinger, 1997). Knowing and treating these obstacles is, therefore, an important step during the adoption of reuse technology, in order to minimize the risks of failure in technology adoption.

In this work, we developed a systematic way to identify and treat factors that facilitate or hinder the adoption of reuse practices in large software organizations. Our approach is based on the study of the underlining belief systems, from the practitioners involved in the process.

All our research is developed through qualitative studies in an industrial setting, a software division of a very large organization. The acquisition and organization of knowledge through the use of empirical methods have become increasingly present in the field of software engineering enabling the understanding of various factors involved in the area, trying to make it more predictable and manageable (Basili et al., 2006 ) (Hofer \& Tichy, 2007) (Sjoberg et al., 2005). The use of an industrial organization setting is a key factor to improve external validity of empirical studies in software engineering (Wohlin et al, 2012). This type of environment provides real processes, significant scale and realistic settings for studies. The use of qualitative methods is more suitable to this type of study and setting. The real world environment is more difficult to control and demands a more constructivist approach where data is collected by reviews and interviews, as opposed as, quantitative measures. In particular, we used an ethnographic approach where one of the researches was inserted in the studied environment during a major effort of reuse technology adoption.

The main contribution of this work is to present a method based on the identification of classes of beliefs to support the process of adoption of reuse technology in a large organization and a catalog of beliefs referring to the reuse technology. We used an approach of re-signification of beliefs that may represent a risk to the technology adoption process. The work is focused on the adoption of software reuse technology, but we also suggest how to extend the use of this method to help the adoption of others software technologies. 


\subsection{MOTIVATION}

The process of software development and evolution is essentially based on human activities. The adoption of a new software technology changes the skills of practitioners, organizational structures and procedures, requiring the definition of the most appropriate strategies for the organization's culture (Shenhar \& Adler, 1990).

Therefore, the human factor - individual characteristics - plays a key role on software technology adoption, facilitating or hindering each adoption process. Several are the strategies used to manage human factors during the software technology adoption processes, all of them based on a high degree of intuition and subjectivity.

Many researchers have contributed to understanding the role of human and social factors for the successful implementation of new technologies in organizations (Chuttur, 2009). What are, specifically the factors involved in the adoption of new software technologies in organizations, to make the process of acceptance of these technologies more predictable?

Practitioners in the field of software engineering usually take technological decisions based on feelings, without using a structured means, such as a paradigm based on evidence to support their decisions. These practitioners use the filter of their beliefs to guide their behavior.

The knowledge of the beliefs system of these practitioners, defining means to map these beliefs and the use of tools to interfere in those beliefs through the resignification of the beliefs that cause difficulties, presents itself as an effective means to support the adoption process of a new technology.

In this work, we use existing theoretical models on the way people act based on their beliefs to develop a method to support the process of adoption of software technologies in large organizations. This method aims to provide means to help organizations deal with the main hindering human factors of this process and reduce the risks involved in adopting new technologies. We had the opportunity to experiment, improve and validate the method in a real case of adoption of reuse technology in a large organization. 


\subsection{RESEARCH GOALS}

The main goal of this work is to propose a method founded on an action model based on classes of beliefs to support the process of adoption of software reuse technology. This method shall allow for the identification and evaluation of the beliefs system of practitioners involved, providing a means to deal with the beliefs that may hinder the adoption process. A process of re-signification beliefs shall allow the treatment in a structured manner of the main factors that may put at risk the adoption process.

The goals of this research are expressed by answering the following research questions:

- RQ1: What factors facilitate or hinder the adoption, acceptance, deployment and use of software reuse practices in a large organization?

- RQ 2: How do you to treat these factors to facilitate the process of technology adoption?

- RQ 3: How to generalize the empirical results obtained, in a model that will support the adoption practices of software reuse technologies in large organizations?

To answer the research question RQ1, it is necessary to develop a method to assist the process of mapping the belief system regarding the reuse of technology between software practitioners involved in the process of adoption of the technology, based on an action model reasoned on beliefs classes. To answer the research question RQ2 these beliefs are processed and properly classified so that all beliefs that cause difficulties to the adoption process are treated through specific re-signification techniques, involving specific groups and technicians. To answer the research question RQ3, the set of beliefs mapped during the research project and validated in the ethnographic case study are submitted to analysis of researchers, which will enable the preparation of a catalog of generic reuse beliefs with beliefs properly weighted by degree of impact. This catalog will serve as a tool to support the processes of adoption of software reuse technology in organizations at large. 


\subsection{WHAT IS OUT OF SCOPE OF THIS DISSERTATION}

This work only proposes a method to identify and re-signify the beliefs of the practitioners involved in the adoption process of software reuse technology in large organizations in order to reduce the risk of failure in implementation.

The following issues are not directly addressed by this work:

- The selection process of the technology to be adopted and the belief systems of those responsible for this definition.

- The belief systems of the management level of the organization in which the technology will be adopted with the necessary resignification.

- How to deal with the organization's management aspects at the highest level of the group responsible for the technology adoption project, which will hinder the adoption process.

\subsection{RESEARCH METHODOLOGY}

To achieve the objectives of this work we structure our research process by dividing it into three phases. Each phase (A, B and C) contains a set of specific activities as seen in the Figure 1: 


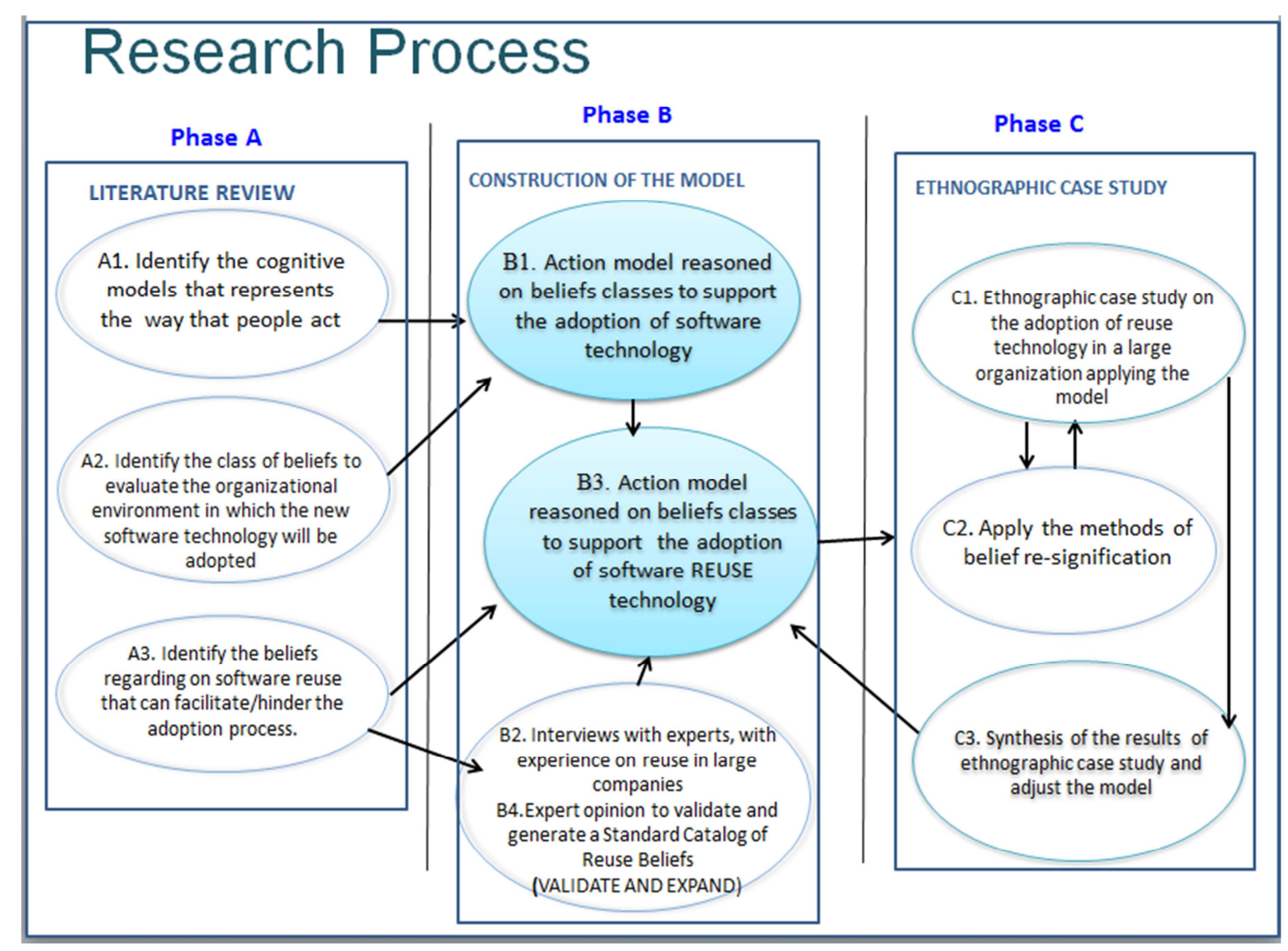

Figure 1 - Research process

In phase $\mathbf{A}$, we conducted a literature review aimed at covering two main objectives: To identify the cognitive models that represent the way people act, and then to identify the class of beliefs to evaluate the organizational environment in which the new software technology will be adopted.

Then we reviewed the literature to identify the beliefs regarding the software reuse that can facilitate or hinder the adoption process in order to instantiate the model generated to phase $\mathrm{B}$, for software reuse technology.

In phase $\mathbf{B}$, from the literature review, we decided to use the action model reasoned on classes of beliefs to support the adoption of software technology. Then this model was instantiated to the adoption process of reuse technology by using the results of the literature review A3. Also in this phase, the identified beliefs were validated and expanded through interviews with the reuse experts of a large company.

In phase $\mathbf{C}$ we ran the long-term ethnographic case study on the adoption of reuse technology in a large organization, applying the model. A group of technicians 
involved in the adoption process had mapped and analyzed their belief system on reuse technology using semi-structured interviews. Then we applied the methods of belief resignification proposed in the model. The results of the ethnographic study were then analyzed and the model was enhanced.

After the conclusion of the three previous steps, we submitted the model of belief classes to a group of experienced researchers from the software reuse area, in order to validate the identified beliefs, validate the classification of these beliefs in the presented classes, verify the possible existence of other significant beliefs and obtain an assessment of the degree of impact of each of these beliefs in the process of technology adoption. The results were analyzed and processed to produce a catalog of weighted beliefs related to adoption of software reuse technology in a large organization.

\subsection{MAIN RESULTS AND CONTRIBUITIONS}

This work presents a method to support the process of software reuse technology adoption in a large organization, based on the identification of belief systems indicators of a potential behavior in the technology adoption process. The proposed model called action model reasoned on classes of beliefs is represented in Figure 2: 


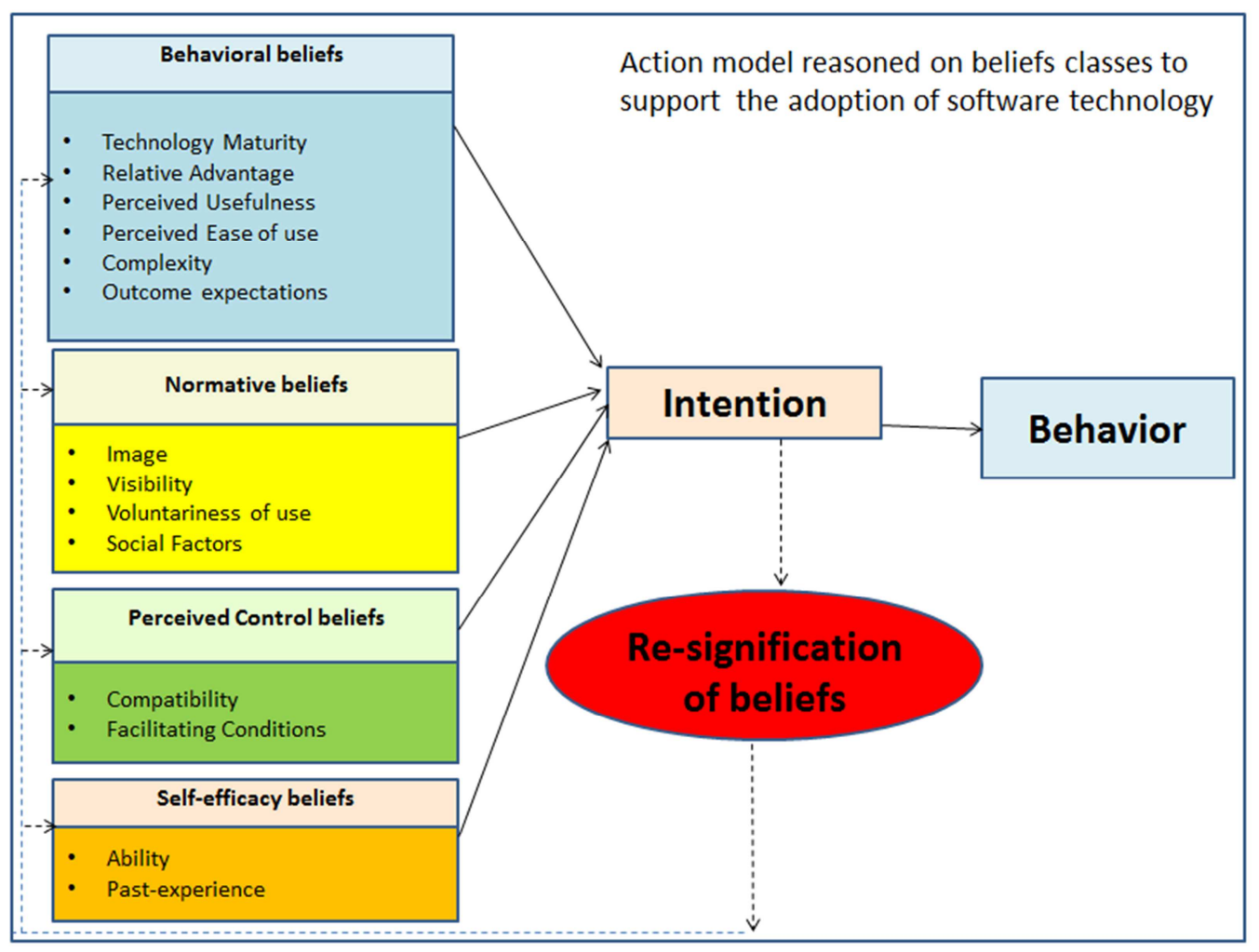

Figure 2 - The Action model reasoned on classes of beliefs

Together with this model, a beliefs identification method for the adoption of reuse technology is provided. An instrument that supports the achievement of semistructured interviews proposed in the method is also defined.

A long term ethnography case study conducted during the adoption of reuse technology in a large organization is presented. The process of application and validation of the method proposed in this case study is described, as is emphasized with the mapping and treatment of belief systems of the practitioners involved in the adoption process. The application of re-signification techniques of the beliefs identified as potential difficulties to the process is shown together with the results obtained.

A catalog of reuse beliefs to support technology adoption is presented after conducting the validation of the identified beliefs with a set of experienced software reuse researchers. These experts also evaluate the impact of each of these beliefs in the technology adoption process. 


\subsection{DISSERTATION OUTLINE}

After this introductory chapter, which describes the motivation, goals and scope of the research, this document is organized as follows:

- CHAPTER 2 - presents the theoretical background and literature review on the topic, describing an overview of the software technology adoption problems and discussing the major cognitive models that represent the way people act based on their beliefs.

- CHAPTER 3 - presents the framework for our method, proposing a model of reasoned action based on classes of beliefs to support the adoption of software technology, defining the main classes of software technology adoption beliefs and a process of re-signification of those beliefs.

- CHAPTER 4 - presents the instantiation of our framework to the adoption of software reuse technology, identifying a belief base regarding this technology through the use of literature reviews in conjunction with interviews with experts.

- CHAPTER 5 - presents an ethnographic case study, developed over two years, regarding the adoption of software reuse technology in a large organization. In this study, the model of reasoned action based on classes of beliefs proposed in Chapter 4 is applied, evaluated and refined.

- CHAPTER 6 - presents the process of validating the software reuse beliefs, and its classification by experts in the area, generating a catalog of reuse beliefs with their impacts on the technology adoption process. 
- CHAPTER 7 - presents the main conclusions and discusses the way that the research questions were answered in this dissertation. It also discusses possible future research in the dissertation subject. 


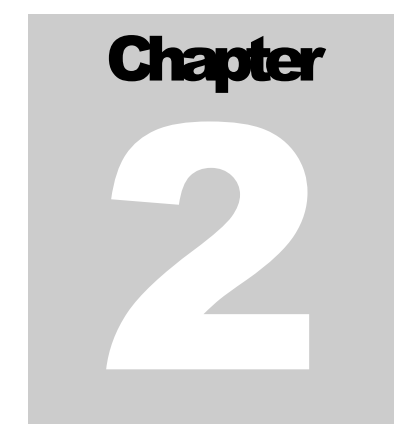

This chapter provides an overview of the foundations for this work and presents the main aspects involved in the process of adoption of new technologies in general and software reuse technologies in particular. It also discusses organizational culture, belief systems and cognitive models that represent the way people act, highlighting the most significant factors related to the adoption of software reuse technology.

\section{BACKGROUND AND RELATED WORK}

\subsection{THE ADOPTION OF NEW TECHNOLOGY IN ORGANIZATIONS}

Organizations are faced with a constant process of change determined by the business environment, new technologies, requirements of customers and internal requirements of process improvements.

The adoption and implementation of new technologies implies in a transition and appears in literature as "diffusion of innovation" (Rogers, 2003), "technology transfer" and "technology deployment" (Tornatzky \& Fleischer, 1990). This occurs in several phases and involves the various elements of the organization (Damanpour and Schneider, 2006).

Rogers (2003) defines diffusion as "the process in which an innovation (new technology) is communicated thorough certain channels over time among the members of a social system". 
Every new technology progresses through three basic phases which are research and development, product development and adoption in organizations. Figure 3 shows a framework for understanding the software technology diffusion proposed by the Software Engineering Institute - SEI (Fowler and Levine, 1993).

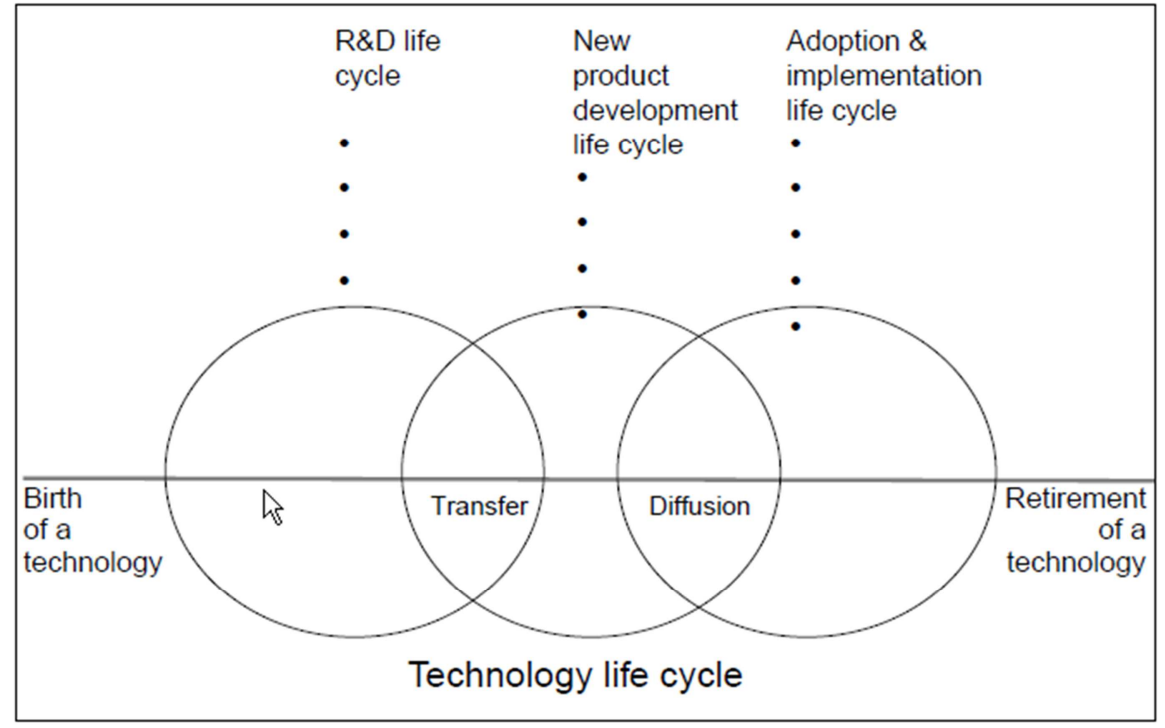

Figure 3 - A Conceptual Framework for Technology Transition

From this framework, in this work, we are especially interested in the adoption and implementation phase. It deals with the actual deployment of technology in the organization, focusing primarily on users of the new technology, the necessary management structure and changes in work habits and preferences. The new technology can cause the construction or modification of communication channels and modify organizational structures. In this case the technology is tested, built-in software or in a well-defined process, having well-defined standards, user manuals, training courses and customer support.

Several studies demonstrate that people facing a process of adopting an innovation have different behavioral characteristics, themselves classified by Rogers (2003) into five categories as shown in Figure 4. 


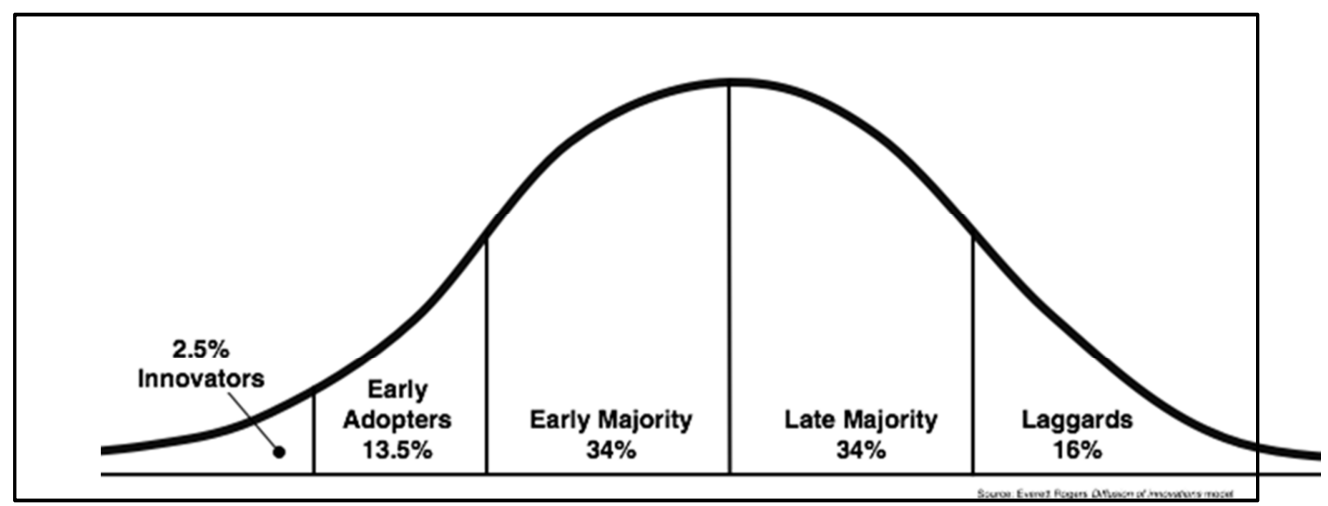

Figure 4 - Five established adopter categories

The Innovators are people who want to be the first to try the innovation. The Early Adopters are people who represent opinion leaders. The Early Majority are people that are rarely leaders, but they adopt new ideas before the average person. The Late Majority are people that are skeptical of change, and will only adopt an innovation after it has been tried by the majority. The laggards are people bound by tradition and very conservative. It is very important for the adoption process to understand the category of people which will be involved.

The new technology that is being adopted may be according to Nord (1987) routine innovation that implements minor adaptations in existing processes or radical innovations that require the complete development of new processes in the organization or significant adjustments to existing processes.

The activities to be developed must be directed to the specific characteristics of the organization's culture in which the technology will be deployed. It is very important to understand the predominant reason for adoption, the greater or lesser ease of acceptance/rejection of these technologies and the choice of transfer mechanism (Bayer \& Melone, 1989).

The time between the availability of an innovation in software technology and its large-scale adoption is established by Redwine \& Riddle, (1985) and shows, based on a study of 17 different technologies of software development between the 60 s and the $80 \mathrm{~s}$, that the maturation time (time for it be popularized and disseminated on a large scale by the technical community) for a software technology is fifteen (15) to twenty (20) years. It is important to understand the factors and processes that influence adoption, delays in execution or rejection of the innovation as well as the various aspects involved 
in order to improve this process. Once a technology is developed, it takes an average of 7.5 years for it to become widely used. A maturation of a technology occurs when $70 \%$ of the industry uses the technology.

Research regarding the diffusion of innovations (Fichman \& Kemerer, 1993) seeks to identify how innovations spread within a group of potential users of this technology, being eminently characterized as a process of communication with emphasis on how adopters know innovation, as and when they learn about them by identifying some attributes of innovation that can facilitate or hinder its spread. These attributes are: relative advantage, compatibility, complexity, ease of experimentation and observability. Furthermore these attributes are associated with economic aspects of the adoption of the investment return. We can see these elements in the table 1.

Table 1 - Attributes of Innovations (Rogers, 2003)

\begin{tabular}{|l|l|}
\hline Relative Advantage & $\begin{array}{l}\text { The degree to which an innovation is seen as better than the } \\
\text { idea, program, or product it replaces. }\end{array}$ \\
\hline Compatibility & $\begin{array}{l}\text { How consistent the innovation is with the values, experiences, } \\
\text { and needs of the potential adopters. }\end{array}$ \\
\hline Complexity & How difficult the innovation is to understand and/or use. \\
\hline Trialability & $\begin{array}{l}\text { The extent to which the innovation can be tested or } \\
\text { experimented with before a commitment to adopt is made. }\end{array}$ \\
\hline Observability & The extent to which the innovation provides tangible results. \\
\hline
\end{tabular}

Society currently has knowledge as a rather significant value and the various technologies represent an important means to make this knowledge more and more useful and available, stimulating constant evolution and innovation in organizations (Lytras, 2011). Understanding the factors that interfere in the process of adoption of new technologies in organizations helps us to predict and manage this adoption process (Partala \& Saari, 2015).

Straub (2009) suggests three conclusions about technology adoption and diffusion: "a) technology adoption is a complex, inherently social, developmental process; (b) individuals construct unique (but malleable) perceptions of technology that 
influence the adoption process; and (c) successfully facilitating a technology adoption needs to address cognitive, emotional, and contextual concerns".

New technology finds barriers in the organization such as incompatibilities with other technologies used, technical skills, resistance of people to change (Hoffman \& Klepper, 2000). In general we see the great importance of the people, their beliefs and organizational culture in a process of technology adoption.

\subsection{THE ADOPTION OF A SOFTWARE TECHNOLOGY}

Technological innovations are largely responsible for economic growth and information technology in the organizations give great support to the implementation of innovations (Zhao et al., 2015). This fact requires that new software technologies are incorporated into these organizations and this is a critical factor for making this process possible (Lytras \& Pablos, 2011).

The diversity and the growing need of organizations in adopting new technologies for the development and evolution of software, has led to a concern in better understanding the factors involved in the process of introducing these technologies.

The technological base of an organization consists of its technology assets, organizational assets (skills of employees and managers, procedures and structure), foreign assets (suppliers and customers) and projects (Adler \& Shenhar, 1990). Adopting a software technology in an organization requires different levels of learning (Fowler \& Levine, 1993), because it changes the skill of the practitioners and the organizational structure and procedures of the company (Shih \& Huang, 2010). This requires the definition of strategies most appropriate to the organization's culture.

A constant problem in most organizations is how to accelerate the rate of diffusion of an innovation, because all improvement processes involve changes (Zelkowitz, 1996) (Zelkowitz et al., 1998). For software technology, we are considering methods and tools for software development and evolution (Punter et al., 2009).

The process of development/evolution of software in large organizations has a lot of standards, procedures, methods, processes, tools and environments for developing 
and managing software. Organizations seek to achieve higher levels of quality and productivity in software development. Auxiliary to the process maturity models have been created that specify progressive of levels of results which companies aspire to by increasing quality, productivity and other desired outcomes.

Among these models we can mention the CMM - Capability Maturity Model, appeared in 1991, (Paulk et al., 1993) developed by the Software Engineering Institute (SEI) involving several disciplines (Software Engineering, Management and Development of Work Force, Integrated Development of Process and Product). This model evolved, being replaced by the Capability Maturity Model Integration (CMMI) (Chrissis, 2004). The CMMI is a process improvement approach which provides companies with the essential elements of effective processes and software focus in the areas of Development, Acquisition and Services. This model integrates many different models into one framework.

Another important maturity model was presented by the International Organization for Standardization (ISO)/International Electrotechnical Commission (IEC) through the family of ISO/IEC 15504 (ISO/IEC, 2003) also known as SPICE. This standard is an evolution of ISO/IEC 12207 (ISO/IEC, 1995) but has levels of capacity for each process, which allow for evaluating the evolution of software process maturity of organizations for continuous or discrete stages. It also presents a orientation guide for the improvement process of development/evolution of software, been used as a process model reference.

All SPI - Software Process Improvement in organizations is aimed at understanding existing processes and modifying them to improve the quality and worker productivity of the processes and reduce the time and cost of development. SPI does not assess the organizational and human aspects involved in the adoption of software technologies in these processes.

Technological changes in software processes should consider the human factor involved as a critical element to their success (Basili et al., 1995) as well as some important aspects that affect the adoption of software engineering technologies as described by Zelkowitz (1996) and Punter et al. (2009): 
- Software development is much more process-oriented than productoriented.

- It is much more dependent on the experience and ability of practitioners than other forms of engineering.

- Most software technologies are processes i.e. sets of rules to be followed by developers.

- Most software professionals are resistant to change.

- Contact between people is the main transfer agent of change.

The adoption of a new software technology is an innovation process in the organization and is directly related to the organizational learning culture, directly interfering with their human resources, capabilities and competences (Argyris \& Schön, 1978) (Shih \& Huang, 2010).

Organizational learning is a complex process of acquisition of new knowledge and serves as a basis for behavior change (Huber, 1991). It emerges when the organization acquires knowledge, know-how, technology and procedures (Argyris \& Schön, 1996). Organizational learning is integrated with the process of individual learning as a way to increase the practice of innovation in organizations (Song \& Chermack, 2008). The organizational learning process has different phases such as information acquisition, information interpretation, and behavioral and cognitive changes.

As the process of software development is eminently based on human activities performed in organizations, strongly influenced by cognitive and social aspects, it is fundamental to build a better theoretical foundation of organizational, social and cognitive psychology. In this way, we can obtain better support to understand, predict and modify human behavior to better plan and manage the process of adoption of technologies to facilitate its acceptance.

A series of studies on technology acceptance (Chuttur, 2009) (Bagozzi, 2007) show the importance that researchers have made in understanding the role of human and social factors for the successful implementation of new technology in organizations. This leads us to consider the need for further studies that allow us to define models that consider these factors to support organizations in the adoption of new software technologies. 
Research to understand the human factors facilitating and hindering the acceptance of new technologies should be based on cognitive models that describe process behavior of individuals.

\subsection{THE ADOPTION OF SOFTWARE REUSE TECHNOLOGY}

Software reuse technology is the process of creating software systems from existing software artifacts rather than building them from scratch (Krueger, 1992). This technology requires that the organization has a core asset base, support processes and appropriate organizational structure.

Software reuse is an important approach for improving the quality and productivity of software development and evolution (SWEBOK, 2007) because it is based on the construction of systems from existing artifacts, representing a significant element for optimizing software processes in large organizations (Krueger, 1992). The introduction of this technology in these organizations has a very positive impact on issues of cost, productivity and quality of software (Basili et al., 1996) (Ezran et al., 2002) (Poulin, 2006).

The literature on reuse in software engineering shows that up to $60 \%$ of the project and $40 \%$ to $60 \%$ of the code can be reused from one business application to another, and up to $75 \%$ of a program's features are common across more than one program (Poulin, 2006). The overall rate of reuse for commercial applications ranging from $15 \%$ to $85 \%$ (Mili et al., 1995), demonstrates the benefits that a large organization can achieve if their processes of development or evolution of software are changed to incorporate domain engineering, domain analysis, design and implementation oriented by reuse.

The adoption of software reuse technology in an organization is costly in terms of time and resources. Failure in this process causes significant damage to the organization, including, with respect to its market share (Frakes \& Isoda, 1994). The transition from a traditional software development process to a process using the 
technology of reuse requires a great deal of change in the way the organization works and the behavior of practitioners involved (Muthig, 2002).

To obtain a higher software development productivity and quality, several companies got together and created the SPC-Software Consortium Productivity Reuse Program which proposed an environment (techniques and tools) in order to achieve these goals through software reuse (Pyster \& Barnes, 1988). The technology developed by this consortium was transferred to the participating companies, representing a systematic process for reuse, based on access tools to a reusable repository of assets, a library asset related to business area and a methodology for software process development with reuse.

Pietro-Diaz (1991) proposed a model of incremental reuse of adoption to reduce the risk involved in the adoption process, emphasizing the importance of the organizational structure for successful adoption.

The CFRP - Conceptual Framework for Reuse Processes (Davis, 1991) defines the life cycle process reuse-oriented models with the main elements focused on processes: a) Reuse Management, focused on planning processes, managing and learning about reuse and b) Reuse Engineering, focused on the processes of creating, maintaining and using reusable assets.

We also found in the literature other significant work on the adoption of reuse among them we can mention (Caldiera, 1991), (Bongard et al., 1993), (Llorens et al. 2006), (Sherif et al., 2006), (Rine, 1997), (Morisio et al., 2002) (Lucredio et al., 2008).

As Griss (1995) said, "Reuse is a business issue that involves technology transition and organizational change. Instituting a reuse culture, providing training, adhering to standards and securing management commitment, are the key success factors". Empirical studies by Morisio (2002) in industrial organizations show that nontechnical factors, such as the organization, processes, business drivers, and human involvement, appear to be the most important factors for a successful reuse adoption process.

Several studies have shown the importance of using a reuse maturity model to help the adoption of reuse, as part of the software development process of the organization. A structured set of techniques, management practices and support to 
implement a program of reuse in the organization software area is needed (Garcia et al., 2007). The level of maturity of the organization's software process is also a significant factor in the deployment of software reuse technology (Ahmed \& Capretz, 2010).

One motivation for the adoption of new models of reuse, the result of observing various organizations, is to reduce the initial risk in adopting reuse (Almeida, 2007) (Garcia et al., 2007) and its integration with the process of software development. So RiSE - Maturity Model emphasizes that the practices of reuse should be grouped according to organizational, business, technology and process perspectives. The dependence of the organizational structure, "background", budget, and other technical and non-technical factors associated with size, experience, and availability of resources and history of the organization (Lucredio et al., 2008) make the adoption process difficult.

The human aspects are presented, (Sherif \& Vinze, 1999), (Sherif \& Vinze, 2003) emphasizing the importance of empirical evidence to demonstrate their degree of influence as a factor to help or hinder the process. Human, organizational, managerial and economic obstacles often outweigh the technical (Sametinger, 1997) and should be considered in each organization to ensure that the risks associated with them are properly handled.

Experiences from the adoption of software reuse technology in organizations present a set of beliefs concerning the use of technology that serve as the basis for instantiating our generic model developed in this work, to the specific case of the adoption of this technology. Thus, we can compose a detailed model as the basis for conducting experimental study in any large organization wishing to adopt this technology and that will be the basis for the experimental study that we perform in the adoption of reuse process in a large enterprise. 


\subsection{ORGANIZATIONAL CULTURE}

Organizational culture has been an element that has a strong influence on the incorporation of innovations and introduction of new technologies that will improve the software process, and the organizations are strongly affected by organizational, personal and social values (Shih \& Huang, 2010). The organizational culture comprises of the context in which software development takes place (Livari \& Livari, 2011) and consists of beliefs, attitudes, values, norms, standards of behavior, customs, practices, symbols and organizational knowledge.

Organizational culture according to Needle (2004) "represents the collective values, beliefs and principles of organizational members and is a product of such factors as history, product, market, technology and strategy, management style and national culture".

According to Ravasi and Schultz (2006), organizational culture "is a set of shared mental assumptions that guide interpretation and action in organizations by defining appropriate behavior for various situations". Organizational culture is "the way we do things around here" (Lundy \& Cowling, 1996).

Culture is so important for an organization that Schein (2004) says that "Culture is an abstraction, yet the forces that are created in social and organizational situations that derive from culture are powerful. If we don't understand the operation of these forces, we become victim to them". It is necessary to look at the organization from the perspective of their culture in order to better understand the things that happen in it. The culture of an organization has a strong influence on behaviors that are observed in the organization.

Culture is the learned result of the Group's experiences and is a consequence of patterns of ideas, moral concepts and beliefs of their individual members. The knowledge of the culture of an organization is a very important element for the success of the process of adopting a new technology in an organization.

Organizational culture can be analyzed at several different levels, at the word level, meaning the degree to which the cultural phenomenon is visible to the observer (Schein, 2004) as we can observe in Figure 5 


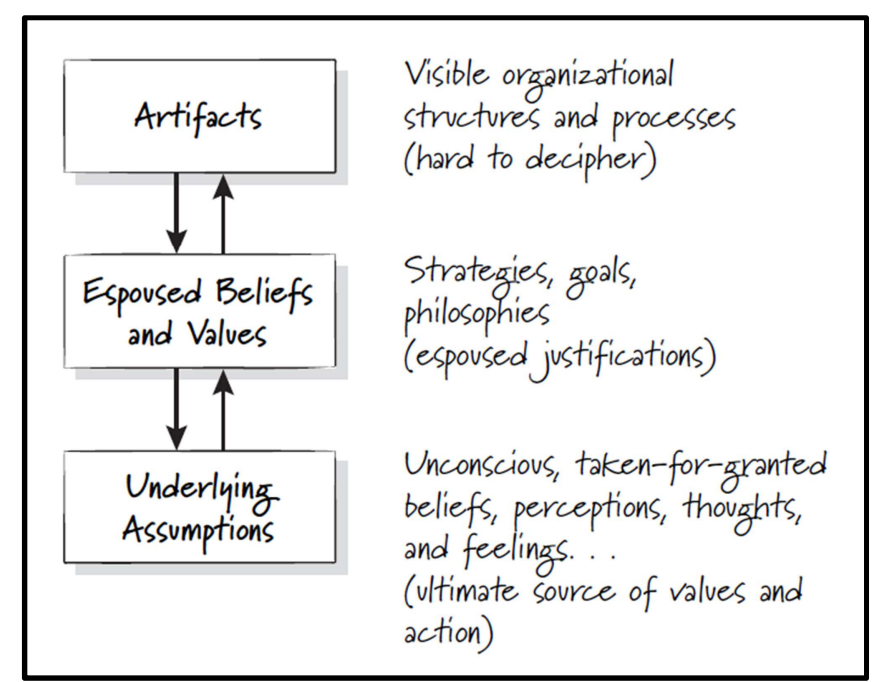

Figure 5 - Levels of Culture (Schein, 2004)

At the highest level, we find artifacts that represent the visible products of the organization such as organizational structure, its processes, its language, behavior patterns, their technologies and products. These elements are easily observed. At the second level, espoused beliefs and values represent the conscious beliefs and values and explain the organization's ideology and goals. These elements will be predictive for the observed behavior at the top level of the artifacts. These beliefs and values are generally not learned a priori and are mentioned in the "espoused theory" (Argyris and Schon, 1978). This theory predicts the desired behavior of people within the organization. At the third level, Underlying Assumptions represents the essence of the organization's culture and is the degree of consensus that results from repeated success in implementing certain beliefs and values. These basic assumptions are nonconfrontable and nondebatable and extremely difficult to change. We have at this third level the values of the organization's members that are shared and to study organizational behavior we need to interview members of the organization at collect their attitudes as members of the organization. Often, for existing standards at the second model level we identify opposite behaviors at the third level of the organization's culture and because of that changes in the organizational are not successful in achieving the organization's goals.

Organizations are constantly faced with the need for change and development which requires a constant learning process. This process will interfere and be interfered 
by the organization's culture demanding an ability to know, analyze and deal with the organization learning problems (Douglas \& Wykowsky, 2010).

The adoption of new technologies adds new knowledge to the organization's culture which will iterate directly with the organization's belief system and with the belief system of its members. The learning of new thing requires a review and generally changes stable portions of the cognitive structure of people in organizations (Argyris et al, 1985). This is a very significant aspect of the process of adoption of new technologies.

\subsection{BELIEF SYSTEM AND KNOWLEDGE}

To understand the process of change in the culture of organizations it is necessary to deal with the concepts of beliefs, belief systems and knowledge and their relationships. Beliefs are the elements that primarily determine the way people act and are the main barriers to the learning process and changes in organizations.

We found in scientific studies, the importance of beliefs as a determinant of the behavior of individuals and groups in different fields such as medicine (Montano \& Taplin, 1991) (Vanlandingham et al, 1995), education (Aguirre \& Speer, 2000), psychology (Blank \& Hennessy, 2012), social science (Randolph et al., 2009), software engineering (Wernick \& Hall, 2004) (Livari \& Huisman, 2007) (Livari \& Livari, 2011) (Passos et al., 2011) (Passos et al., 2013) among many others.

In a general, a belief is the feeling of being certain that something exists or is true. (Cambridge Dictionary, 2015), or a feeling of being sure that someone or something exists or that something is true that something is good, right, or valuable or feeling of trust in the worth or ability of someone (Merriam-webster, 2015). It ils an acceptance that something exists or is true, especially one, without proof (Oxford-Dictionary, 2015).

Belief is a proposition or premise or even an opinion formed or conviction that an individual holds as true (Schwitzgebel, 2006). This refers to the subjective probability of judging people on some aspect of their environment, focusing on the understanding of the person about oneself and the environment. We can tell a person's belief about a particular object of the environment in which it is embedded. It is the subjective probability that an 
object (person, group of people, an institution, a behavior policy, an event, etc.) has a particular attribute (trait, property, feature, etc.).

Belief is a mental representation or cognitive representation, treated especially in philosophy and psychology, as a sentient being's attitude toward the likelihood or truth of something (Schwitzgebel, 2006). Beliefs are the foundation for our actions before the various situations that arise in our day to day (Ajzen \& Gilbert, 2008).

Beliefs are generated from several individual and organizational mechanisms. This is emphasized by several authors showing that en par with the importance of beliefs in organizational culture are the individual beliefs.

A belief system is a set of beliefs which guide and govern a person's attitude. It is directed towards a system such as a religious, philosophic, ideological or technological system. Attitudes and beliefs in these systems are closely associated with one another and retained in memory (Psychology Dictionary, 2015). Our belief system is the set of precepts which govern our thoughts, words, and actions.

Every organization has its belief system that is at level two, espoused beliefs and values of the Schein's model (2004) of organizational culture and each individual who composes it has his own belief system.

The beliefs that compose the person's belief system has a representation in her head or mind and this representation may appear as sentences in the internal language of thought (Fodor, 1981). These sentences (propositions) are processed and correlated producing actions.

Beliefs are formed from several different sources as our own experiences, observations, readings, hearing, reflections, generalizations, learning, advertisements, acceptance of what is said by people who are references, influences from the environment. People often examine the captured information against evidence and facts and produce their inferences with a greater or lesser degree of analysis. Once are beliefs formed, changes in them are usually not made easily.

Knowledge can refer to a theoretical or practical understanding of a subject. It can be implicit (as with practical skill or expertise) or explicit (as with the theoretical understanding of a subject); it can be more or less formal or systematic (OxfordDictionaries, 2015). 
Knowledge has a philosophical definition that says it is the justified true belief in the "standard analysis" (Douglas \& Wykowsky, 2010). This means that when someone knows something, they have to believe in it (belief condition), this thing is true (truth) and supported by evidence (justified). This requires that the evidence for the belief necessitates its truth.

Truth is the quality or state of one thing being true. The state that one thing exists and can be grasped. This means that our belief is in accordance with reality and common sense. Otherwise the belief is false.

Justification is the basis for what has to be considered a true belief. It is the evidence or a set of facts which provide the basis to confirm the belief and allow it to be used for inference similar future situations. It makes belief a normative conception. The organizations have a function "to put knowledge to work" - on tools, processes, and products and they must be organized for constant changes (BonJour, 1985).

The process of acquiring new knowledge, modifying or enhancing existing knowledge is called learning. The learning process is highly influenced by the organization's belief system and of its members (Terry, 2006). It is a usually a goalsoriented process and highly facilitated by motivational factors. The learning can occur consciously or without conscious awareness. Individual beliefs are the primary barriers to learning and changing in the organization's culture (Douglas \& Wykowsky, 2010).

The adoption of a new technology in an organization implies a process of knowledge transfer changing the organization's belief system and the individuals who compose it. Learning is a process of growth of knowledge and takes place on a large scale during the adoption process.

\subsection{COGNITIVE MODELS THAT REPRESENT THE WAY PEOPLE ACT}

Cognitive psychology is the study of mental processes such as "attention, language use, memory, perception, problem solving, creativity and thinking" (American 
Psychological Association, 2013). Its focus is the mental processes that affect people's behavior. We selected some models that will be the basis for the model that we propose to support the adoption of new technologies.

Argyris and Schon (1978), to explain the way people act, developed the theory of Action Science "aimed at exploring the reasoning and attitudes which underlie human actions, and producing more effective learning" in organizations and other social systems. People keep maps in their minds that lead them to plan their actions to achieve desired consequences and monitor them to learn if these actions are effective. They define three models, the model-1, model-I-O and model -2 in order to enable people to effectively manage their behavior through an understanding of what drives their actions.

Argyris, Putnam, and McLain Smith (1985) characterized the approach as well saying "To see human behavior under the aspect of action is to see it constituted by the meanings and intentions of agents. Agents design action to achieve intended consequences, and monitor themselves to learn if their actions are effective".

The models are represented by the graph below:

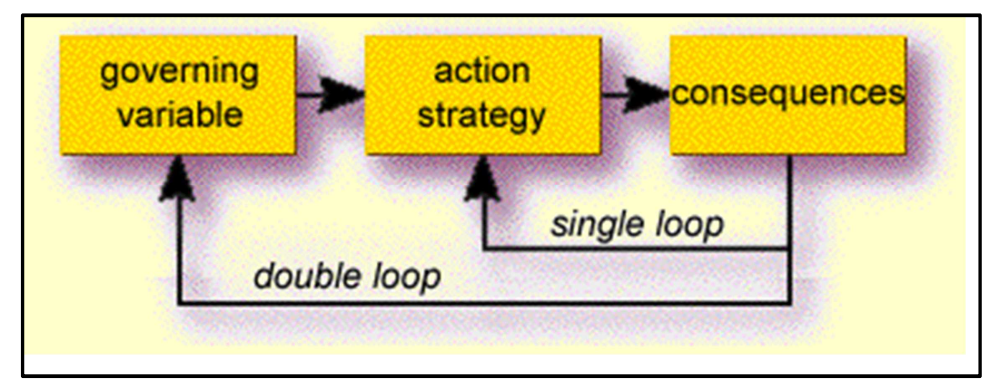

Figure 6 - Model of Single and Double-loop learning

Governing variable is values that the person seeks to achieve and maintain within an acceptable range. Action strategy is strategies used by people to keep their governing variables in an acceptable range, i.e. the behaviors they adopt. Consequences (for people, groups, organizations and systems) represent the effect of the action strategy.

In model 1 or Single-loop learning, when a strategy does not meet the governing variables, this strategy is modified to seek answers for them. The changes are only in the actions. The O-I model incorporates the first model, the organizational aspect and emphasizes the fact that the individual is influenced by the behavioral and cultural 
world of the organization. (Argyris \& Schön, 1978). The model-2 or double-loop learning, beyond the change of actions, allows for changes of governing variables.

In social psychology, we find three theories developed by Fishbein \& Ajzen. The first, called the Theory of Reasoned Action - TRA (Fishbein \& Ajzen, 1975) presents a model to represent the way people act. According to TRA, people construct beliefs about various personal, technological and environmental aspects, which may facilitate or complicate their attempts to adopt certain behaviors. The TRA suggests that beliefs, attitudes and intentions are the main determinants of human behavior, and there are additional elements such as knowledge, skills, and environmental factors. The diagram below represents this model.

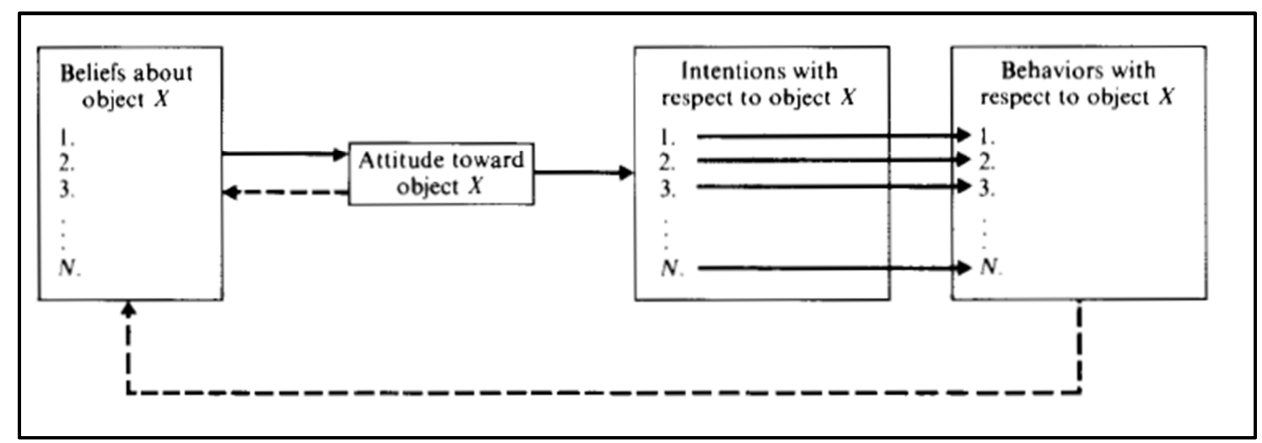

Figure 7 - Conceptual framework of TRA - (Fishbein \& Ajzen, 1975)

The basic elements of this theory are:

- Belief - This refers to the subjective probability of judging people on some aspect of their environment, focusing on the understanding of the person about oneself and the environment. We can tell a person's belief about a particular object of the environment in which it is embedded. It is the subjective probability that an object (person, group of people, an institution, a behavior policy, an event, etc.) has a particular attribute (trait, property, feature, etc.).

- Attitude - Disposition or latent tendency to respond in a favorable or unfavorable way to an object. A person's attitude to the object is the result of its evaluation of attributes. 
- Intention - indication of the promptness of a person to perform a behavior. Allows estimating the probability of the person to perform certain behavior.

- Behavior - observable acts that are performed by the person. The intention is the immediate antecedent of behavior.

The TRA has been extended, aimed to predict and explain human behavior in specific context, having been baptized as Theory of Planned Behavior-TPB (Ajzen, 1991). As in the TRA, the central element in the theory of planned behavior TPB is the individual intention to perform a given behavior, plus another element called Perceived behavioral control (perception of people the ease/difficulty performing the behavior) that affect people's intentions. The TPB also discusses the beliefs relevant to the behavior, which are the antecedents of attitudes and perceptions. The TPB beliefs can be of three types: behavioral, normative and control.

Behavioral beliefs are those according to which people have judgments about the positive or negative consequences of a behavior. Expectations of results will determine the attitude of people regarding the realization of personal behavior. A positive or negative evaluation of performance generates a more or less favorable attitude. E.g. Reuse technology is complex and expensive.

Normative beliefs are ones that people form on the approval or disapproval of their behavior by individuals or groups important in their lives. The approval or disapproval of significant groups leads people to realize a norm or social pressure regarding the behavior, encouraging a more or less favorable intention. E.g.: The large companies are using technology reuse.

Perceived control beliefs of are those that people form about the personal and environmental factors that can help or hinder one's attempts to perform the behavior. They produce an assessment of high or low efficacy with respect to their behavior. It can generate facilitative or inhibitory behavioral intentions. E.g.: The software process of the organization does not provide the technology reuse.

The two theories were consolidated (Fishbein \& Ajzen, 2010) and called theory of behavioral prediction-TBP, where "human social behavior follows reasonably 
and often spontaneously from the beliefs people possess about the behavior under consideration ". The authors present cases of use in various experimental studies and its uses were cited in over 1000 experiments in different areas such as (Blank \& Hennessy, 2012) (Roberto et al., 2011) (Randolph et al., 2009 (Peslak, et al., 2011) (Limayem et al., 2007) (García, et al., 2011) (Mishra et al., 2014).

The TBP model describes the reasoned action represented by the framework below:

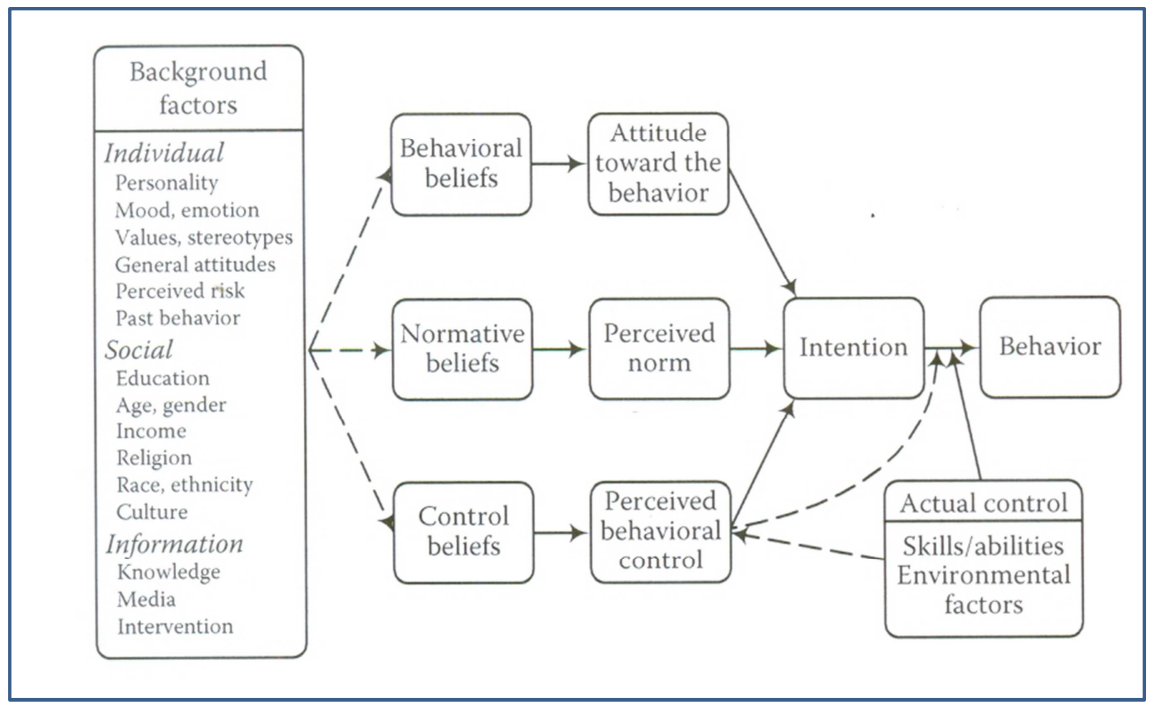

Figure 8 - Schematic presentation of the model Reasoned

Action (Fishbein \& Ajzen, 2010)

In social cognitive perspective Bandura (1986) proposes that the actions and reactions of the individual, including their social behavior and cognitive processes are influenced by the actions they observe in oneself and others, and the theory of selfefficacy has a central role in this context (Bandura, 1991). The concept of perceived selfefficacy is defined as people's beliefs about their capabilities to achieve certain levels of performance. These beliefs have an important role in thinking, motivation and behavior of these people. The four main sources of self-efficacy are successful personal experiences, similar experiences of similar social groups, social persuasion that one possesses, sufficient capacity to perform the activity and the emotional state of the person in relation to the behavior. Beliefs on personal efficacy affect the choices, level of motivation, and resilience to adversity and vulnerability to stress. Human behavior is 
considerably driven and regulated by self-perceived efficacy (Bandura, 1994). Bandura (2012) presents significant aspects of use of the theory of self-efficacy in human development, adaptation and changes at the individual and collective level.

Another model based on the concept of psychological needs seeks to understand the behavior of people who will use a technology as described in Selfdetermination theory - SDT (Ryan \& Deci, 2000) (Deci \& Ryan, 1985, 2014) (Lee et al., 2015). They report three basic elements to determine human behavior: intrinsic motivation (doing an activity for the inherent satisfaction of the activity itself), the extrinsic motivation (self-regulation that people suffer due to from social values and contingency) and the needs relating to health and well-being. This model has been applied in several studies that have determined that autonomy, competence and relatedness and (to care for and be related to others) are the three main needs that motivate behavior. They were also identified (Sheldon et al., 2001) other needs like self-actualizationmeaning, physical thriving, pleasure-stimulation, money-luxury, security, self-esteem, and popularity-influence.

The growing diversity of information technology and the need to explain the acceptance or rejection of these technologies led to Davis's proposition Technology Acceptance Model -TAM (Davis, 85) (Davis et al., 89) which determined three motivating behavioral factors: Perceived Ease of Use, Perceived Usefulness and Attitude Toward Using. TAM is an adaptation of the TRA version to emphasize characteristics of the behavior of users of computer technology. The TRA is used to analyze the links of two key beliefs: perceived usefulness and perceived ease of use as well as attitudes, intentions and behaviors of users for adoption of these technologies. It is a less general model than the TRA. It was extended later to incorporate new features proposed for the evolution of the TRA and generated the TAM2 (Venkatesh \& Davis, 2000) by identification of the external variables to characterize the general determinants of perceived usefulness: subjective norm, image, job relevance, output quality, result demonstrability. To characterize the perceived ease of use, the variables of experience and voluntariness were defined. This model represents the social influence process (subjective norm and image) and captures the influence or cognitive processes (job relevance, output quality, result demonstrability and perceived usefulness). 
We also have The Unified Theory of Acceptance and Use of Technology UTAUT proposed by Venkatesh et al., (2003) to understand the acceptance of information technologies by users for the prediction of behavioral intention to use a technology in organizational contexts. It considers ease of use and perceived intentions of use in terms of social influences and cognitive process. It is an extension to the TAM model by adding new constructs, such as: performance expectancy, effort expectancy and social influence. Venkatesh et al., (2012) presented an extension to UTAUT by adding constructors (hedonic motivation, price and value, experience and habit) and new relationships that allow for evaluating the technology consumers' user context of and named as UTAUT2.

The third version of the TAM model called TAM3 was proposed by Venkatesh and Bala (2008) by adding determinants of perceived ease of use (self-efficacy computer, perceptions of external control, computer anxiety, computer playfulness, perceived enjoyment and usability objective) which aims at making the process of adopting a new technology more precise. These variables are grouped into three categories: control beliefs, intrinsic and extrinsic motivations and emotions. The identification of these elements allows organizations to adopt effective interventions in the process of adoption and use of technology.

The user experience (UX) (Hassenzahl \& Tractinsky, 2006) seeks to study the various factors that affect the interaction of users with systems and products using the usability paradigm. UX is based on the approach of technology as experience, emphasizing that emotion and experience are inseparable (McCarthy and Wright, 2004). Hassenzahl (2010) "establishes need fulfillment as a major source of positive (emotional) experiences with technology and clarifies the links between needs, affect, and product perception".

Other models of acceptance of technologies have relevance to our work: The Innovation Diffusion Theory (IDT) (Rogers, 1995) that purpose to describe the patterns of adoption, explain the mechanism, and assist in predicting whether and how a new invention will be a success. Motivation Model (MM) (Vallerand, 1997) based on researches in psychology has supported general motivation theory as an explanation for the behavior. The Social Cognitive Theory (SCT) (Bandura, 1986) presents a model of 
human behavior and has been extended and applied to the context of computer utilization (Compeau et al., 1999). The work of Moore \& Benbasat proposes ways to measure the perception of adopting information technology (Moore \& Benbasat, 1991).

The importance of the software teams' beliefs system for the decision-making process in regards to new technologies is emphasized by Passos et al (2014). The authors state that "Important decisions are made through an interactive process involving people who influence each other. So, the beliefs and values of the project team can guide interactions between its members, and especially actions oriented toward certain software practices." In this paper (Passos et al., 2014) a long term study in several software companies is presented and the importance of beliefs in organizational contexts and how they actually impact practices and processes on projects in the software industry are well characterized.

The TBP presents the fundamental characteristics as the basis for the model that we propose to support the adoption process of software technologies in large organizations, since it emphasizes the identification of a tiered system of beliefs as a basis for identification of the potential behavior of software practitioners. It is complemented with elements in other presented models and data collected through a case study with ethnography as we will see throughout this work. 


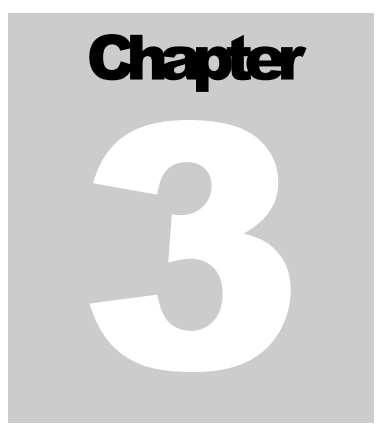

This chapter describes the construction of our action model reasoned on classes of beliefs to support the adoption of software technology proposed, to be used in large organizations, in order to reduce the risks of the process of adoption of new technologies. The basic building blocks of the model are presented and the method of use and treatment of identified beliefs is described.

\section{A METHOD BASED ON AN ACTION MODEL REASONED ON CLASSES OF BELIEFS TO SUPPORT THE ADOPTION OF SOFTWARE TECHNOLOGY}

The method that we propose has as basic model, the theory of TBP-behavioral prediction (Fishbein \& Ajzen, 2010). This choice is a consequence of their conceptual scope and its wide range of use in experiments in various fields of knowledge. This model was the basis for several other models and theories as presented in chapter two. The TBP presents the general structure and the basic building, necessary for the development of the action model reasoned on beliefs classes that will be developed in this chapter.

The reasoned action approach of TBP provides theoretical support to understand, predict, and modify human behavior and plan how to implement interventions to change behavior. The main goal is the prediction and understanding of human behavior. It is important to consider that behavior is an observable event, which must occur in a particular context and at a certain point of time, being directed to any target. Thus, behavior is composed of four elements: the action performed, the target in which the action is directed, the context in which it is held, and the time is performed. 
We adapt this model to support the planning process of adopting a software technology in an organizational environment and use the models previously cited as support for the creation of classes of beliefs.

\subsection{THE STRUCTURE OF THE MODEL}

Belief is a proposition or premise or even an opinion formed or conviction that an individual holds as true (Schwitzgebel, 2006),

A belief generates an attitude (latent disposition or tendency to respond in a favorable or unfavorable degree to an object) which in turn produces an intention (promptness of a person to perform the behavior) which in turn determines behavior (observable acts that are performed by the person in question).

For the process of adoption of reuse technology, we can cite an example of chaining these elements by a practitioner of an organization. The belief "Technology reuse is complex and expensive," generates an attitude "Unfavorable to the deployment of reuse technology", causes one intention "Resist the deployment of reuse technology" produces the behavior "Do not engage/ hinder the execution of the tasks of adoption."

The stronger the intention, the more likely it is that the behavior is performed. People tend to run a behavior because they intend to do this, have the necessary abilities and there are no environmental constraints that impede the realization of his intentions. Beliefs may be inaccurate, tendentious and even irrational, but when a group of them are formed, they serve as the cognitive basis for the behaviors.

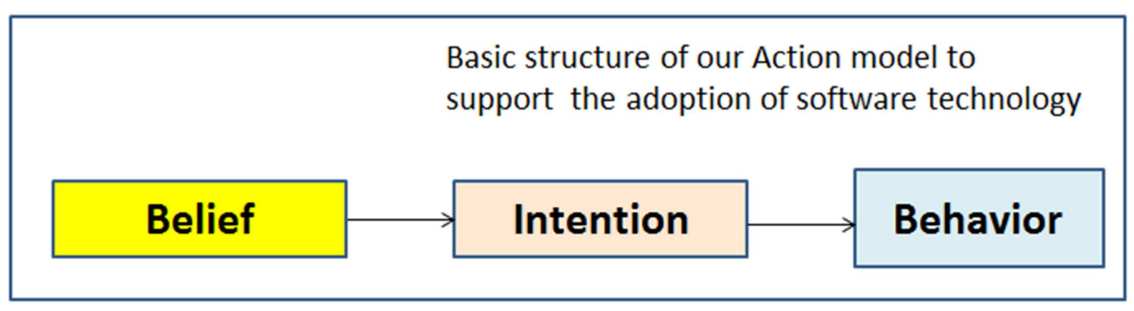

Figure 9 - Basic structure of our Action model 
While investigating the beliefs system of software practitioners we can identify their latent intentions and consequently predict possible behaviors against the process of technology adoption.

The model to support the adoption of software technologies proposed here, in order to facilitate the identification of beliefs, is stratified into three levels: types of beliefs, classes of beliefs and beliefs. The types of beliefs represent the highest level of abstraction of the model and aims to make it more generic to be instantiated for various technologies by defining the classes of beliefs.

The model consists of four types of beliefs. The first three types of beliefs: behavioral, normative and of control were previously described in the theory of behavioral prediction-TBP and in the Technology Acceptance Model - TAM-2 and TAM3 , referred to in chapter 2, pgs.57 and 59. The fourth type is the beliefs of self-efficacy (Bandura, 1991) (Bandura, 2012) referred to in chapter 2, pgs.57 and 58, defined as people's capacity to produce certain levels of performance, being the skills and abilities (lack or presence) to prevent or encourage them to take action and also defined in TAM3. Table 2 shows the relationship between the models and the types of beliefs defined.

Table 2 - Types of beliefs from models

\begin{tabular}{|l|c|c|l|l|l|}
\hline \multirow{2}{*}{$\begin{array}{l}\text { Intention } \\
\text { determinants }\end{array}$} & \multicolumn{5}{|c|}{ Model and theories } \\
\cline { 2 - 6 } & $\begin{array}{l}\text { TRA } \\
\text { +TPB+Theory of } \\
\text { behavioral } \\
\text { prediction-TBP }\end{array}$ & $\begin{array}{l}\text { Theory of } \\
\text { self- } \\
\text { efficacy }\end{array}$ & $\begin{array}{l}\text { Social } \\
\text { Cognitive } \\
\text { Theory- } \\
\text { SCT }\end{array}$ & $\begin{array}{l}\text { Technology } \\
\text { Acceptance } \\
\text { Model- } \\
\text { TAM2 }\end{array}$ & $\begin{array}{l}\text { Technology } \\
\text { Acceptance } \\
\text { Model- } \\
\text { TAM3 }\end{array}$ \\
\hline $\begin{array}{l}\text { Behavioral beliefs } \\
\text { Normative } \\
\text { beliefs/subjective } \\
\text { norm }\end{array}$ & $\mathrm{X}$ & & & & $\mathrm{X}$ \\
\hline $\begin{array}{l}\text { Perceived control } \\
\text { beliefs }\end{array}$ & $\mathrm{X}$ & & & & $\mathrm{X}$ \\
\hline Self-efficacy & $\mathrm{X}$ & & $\mathrm{X}$ & & $\mathrm{X}$ \\
\hline
\end{tabular}

A refined action model to support the adoption of software technologies that we are proposing is represented as follows: 


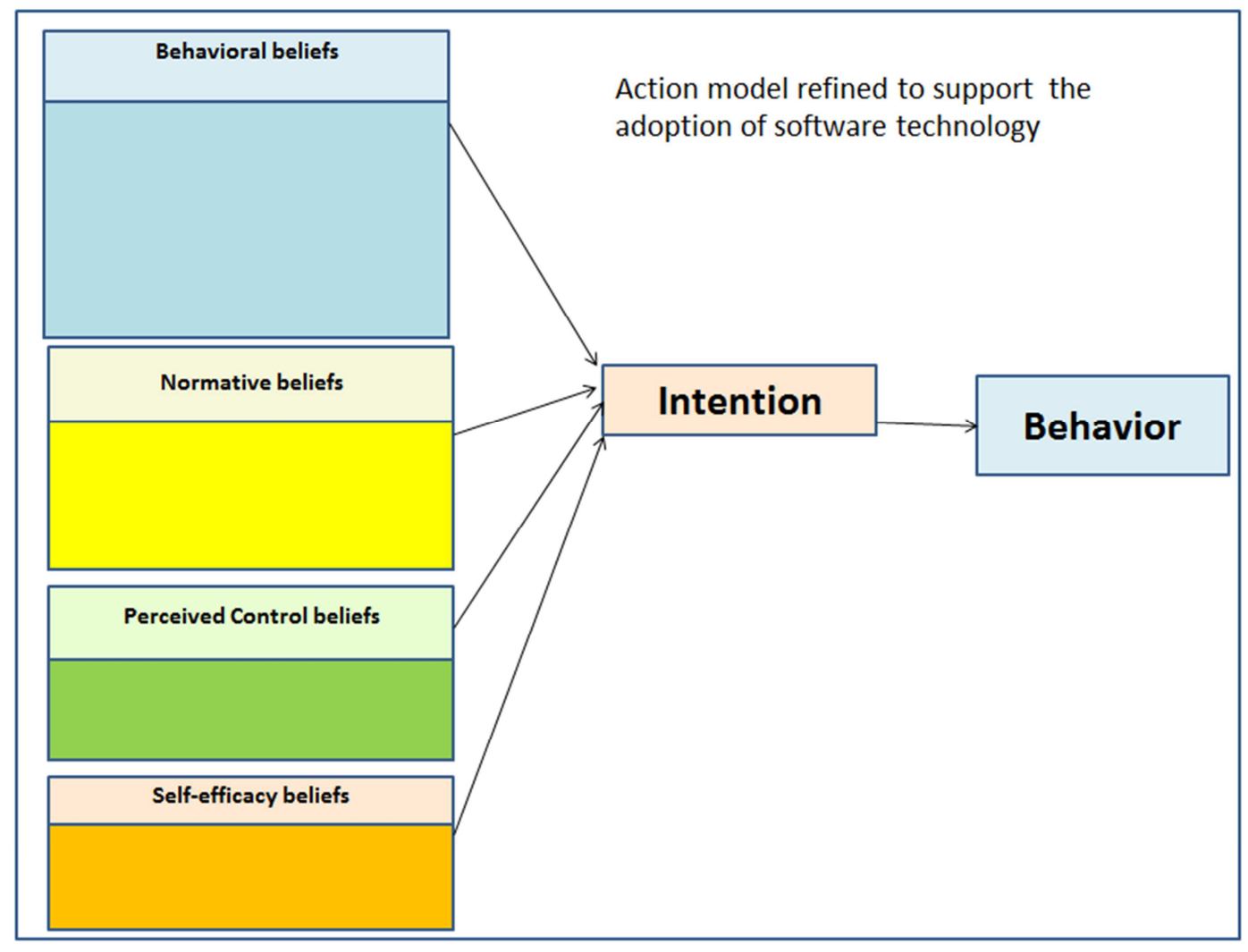

Figure 10 - Refined action model to support the adoption of software technology

\subsection{DEFINING A BASIC SET OF CLASSES OF BELIEFS}

To structure the process of identifying the beliefs in the software technology area, we stratify each basic type of belief in a set of significant classes of beliefs to be mapped to support the adoption of new software technology.

Classes of beliefs are significant aspects related to software technology that guide the identification of beliefs. From an analysis of the various existing models in the literature, relative to others models of acceptance of technologies presented in chapter 2 pg. 60, we construct classes of beliefs by grouping the main aspects identified (intention determinants) for each basic type of belief. 
We can summarize all the intention determinants presented, as mapped in the Table 3: 
Table 3 - Intention Determinants from Models and Theories presented

\begin{tabular}{|c|c|c|c|c|c|c|c|c|}
\hline \multirow[t]{2}{*}{$\begin{array}{l}\text { Intention } \\
\text { determinants }\end{array}$} & \multicolumn{8}{|c|}{ Model and theories } \\
\hline & \begin{tabular}{|l|} 
Self- \\
determin \\
ation \\
theory - \\
SDT \\
\end{tabular} & \begin{tabular}{|l} 
Inovati \\
on \\
Difusio \\
n \\
Theory \\
IDT \\
\end{tabular} & \begin{tabular}{|l|} 
Social \\
Cogniti \\
ve \\
Theory. \\
SCT \\
\end{tabular} & \begin{tabular}{|l|} 
Technolo \\
gy \\
Acceptan \\
ce Model- \\
TAM \\
\end{tabular} & \begin{tabular}{|l} 
Motivati \\
onal \\
Model- \\
MM \\
\end{tabular} & $\begin{array}{l}\text { The Unified } \\
\text { Theory of } \\
\text { Acceptance } \\
\text { and Use of } \\
\text { Technology - } \\
\text { UTAUT }\end{array}$ & \begin{tabular}{|l|} 
Techno \\
logy \\
Accept \\
ance \\
Model- \\
TAM2 \\
\end{tabular} & \begin{tabular}{|l|} 
Technol \\
ogy \\
Accepta \\
nce \\
Model- \\
TAM3 \\
\end{tabular} \\
\hline Self-efficacy & & & $\mathrm{x}$ & & & & & $\mathrm{x}$ \\
\hline $\begin{array}{l}\text { Intrinsic motivation } \\
\text { (doing an activity for the } \\
\text { inherent satisfaction of the } \\
\text { activiry itself) }\end{array}$ & $\mathrm{x}$ & & & & $\mathrm{x}$ & & & \\
\hline $\begin{array}{l}\text { Extrinsic } \\
\text { motivation(seif- } \\
\text { regulation that people suffer } \\
\text { due to from social values } \\
\text { and contingency) } \\
\end{array}$ & $\mathrm{x}$ & & & & $\mathrm{x}$ & & & \\
\hline $\begin{array}{l}\text { Needs relating to } \\
\text { health and well-being }\end{array}$ & $\mathrm{x}$ & & & & & & & \\
\hline $\begin{array}{l}\text { Other needs(self- } \\
\text { actualization-meaning, } \\
\text { physical thriving, } \\
\text { pleasure-stimulation, } \\
\text { money-luxury, } \\
\text { security, self-esteem, } \\
\text { and popularity- } \\
\text { influence) } \\
\end{array}$ & $\mathrm{x}$ & & & & & & & \\
\hline $\begin{array}{l}\text { Relative } \\
\text { advantage/Results } \\
\text { Demonstrability } \\
\end{array}$ & & $\mathrm{x}$ & & & & & $\mathrm{x}$ & $\mathrm{x}$ \\
\hline Perceiveid Ease of Use & & $\mathrm{x}$ & & $\mathrm{x}$ & & & $\mathrm{x}$ & \\
\hline Image & & $\mathrm{x}$ & & & & & $\mathrm{x}$ & $\mathrm{x}$ \\
\hline Visibility & & $\mathrm{x}$ & & & & & & \\
\hline $\begin{array}{l}\text { Compatibility with } \\
\text { values and past } \\
\text { experiences }\end{array}$ & & $\mathrm{x}$ & & & & & & \\
\hline Voluntariness of Use & & $\mathrm{x}$ & & & & & & $\mathrm{x}$ \\
\hline $\begin{array}{l}\text { Outcome Expectations- } \\
\text { Performance and } \\
\text { Quality Expectacy }\end{array}$ & & & $\mathrm{x}$ & & & $\mathrm{x}$ & $\mathrm{x}$ & $\mathrm{x}$ \\
\hline $\begin{array}{l}\text { Outcome Espectations- } \\
\text { Personal }\end{array}$ & & & $\mathrm{x}$ & & & & & \\
\hline Affect & & & $\mathrm{x}$ & & & & & \\
\hline Anxiety & & & $\mathrm{x}$ & & & & & $\mathrm{x}$ \\
\hline
\end{tabular}


Based on Table 2, we identify a basic set of classes of beliefs that will assist the mapping of the software practitioners' belief system about one specific technology. These classes of beliefs can be enhanced with the use of the model for different software technologies.

In Fig. 11 we show our action model reasoned on beliefs classes.

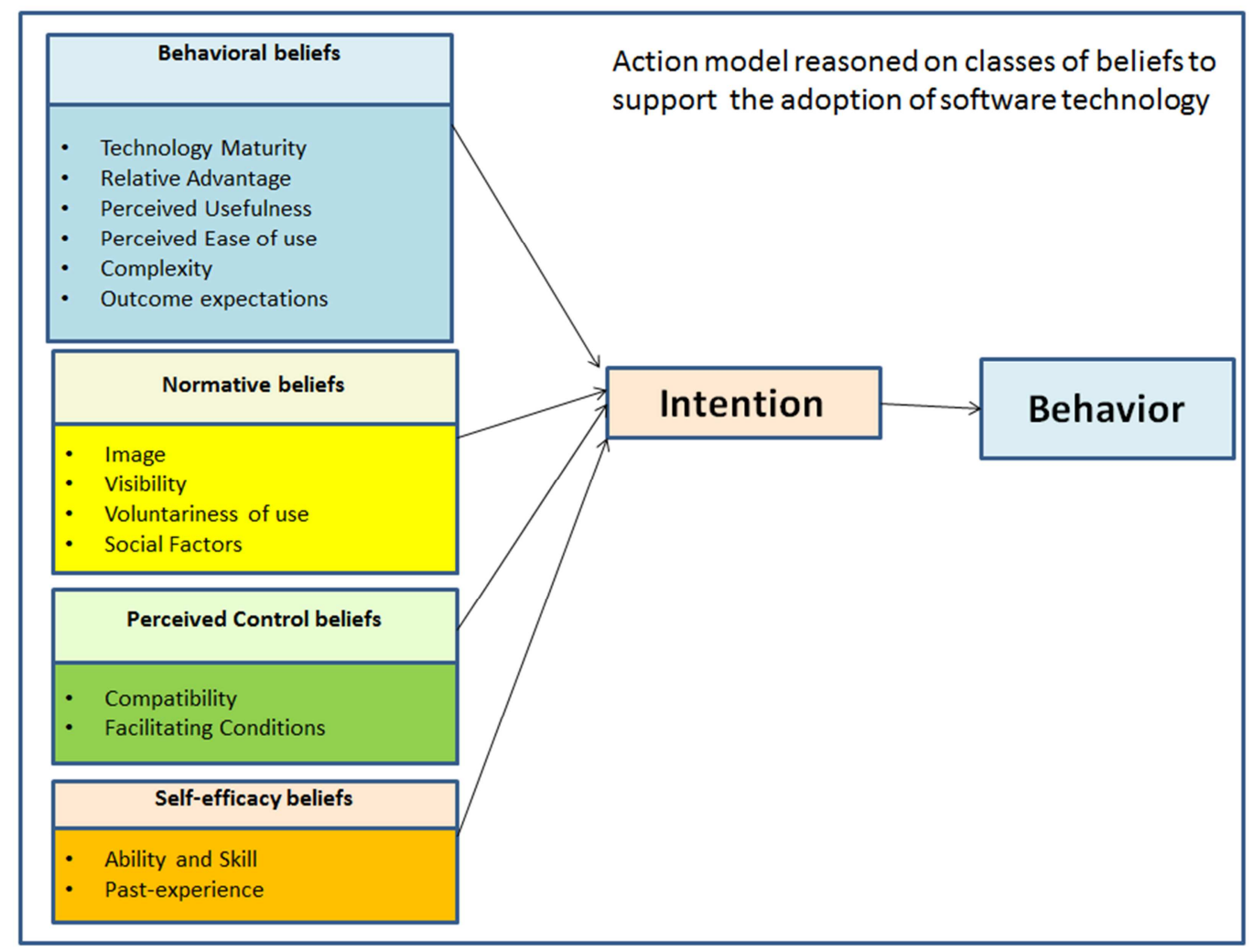

Figure 11 - Action model reasoned on beliefs classes

The Behavioral beliefs are defined as "people hold beliefs about the positive or negative consequences they might experience if they performed the behavior" (Fishbein \& Ajzen, 2010). Expectations positive or negative of their performance, creating a more or less favorable attitude will determine the attitude of people towards the achievement of personal behavior. Such beliefs have the following classes of beliefs:

1. Technology Maturity - level of popularization and dissemination on a large scale by the technical community (Redwine \& Riddle, 1985) 
2. Relative Advantage - the degree to which using an innovation is perceived as being better than using its precursor. (Moore \& Benbasat, 1991)

3. Perceived Usefulness - the degree to which a person believes that using a particular system would enhance his or her job. (Davis et al, 1989)

4. Perceived Ease of Use - the degree to which a person believes that using a system would be free of effort. (Davis et al, 1989)

5. Complexity - the degree to which a system is perceived as relatively difficult understand. (Thompson et al, 1991)

6. Outcome expectations - relate to the consequences of the behavior. (Compeau et al., 1995)

The Normative beliefs are defined "as people form beliefs that important individuals or groups in their lives would approve or disapprove of their performing the behavior as well as beliefs that these referents themselves perform or don't perform the behavior in question" (Fishbein \& Ajzen, 2010). Make people feel a social norm or pressure in behavior, encouraging a more or less favorable intention. Such beliefs have the following classes of beliefs:

1. Image - the degree to which the use of an innovation is perceived to enhance one's image or status in one's social system. (Moore \& Benbasat, 1991)

2. Visibility - the degree to which one can see others using the system in the organization (Moore \& Benbasat, 1991)

3. Voluntariness of use - the use of the innovation is perceived as being voluntary or of free will (Moore \& Benbasat, 1991)

4. Social Factors - the individual's internalization of the reference group's subjective culture, and specific interpersonal agreements that the individual has made with others, in specific social situations. (Thompson et al., 1991)

The Perceived Control Beliefs are defined as "people form beliefs about personal and environmental factors that can help or hinder their attempts to perform the behavior" (Fishbein \& Ajzen, 2010). They produce a feeling of high or low reliability 
regarding the behavior and generate facilitative or inhibitory behavioral intentions. Such beliefs have the following classes of beliefs:

1. Compatibility - the degree to which an innovation is perceived as being consistent with the existing values, needs, and past experiences of potential adopters. (Moore \& Benbasat, 1991)

2. Facilitating Conditions - objective factors in the environment that observers agree to make an act easy to accomplish. (Thompson et al., 1991)

The Self-efficacy beliefs are defined as "people's ability to produce welldefined performance levels" (Bandura, 1991) (Bandura, 2012). Experience and abilities (lack or presence) are important to prevent/encourage people to take action. Such beliefs have the following classes of beliefs:

1. Ability and Skill - judgment of one's ability to use a technology to accomplish a particular job or task. (Compeau et al., 1995)

2. Past-experience - capacity to handle similar problems successfully (Venkatesh \& Bala 2008)

The intention determinants intrinsic motivation and extrinsic motivation were not used because they are a high level of abstraction, having already been covered by others with a greater level of detail. The intention determinants: Needs relating to health and well-being, Affect, Anxiety and Playfulness are not applied. Needs for other classes to assisting the process of identification of beliefs hasn't been identified in this work.

\subsection{INSTANTIATION OF THE CLASSES OF BELIEFS FOR THE DOMAIN OF A SPECIFIC SOFTWARE TECHNOLOGY}

As presented above, beliefs classes are generic to any software technology. For one to use the model for a specific software technology, it becomes necessary to 
identify the main beliefs for each class present in this specific context. By identifying this set of beliefs for a given technology, we can create a standard set to assist the mapping of the belief system of practitioners in a specific organization.

The identification of these beliefs can be done through a literature review, if we are dealing with a mature technology. This task is done by reading the selected bibliography and extracting of parts of the text that represent significant beliefs about the technology within each belief class.

Another way to identify these beliefs is to interview experts from the field of the application of the technology and select the beliefs from their narrative.

For very new technology, immature and with little literature on adoption cases, we have to primarily use interviews with experts in its use. Beliefs classes represent a structural framework to assist in the process of interviews with these experts as a way to map an initial list of beliefs.

Once mapped, it is recommended to revise these beliefs with domain experts to characterize which beliefs are facilitators and which are hinders of the adoption process.

In our work, we used both approaches (literature review and interviews) to map reuse software technology beliefs, as seen in chapter 4 .

\subsection{CAPTURE OF PRACTITIONER' INTENTIONS IN A SOFTWARE ORGANIZATION}

The software practitioners group involved in a technology adoption is defined at the beginning of the process. The next step of our method is to identify a qualified belief system for each person involved in the process. For that, we use an interview with open and close questions. For each belief listed in the previous model, we apply two closed questions. One question seeks to capture the degree of agreement of the practitioner with respect to a belief. This degree of agreement is measured on a four value 
ordinal scale as <zero, weak, medium or strong> agreement with the belief. The second question seeks to capture the importance that the practitioner gives to the belief, or the impact that he perceives that the belief will really have in the technology adoption process. This importance is measured on a three value ordinal scale as <low, medium, or high> impact. In the open questions, we seek to capture two thinks. One is the rationale behind each answer for the closed questions. The other is to encourage the practitioners to suggest new beliefs that are possibly missing in our model.

The interview reveals the practitioners' intention to engage certain behaviors during the technology adoption process. These intentions, if materialized in actions could facilitate or hinder the adoption process.

To complement the process of capturing beliefs, we also perform an observation of software practices and the actual behavior of practitioners in the organization. The product to be generated from the analysis of the collected data is a set of properly qualified beliefs, with respect to the practitioners' agreement with the beliefs, and with respect to the importance that the practitioners give to them.

The identified qualified beliefs can be classified in three groups that should be treated accordingly to support the process of technology adoption, see Figure 8.

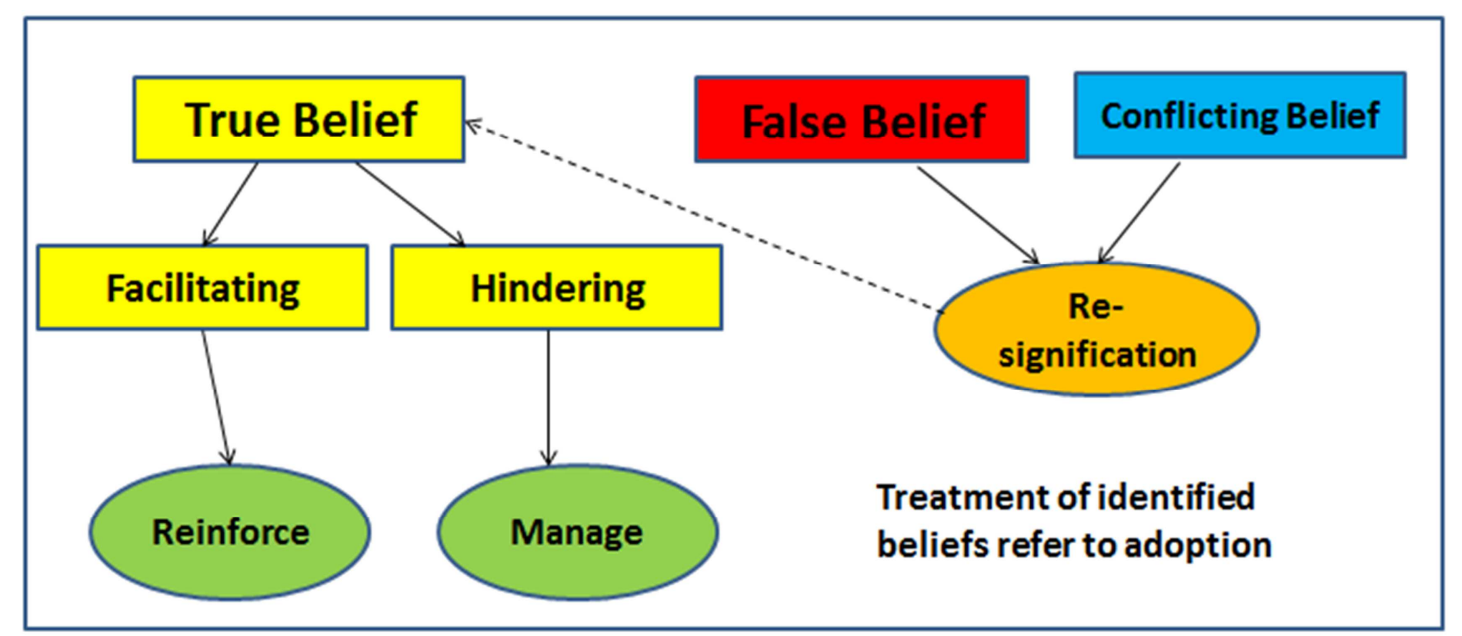

Figure 12 - Treatment of identified beliefs refer to adoption

The first group is named true beliefs. This group contains qualified beliefs that are mostly aligned with the current knowledge of the community or the organization's 
environment where it will be adopted. This means that most of the practitioners' qualified beliefs agree with the current knowledge of the community.

The second group is named false beliefs. This group contains qualified beliefs that are mostly not aligned with the current knowledge of the community or the organization's environment where it will be adopted. They are usually produced by unawareness of the technology or its use method or by out of context past experiences. They are the result of lack of knowledge, incomplete knowledge or wrong or unfounded knowledge of the technology.

The third group is named conflicting beliefs. This group contains qualified beliefs that have mixed opinions among the practitioners. Some are aligned and some are not aligned with the current knowledge of the community or the organization's environment where it will be adopted. Conflicting beliefs are characterized by having at least $25 \%$ of practitioners considering agreement grade zero or weak AND at least $25 \%$ agreement grade medium or strong among the interviewed population.

The true beliefs represent facilitating elements for adoption of the technology. The beliefs that fall in this class and facilitates the technology adoption should be reinforced with the group. The beliefs that fall in this class and hinders the technology adoption should be managed. This usually indicates that specific planning is needed in that specific topic to reduce the risk of failure during the technology adoption process.

Lastly, false and conflicting beliefs should be treated through the re-signification activities. Those activities involve different mechanics for false and conflicting beliefs. This topic is the subject of the next section.

\subsection{RE-SIGNIFICATION OF BELIEFS}

The re-signification of beliefs, also cited in the literature as "change beliefs" or "beliefs revision" (Chi, 2008) (Douglas \& Wykowski, 2011), "changing the mind" (Gardner, 2006), or reconstruction of beliefs, is defined as the process that leads the 
individual to assign new meaning to objects or events through a change of vision (Moskovitz, 2009). Through it, the individuals learn to think differently about things, seeing new points of view or considering other factors as stated by Gardner (2006): "The key to change the mind is to shift the way a person perceives, codes, retains and accesses information".

Cognition involves the act or process of belief formation, acquisition of knowledge and reasoning. This process can be conscious or unconscious (Douglas \& Wykowski, 2011) being related to perception, memory and emotion. Techniques that encourage individuals to adapt or change their beliefs from the identification and awareness regarding false beliefs and elicitation of conflicting true beliefs are developed. The formation of new true beliefs and alignment of other beliefs with reality are stimulated, thus creating a process for enabling the acquisition of knowledge. Emotions, fear, anxiety and wrong perceptions often lead the individual to have defensive thoughts and false beliefs which make the process of re-signification a difficult task that requires the use of appropriate techniques for each type of situation.

Gardner (2006) characterizes the process of "changing minds" as a hard process and dependent on seven factors, six facilitators (reason, research, resonance, redescription, resources and real world events) and a complicating factor called resistances.

- $\quad$ Reason is employed by way of argument in order to persuade.

- Research is used in order to collect facts, also with the purpose of persuading.

- Resonance appeals to the feeling part of the human personality. Some people rely heavily upon resonance, and prefer it to a reasoned and researched position.

- $\quad$ Redescription can be profoundly effective. Matters are often expressed in the negative, but when changed into a positive form of expression, convey a completely different and more attractive meaning.

- $\quad$ Resources and rewards are an important part of any negotiation.

- $\quad$ Real world events can have the effect of completely changing perceptions. 
The model proposed in this work identifies false, true and conflicting group of beliefs with the practitioners involved. At the end, re-signification activities have to act mostly upon false individual beliefs and conflicting beliefs.

False individual beliefs can fall into three categories. First, it is aligned with the other beliefs in their group, when most of the other practitioners have the same false beliefs (the group is False). Second, it is unaligned with the group, when most of the other practitioners have the true beliefs (the group is true). Third, the individual have false belief and the group is split among false and true (the group is conflicting).

During the re-signification of the individuals that have false belief and the group is split among false and true (conflicting), we also have to manage the individuals that have true beliefs.

In summary, we have several re-signification scenarios. This proposal will not deal with all those scenarios at this point. In this section, we will focus instead in establishing the theoretical basis for re-signification of beliefs.

Figure 13 adds the process of re-signification of beliefs to the Action Model Reasoned on classes of beliefs of Figure 11, as a key element to support the technology adoption process. 


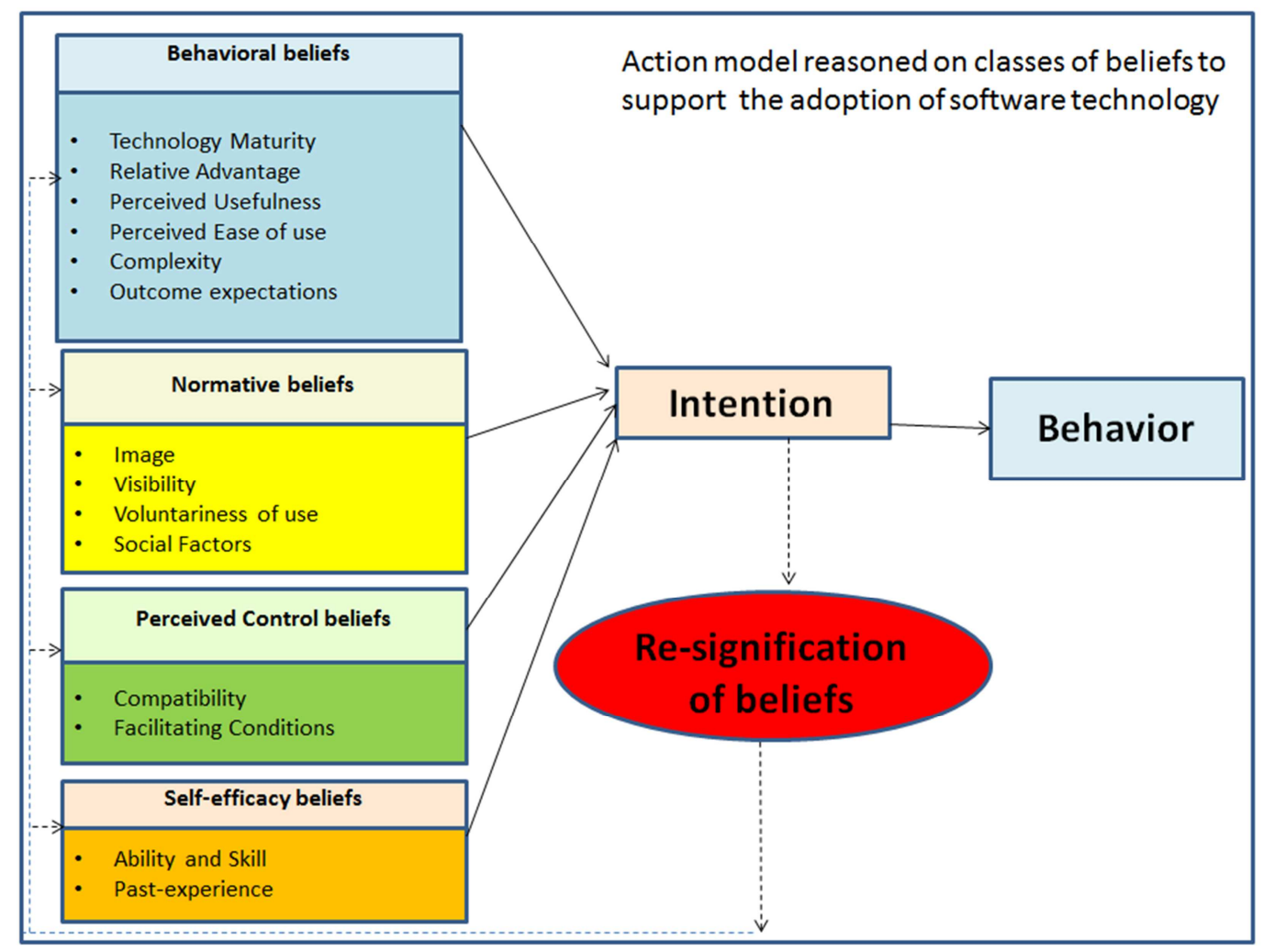

Figure 13 - The complete Action model reasoned on classes of beliefs

The beliefs that cause difficulties in the adoption process or false beliefs related to new technology are the most frequent cause of misconceived knowledge (Broughton et al., 2007) such as missing or incomplete knowledge or wrong knowledge. Other significant causes are past experiences in conflict with the new conception (Chi, 2008) and distorted perceptions of environmental factors.

For missing or incomplete beliefs, we seek to develop new beliefs through the provision of new knowledge. From incorrect or misconceived beliefs, we will use the explicit or implicit refutation (Tippett, 2010) (Chi, 2008) to support belief revision by employing the techniques mentioned below.

In our method, we can use re-signification techniques such as reading process, reflective process, discussion and presentation of cases, experience with alternative models (Chi, 2008).

The reading process consists of the presentation of texts which would include arguments and elements that modify the misconceptions of readers, showing correct concepts regarding technology or showing successful experiences with its use. It 
is recommended to use refutation text that is, a text structure that includes elements of argumentation that conducts a person to change his belief. A refutation text has been described as one of the most effective text-based means for modifying readers' misconceptions (Tippett, 2010). Tippet (2010) emphasizes that "two decades of research indicate that reading refutation text rather than traditional expository text is more likely to result in conceptual change". A refutation text has two components: "the statement of a commonly held misconception, and an explicit refutation of that misconception with an emphasis on the currently accepted scientific explanation" (Guzzetti, 2000).

The reflective process consists of forming groups where people presents and discusses contradictory aspects regarding the belief that we want to re-signify leading the participants to work different views on significant aspects of the technology.

The presentation and discussion of cases consists of selecting cases for the use of technology that addresses the issues you want to re-signify. Each case is presented to the group by a member of the group or external moderator and discussed with the people in the group with participation encouragement for all members of the group.

Through experience with alternative models participants of the object of belief re-significance group is taken to develop experimental use cases of technology that allows them to have a good experience that may modify their beliefs. 


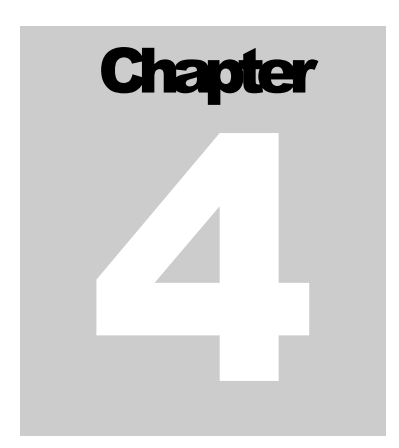

This chapter presents the instantiation of the class of beliefs for adoption of software reuse technology in large organizations, based on the literature review and interview with expert practitioners from the enterprise and consolidates the results in a basic catalog of beliefs to assist in the belief capturing process from the practitioners involved in reuse adoption in a large organization.

\section{INSTANTIATING A BELIEFS CATALOG FOR SOFTWARE REUSE TECHNOLOGY ADOPTION IN A LARGE ORGANIZATION}

To identify the beliefs regarding the adoption of reuse in each class of beliefs we use a research process that consists of three steps.

In step-1, review and analysis of literature, publications were identified and selected on the topic under study. These publications were analyzed and the beliefs presented were identified. A list of beliefs for each class presented above was produced.

In step-2 were conducted interviews with experts, with experience of reuse in large companies, with the objective of validating and expanding the list of beliefs identified in step-1.

In step-3, an ethnographic study case was done in the process of adoption of reuse technology in a large company where the researcher sought to observe among the practitioners involved throughout the adoption process, existing beliefs and how those beliefs evolved.

A review and analysis of the literature was performed with the use of search engines with search strings defined to select articles, books and conferences on the 
subject. The selected publications were analyzed and marked the identified beliefs (Bastos et al., 2011) (Joanes \& Northrop, 2010), (Ahmed et al, 2009), (Catal, 2009), (Li \& Chang, 2009), (Lucredio et al., 2008), (Garcia et al., 2007), (Ahmed et al, 2007), (Frakes \& Kang, 2006), (Poulin, 2006), (Northrop, 2004), (Sherif \& Vinze, 2003), (Mannion, 2002), (Morisio et al., 2002), (Bosch, 2001), (Gacek et al, 2001), (Knauber et al, 2000), (Sherif \& Vinze, 1999), (Rine \& Sonnemann, 1998), (Lynex \& Layzell, 1998), (Sharp, 1998), (Rine, 1997).

These publications were read and aspects related to beliefs identified were marked and extracted. Then, these beliefs were consolidated and fairly categorized in their belief classes. A preliminary list of beliefs grouped in classes was produced, which was submitted to analysis and complementation by practitioner with reuse experience in the organization.

\subsection{IDENTIFICATION OF BELIEFS TO REUSE ADOPTION}

In the literature analysis (step 1) the selected texts were read and the parts where we can identify the presence of possible beliefs concerning the adoption of reuse technology were marked. From these markings in specific segments of text, statements that represent the identified beliefs that may be presented by only one author or several authors were categorized and formulated.

We can cite some examples that show how the identification of beliefs took place as we see in Table 4: 
Table 4 - Example reuse beliefs identification from the literature

\begin{tabular}{|c|c|c|}
\hline Reference & Marked part in analysis & Belief \\
\hline $\begin{array}{l}\text { (Sherif \& Vinze, } \\
2003)\end{array}$ & $\begin{array}{l}\text { Problems arising are mainly due to } \\
\text { incompatibility of reuse activities with the } \\
\text { organization's traditional development } \\
\text { methodology. Traditional methodologies } \\
\text { like the Waterfall Model may not be suitable. }\end{array}$ & $\begin{array}{l}\text { 35. The reuse activities have } \\
\text { incompatibility with the } \\
\text { methodology of software } \\
\text { development organizations. }\end{array}$ \\
\hline (Northrop, 2004) & $\begin{array}{l}\text { Organizations have achieved significant } \\
\text { reductions in cost and time to market and, at } \\
\text { the same time, increased the quality of } \\
\text { families of their software systems }\end{array}$ & \multirow[t]{2}{*}{$\begin{array}{l}\text { 3. Reuse promises a quick } \\
\text { time to market and a } \\
\text { reduction in cost. }\end{array}$} \\
\hline $\begin{array}{l}\text { (Sherif \& Vinze, } \\
2003)\end{array}$ & $\begin{array}{l}\text { While reuse promises a quick time to market } \\
\text { and a reduction in cost, it requires an } \\
\text { investment in both time and resources to } \\
\text { deliver these benefits }\end{array}$ & \\
\hline (Morisio et al., 2002) & $\begin{array}{l}\text { Unfortunately, reuse is seldom part of } \\
\text { software engineering curricula, so students } \\
\text { do not contribute to advancing the state of } \\
\text { knowledge when they are hired in } \\
\text { companies. }\end{array}$ & $\begin{array}{l}\text { 60. Reuse education isn't } \\
\text { common. }\end{array}$ \\
\hline (Morisio et al., 2002) & $\begin{array}{l}\text { They introduced a complex policy to reward } \\
\text { both producers and consumer of assets. }\end{array}$ & $\begin{array}{l}\text { 56. The previous } \\
\text { development of reusable } \\
\text { assets is important for the } \\
\text { process of reuse. }\end{array}$ \\
\hline $\begin{array}{l}\text { (Frakes \& Kang, } \\
\text { 2006) }\end{array}$ & $\begin{array}{l}\text { Development of reusable assets often } \\
\text { requires a capital investment and there } \\
\text { should be a strategic decision as to whether } \\
\text { investment will be made proactively or } \\
\text { reactively. }\end{array}$ & $\begin{array}{l}\text { 40. Managerial difficulty } \\
\text { to allocate the necessary } \\
\text { resources to implement the } \\
\text { necessary infrastructure is } \\
\text { an obstacle for adoption of } \\
\text { reuse. }\end{array}$ \\
\hline $\begin{array}{l}\text { (Frakes \& Kang, } \\
2006)\end{array}$ & $\begin{array}{l}\text { This approach tends to require a large } \\
\text { upfront investment, and returns on } \\
\text { investment can only be seen when products } \\
\text { are developed and maintained. }\end{array}$ & $\begin{array}{l}\text { 4. The cost of adoption of } \\
\text { reuse technology is } \\
\text { described as very high } \\
\text { without significant short- } \\
\text { term retums }\end{array}$ \\
\hline $\begin{array}{l}\text { Frakes \& Kang, } \\
2006)\end{array}$ & $\begin{array}{l}\text { There is also a need for library environments } \\
\text { that include facilities for configuration } \\
\text { management and that integrate facilities for } \\
\text { measurements such as usage and return on } \\
\text { investment. }\end{array}$ & $\begin{array}{l}\text { 47. The lack of a well- } \\
\text { organized and indexed } \\
\text { software repository with } \\
\text { appropriate search engines is } \\
\text { a barrier to reuse adoption. } \\
53 \text {. Configuration } \\
\text { management is an essential } \\
\text { element for a reuse program }\end{array}$ \\
\hline
\end{tabular}


Table 4 - Example reuse beliefs identification from the literature

\begin{tabular}{|c|c|c|}
\hline Reference & Marked part in analysis & Belief \\
\hline $\begin{array}{l}\text { Frakes \& Kang, } \\
2006)\end{array}$ & $\begin{array}{l}\text { Measurement and experimentation of reuse } \\
\text { and domain engineering is one area where } \\
\text { much more work is needed. }\end{array}$ & $\begin{array}{l}\text { 9. The lack of metrics for } \\
\text { reuse makes it difficult to } \\
\text { identify costs and benefits. }\end{array}$ \\
\hline $\begin{array}{l}\text { (Sherif \& Vinze, } \\
2003)\end{array}$ & $\begin{array}{l}\text {...are the expenses of developing a reuse } \\
\text { infrastructure that includes tool support, } \\
\text { training and educating staff, and } \\
\text { restructuring the organization to adapt to } \\
\text { changes in software development. }\end{array}$ & $\begin{array}{l}\text { 39. The organization is } \\
\text { resistant to a structure } \\
\text { required to support the reuse } \\
\text { technology which makes the } \\
\text { adoption process very hard. }\end{array}$ \\
\hline $\begin{array}{l}\text { (Sherif \& Vinze, } \\
2003)\end{array}$ & $\begin{array}{l}\text { The lack of quantitative measures to assess } \\
\text { the benefits and costs is another justification } \\
\text { for management aversion to reuse. }\end{array}$ & $\begin{array}{l}\text { 10. Managers react to } \\
\text { implementation reuse due to } \\
\text { lack of quantitative } \\
\text { measures to assess the } \\
\text { benefits and costs of their } \\
\text { utilization. }\end{array}$ \\
\hline $\begin{array}{l}\text { (Sherif \& Vinze, } \\
2003)\end{array}$ & $\begin{array}{l}\text { Resistance to systematic reuse is also caused } \\
\text { by some software developers' belief that } \\
\text { reuse will inhibit creativity: the "Not } \\
\text { Invented Here" syndrome. }\end{array}$ & $\begin{array}{l}\text { 26. Software developer's } \\
\text { belief that reuse will inhibit } \\
\text { creativity: the "Not } \\
\text { Invented Here"' syndrome. }\end{array}$ \\
\hline (Lucrédio et al., 2008) & $\begin{array}{l}\text { This is a clear indication that the adoption of } \\
\text { a quality model has great influence on } \\
\text { software reuse. }\end{array}$ & $\begin{array}{l}\text { 43. The quality model } \\
\text { usage has a strong influence } \\
\text { on reuse success. }\end{array}$ \\
\hline (Lucrédio et al., 2008) & $\begin{array}{l}\text { we conclude that the team experience has a } \\
\text { weak influence on software reuse success. }\end{array}$ & $\begin{array}{l}\text { 63. To have previous reuse } \\
\text { experience is not necessary. }\end{array}$ \\
\hline (Lucrédio et al., 2008) & $\begin{array}{l}\text { we verified that few organizations had } \\
\text { independent teams for developing reusable } \\
\text { assets }\end{array}$ & $\begin{array}{l}\text { 42. The lack of funding } \\
\text { to allocate to staff for the } \\
\text { development of reusable } \\
\text { assets hinders adoption. }\end{array}$ \\
\hline (Lucrédio et al., 2008) & $\begin{array}{l}\text { we conclude that the software organizations } \\
\text { that develop software based on a product } \\
\text { family have a significant advantage in the } \\
\text { reuse success levels, when compared to the } \\
\text { software organizations that develop isolated } \\
\text { products }\end{array}$ & $\begin{array}{l}\text { 51. Organizations that } \\
\text { develop software based on } \\
\text { a product family have } \\
\text { advantages when } \\
\text { compared to the software } \\
\text { organizations that develop } \\
\text { isolated products. }\end{array}$ \\
\hline $\begin{array}{l}\text { (Joanes \& Northrop, } \\
2010 \text { ) }\end{array}$ & $\begin{array}{l}\text { the technical staff needs to have more than } \\
\text { traditional software engineering skills }\end{array}$ & $\begin{array}{l}\text { 62. Technicians use reuse } \\
\text { without specific training. }\end{array}$ \\
\hline (Li \& Chang, 2009) & $\begin{array}{l}\text { Lack of disciplined core assets development } \\
\text { practice }\end{array}$ & $\begin{array}{l}\text { 56. The previous } \\
\text { development of reusable } \\
\text { assets is important for the } \\
\text { process of reuse. }\end{array}$ \\
\hline
\end{tabular}


The expert interviews (step 2) were conducted based on the set of beliefs previously identified from the literature review. These beliefs served as motivating factors to encourage respondents to talk about other aspects that are significant to them. Segments of texts that were characterized as beliefs and classified in order to allow consolidation of the results were selected from the interviews.

To illustrate the process of extraction of these beliefs, Table 5 show extracts from the interviews and the beliefs identified. 
Table 5 - Beliefs identification from experts interviews analysis

\begin{tabular}{|c|c|}
\hline Extracts from interviews & Belief \\
\hline $\begin{array}{l}\text {... reuse has already been used for a very a long time being } \\
\text { mature brings security for those who will use. (....o reuso já é } \\
\text { muito usado a bastante tempo e o fato de ser maduro da } \\
\text { segurança para quem vai usar). }\end{array}$ & \multirow[t]{2}{*}{ 1. The reuse technology is mature. } \\
\hline $\begin{array}{l}\text {... is a technology already well tested in several large } \\
\text { companies (...é uma tecnologia já bastante testada em varias } \\
\text { empresas de grande porte) }\end{array}$ & \\
\hline $\begin{array}{l}\text {... there are several works that define the assets development } \\
\text { process. .... existem varios trabalhos que definem processo de } \\
\text { desenvolvimento de assets) }\end{array}$ & \multirow[t]{2}{*}{$\begin{array}{l}\text { 2. The reuse technology has a well } \\
\text { defined development methodology } \\
\text { of assets. }\end{array}$} \\
\hline $\begin{array}{l}\text {..the assets identification and construction is made in a well- } \\
\text { defined form. (...a identificação e construção de assets é feita } \\
\text { de forma bem definida) }\end{array}$ & \\
\hline $\begin{array}{l}\text {..because we change the development process and how the } \\
\text { practitioner works, reuse is difficult to implement in an } \\
\text { organization. (..por alterar o processo de desenvolvimento e a } \\
\text { forma de trabalho dos tecnicos o reuso é de dificil } \\
\text { implementação em uma organização) }\end{array}$ & $\begin{array}{l}\text { 11. Reuse is difficult to } \\
\text { implement in an organization. }\end{array}$ \\
\hline $\begin{array}{l}\text {... when using a ready and tested component we are } \\
\text { increasing application quality. (...ao usar componente } \\
\text { prontos e testados estamos aumentando a qualidade da } \\
\text { aplicação) }\end{array}$ & $\begin{array}{l}\text { 16. Developers believe that } \\
\text { reuse increases the quality of a } \\
\text { new application. }\end{array}$ \\
\hline $\begin{array}{l}\text {..the need to identify, build and maintain assets makes the } \\
\text { adoption of reuse in an organization complex. (..a } \\
\text { necessidade de identificar, construir e manter assets torna } \\
\text { complexo a adoção do reuso em uma organização) }\end{array}$ & \multirow[t]{2}{*}{$\begin{array}{l}\text { 19. Reuse technology is } \\
\text { complex because it involves the } \\
\text { identification, construction, and } \\
\text { maintenance of assets availability. }\end{array}$} \\
\hline $\begin{array}{l}\text {..the construction of assets and the need to disseminate them } \\
\text { makes the use of reuse complex. (... construção de assets e a } \\
\text { necessidade de divulgar torna complexo o uso do reuso) }\end{array}$ & \\
\hline $\begin{array}{l}\text {..to reuse components, it is necessary that they existed } \\
\text { before, this complicates the process (..para reusar } \\
\text { componentes é necessario que eles existem antes, isso } \\
\text { dificulta o processo) }\end{array}$ & \multirow[t]{2}{*}{$\begin{array}{l}24 . \quad \text { The lack of reusable } \\
\text { components to meet the future } \\
\text { needs of a domain limits the } \\
\text { success of technology adoption. }\end{array}$} \\
\hline $\begin{array}{l}\text {..the assets need to be ready and meet the developer's needs. } \\
\text { (..os assets precisam estar pronto e atender as necessidades do } \\
\text { desenvolvedor) }\end{array}$ & \\
\hline $\begin{array}{l}\text {.. using reuse in my job puts me and my company in a better } \\
\text { market position. (..usar reuso em meu trabalho coloca a mim } \\
\text { e a minha companhia numa melhor posição no mercado) }\end{array}$ & $\begin{array}{l}\text { 31. To develop software with } \\
\text { reuse is a positive differential for } \\
\text { my company and for me as a } \\
\text { professional. }\end{array}$ \\
\hline
\end{tabular}


Table 5 - Beliefs identification from experts interviews analysis

\begin{tabular}{|c|c|}
\hline Extracts from interviews & Belief \\
\hline $\begin{array}{l}\text {.. I have already used reuse for a long time independently } \\
\text { away my work's software process . (..já faço reuso há muito } \\
\text { tempo no meu trabalho independente do processo) }\end{array}$ & \multirow[t]{3}{*}{$\begin{array}{l}\text { 33. I use the reuse technology } \\
\text { voluntarily in my work. }\end{array}$} \\
\hline $\begin{array}{l}\text {... I have some ready components that I developed to speed } \\
\text { up my work. (...tenho alguns componentes prontos que } \\
\text { desenvolvi e agilizam meu trabalho) }\end{array}$ & \\
\hline $\begin{array}{l}\text {..the organization has some components that I usually use } \\
\text { (..a organização dispõe de alguns componentes que costumo } \\
\text { usar.) }\end{array}$ & \\
\hline $\begin{array}{l}\text {..the software development process does not predict the } \\
\text { utilization of reuse. (..o processo de desenvolvimento de } \\
\text { software não preve a utilização de reuso) }\end{array}$ & \multirow[t]{3}{*}{$\begin{array}{l}35 . \quad \text { The reuse activities have } \\
\text { incompatibility with the } \\
\text { methodology of software } \\
\text { development organizations. }\end{array}$} \\
\hline $\begin{array}{l}\text {... software development methodology not allow for a } \\
\text { domain analysis. (.... metodologia de desenvolvimento de } \\
\text { software não permite a realização analise de dominio.) }\end{array}$ & \\
\hline $\begin{array}{l}\text {..the development methodology does not predict the } \\
\text { reusable components certification. (..a metodologia de } \\
\text { desenvolvimento não preve a certificação de componentes } \\
\text { reusaveis.) }\end{array}$ & \\
\hline $\begin{array}{l}\text {... Without automated tools it is hard to find and use } \\
\text { components. (...sem ferramentas automatizadas fica dificil } \\
\text { achar e usar componentes) }\end{array}$ & \multirow[t]{2}{*}{$\begin{array}{l}50 . \quad \text { The use of automated tools } \\
\text { is important for reuse adoption. }\end{array}$} \\
\hline $\begin{array}{l}\text {..the use of a Case tool with access to the repository is an } \\
\text { important factor for reuse deployment. (..a utização de Case } \\
\text { com acesso ao repositorio de componentes é importante para } \\
\text { implantação de reuso) }\end{array}$ & \\
\hline $\begin{array}{l}\text {... how do we demonstrate the money saved by the adoption } \\
\text { of reuse. (...como demonstrar a economia trazida pelo adoção } \\
\text { do reuso) }\end{array}$ & $\begin{array}{l}55 . \quad \text { Measurement of the reuse } \\
\text { levels should show return on } \\
\text { investment. }\end{array}$ \\
\hline $\begin{array}{l}\text {... one systematic process of domain analysis is a success } \\
\text { factor for reuse adoption. (...um processo sistematico de } \\
\text { analise de dominio é fator de sucesso para uso de reuso) }\end{array}$ & \multirow[t]{3}{*}{$\begin{array}{l}\text { 64. To have used a structured } \\
\text { software development process is a } \\
\text { success factor for reuse use. }\end{array}$} \\
\hline $\begin{array}{l}\text {... a defined process for development and component testing } \\
\text { is indispensable. (...um processo definido para } \\
\text { desenvolvimento e teste de componentes é indispensavel) }\end{array}$ & \\
\hline $\begin{array}{l}\text {..it's is necessary that all practitioners working within a } \\
\text { common systematic. (..é necessario que todos trabalhem } \\
\text { dentro de uma sistematica comum) }\end{array}$ & \\
\hline
\end{tabular}


As a result of these steps (1 and 2) the following beliefs properly classified according to the model presented above were identified. The source of each belief is identified beside each belief.

\section{A. Behavioral beliefs}

\section{Technology Maturity}

1. The reuse technology is mature. (Interview with experts)

2. The reuse technology has a well-defined development methodology of assets. (Interview with experts)

\section{Relative Advantage}

3. Reuse promises a quick time to market and a reduction in cost. (Northrop, 2004) (Interview with experts)

4. The cost of adoption of reuse technology is described as very high without significant short-term returns. (Frakes \& Kang, 2006)

5. Managerial levels think the investment with reuse is accounted for indirect costs not directly related to application development. (Northrop, 2004) (Lynex \& Layzell, 1998)

\section{Perceived Usefulness}

6. Developers believe that reuse reduces the cost and time for the development of a new application. (Gacek et al, 2001) (Interview with experts)

7. Reuse would require a structured process for quality release of the assets which would slow down the development process. (Lucredio et al., 2008)

8. The benefits of reuse will depend on the range of products the asset is planned to assist and the stability of the domains. (Interview with experts)

9. The lack of metrics for reuse makes it difficult to identify costs and benefits. (Frakes \& Kang, 2006) (Sherif \& Vinze, 2003) 
10. Managers react to implementation reuse due to lack of quantitative measures to assess the benefits and costs of their utilization. (Sherif \& Vinze, 2003) (Interview with experts)

\section{Perceived Ease of Use}

11. Reuse is difficult to implement in an organization. (Interview with experts)

12. The use of object orientation facilitates the creation of reusable assets. (Sherif \& Vinze, 2003)

13. The communication between creators and users of assets facilitates the adoption process. (Sherif \& Vinze, 2003)

14. The cost of developing a reusable asset depends on the technical competence of the staff in the methodology used. (Interview with experts)

15. The cost of developing a reusable asset depends on the quality of the development methodology used. (Interview with experts)

16. Developers believe that reuse increases the quality of a new application. (Interview with experts)

17. A systematic reuse process increases the developer's productivity. (Morisio et al., 2002) (Rine, 1997) (Interview with experts)

\section{Complexity}

18. Building reusable assets and assembling them to build future systems is a complex activity. (Sherif \& Vinze, 2003)

19. Reuse technology is complex because it involves the identification, construction, and maintenance of assets availability. (Interview with experts)

20. Developers believe that reuse is an opportunistic "hunter/gatherer" process that depends on the cognitive abilities of developers to locate the right domains and components. (Sherif \& Vinze, 2003)

21. The use of assets of limited scope or wide scope requires excessive effort to adapt to the new context. (Interview with experts)

22. The excess of parameterization of assets requires a high investment in the testing process. (Interview with experts) 


\section{Outcome expectations}

23. Developers are wary of the quality and performance of the assets to be reused. (Sherif \& Vinze, 2003) (Interview with experts)

24. The lack of reusable components to meet the future needs of a domain limits the success of technology adoption. (Interview with experts)

25. The lack of adequate assets documentation hinders and limits its use in the development process. (Knauber et al, 2000) (Interview with experts)

26. Software developer's belief that reuse will inhibit creativity: the "Not Invented Here', syndrome. (Sherif \& Vinze, 2003)

27. The evolution of the assets may create problems with older applications that use them. (Interview with experts)

28. Architecture of many levels that can be used in different applications is a critical factor for success of reuse implantation. (Rine \& Sonnemann, 1998) (Interview with experts)

29. A Quality Management assets approach has a significant impact on the development process. (Lucredio et al., 2008) (Sherif \& Vinze, 2003)

30. The quality of the assets is important to obtain the desired benefits such as defect/time reduction. (Lucredio et al., 2008) (Interview with experts)

\section{B. Normative beliefs}

\section{Image}

31. To develop software with reuse is a positive differential for my company and for me as a professional. (Interview with experts)

\section{Visibility}

32. Participate in a project with reuse is a positive factor for my work in the company. (Interview with experts) 


\section{Voluntariness of use}

33. I use the reuse technology voluntarily in my work. (Interview with experts)

\section{Social Factors}

34. The use of the technology reuse will facilitate my interaction with other technicians within and outside of my company. (Interview with experts)

\section{Control Beliefs}

\section{Compatibility}

35. The reuse activities have incompatibility with the methodology of software development organizations. (Sherif \& Vinze, 2003)

36. The use of asset repository when it is not considered a critical factor of success breeds dissatisfaction with the use of technology reuse. (Morisio et al., 2002) (Interview with experts)

37. Elements such as the organizational structure of the reuse group and their way to work hinder the deployment of technology reuse. (Joanes \& Northrop, 2010)

38. The lack of an educational and training program/mentoring program is a complicating factor for reuse. (Li \& Chang, 2009) (Catal, 2009)

39. The organization is resistant to a structure required to support the reuse technology which makes the adoption process very hard. (Sherif \& Vinze, 2003) (Interview with experts)

40. Managerial difficulty to allocate the necessary resources to implement the necessary infrastructure is an obstacle for adoption of reuse. (Frakes \& Kang, 2006)

\section{Facilitating Conditions}

41. Difficulty to locate reusable assets affects deployment. (Morisio et al., 2002) (Interview with experts)

42. The lack of funding to allocate to staff for the development of reusable assets hinders adoption. (Lucredio et al., 2008) (Mannion, 2002) 
43. The quality model usage has a strong influence on reuse success. (Sherif \& Vinze, 2003)

44. A repository of assets disintegrated from the development environment significantly complicates the process of reuse. (Sherif \& Vinze, 2003) (Interview with experts)

45. The availability of technician's talented creators of assets facilitates the adoption process. (Catal, 2009)

46. A pilot project success with metrics stimulates the adoption of reuse in the organization. (Interview with experts)

47. The lack of a well-organized and indexed software repository with appropriate search engines is a barrier to reuse adoption. (Frakes \& Kang, 2006)

48. An independent reusable assets development team has an influence on reuse success. (Lucredio et al., 2008)

49. Lack of experience of the technicians to analyze and design solutions for a range of applications of a specific domain rather than only one, hinders the adoption of reuse. (Joanes \& Northrop, 2010)

50. The use of automated tools is important for reuse adoption. (Lucredio et al., 2008) (Interview with experts)

51. Organizations that develop software based on a product family have advantages when compared to the software organizations that develop isolated products. (Lucredio et al., 2008)

52. Reusing assets extracted from existing products is the best way for success in reuse adoption. (Lucredio et al., 2008)

53. Configuration management is an essential element for a reuse program. (Frakes \& Kang, 2006) (Morisio et al., 2002) (Interview with experts)

54. Measuring the level of reuse in software is important for each adoption of reuse. (Poulin, 2006) (Lucredio et al., 2008)

55. Measurement of the reuse levels should show return on investment. (Poulin, 2006) (Lucredio et al., 2008) (Interview with experts)

56. The previous development of reusable assets is important for the process of reuse. (Li \& Chang, 2009) (Interview with experts) 
57. Reuse has to be adopted in a bottom-up approach to be effective. (Interview with experts)

58. The principal focus of developers is in projects not in reuse. (Catal, 2009)

59. A lack of a structured methodology to adoption is a bad factor for the process. (Northrop, 2004)

\section{Self-efficacy beliefs}

\section{Ability and Skill}

60. Reuse education isn't common. (Morisio et al., 2002) (Interview with experts)

61. Developers use reuse individually or informally in a common way. (Interview with experts)

62. Technicians use reuse without specific training. (Joanes \& Northrop, 2010) (Interview with experts)

\section{Past experience}

63. To have previous reuse experience is not necessary. (Lucredio et al., 2008)

64. To have used a structured software development process is a success factor for reuse use. (Interview with experts)

65. The use of object orientation is important for the adoption of reuse. (Interview with experts)

66. Reuse portions of code is a good practice. (Interview with experts)

67. The use of ready-made components has facilitated my work. (Interview with experts)

68. I had troubles using third party software. (Interview with experts) 


\subsection{MAPPING THE BELIEFS SYSTEM OF THE PRACTITIONERS INVOLVED IN A REUSE PROCESS ADOPTION}

We are proposing an instrument to support the structured part of individual interviews to capture of the belief's system of the practitioners involved in the organization's reuse technology adoption process, as described in item 3.3.

This instrument present the set of beliefs previously mapped and facilitates the assessment of the interviewee in its adherence to each belief and on the impact that those beliefs have in the process of technology adoption.

Fig. 14 presents an extract of the form established with all beliefs previously mapped.

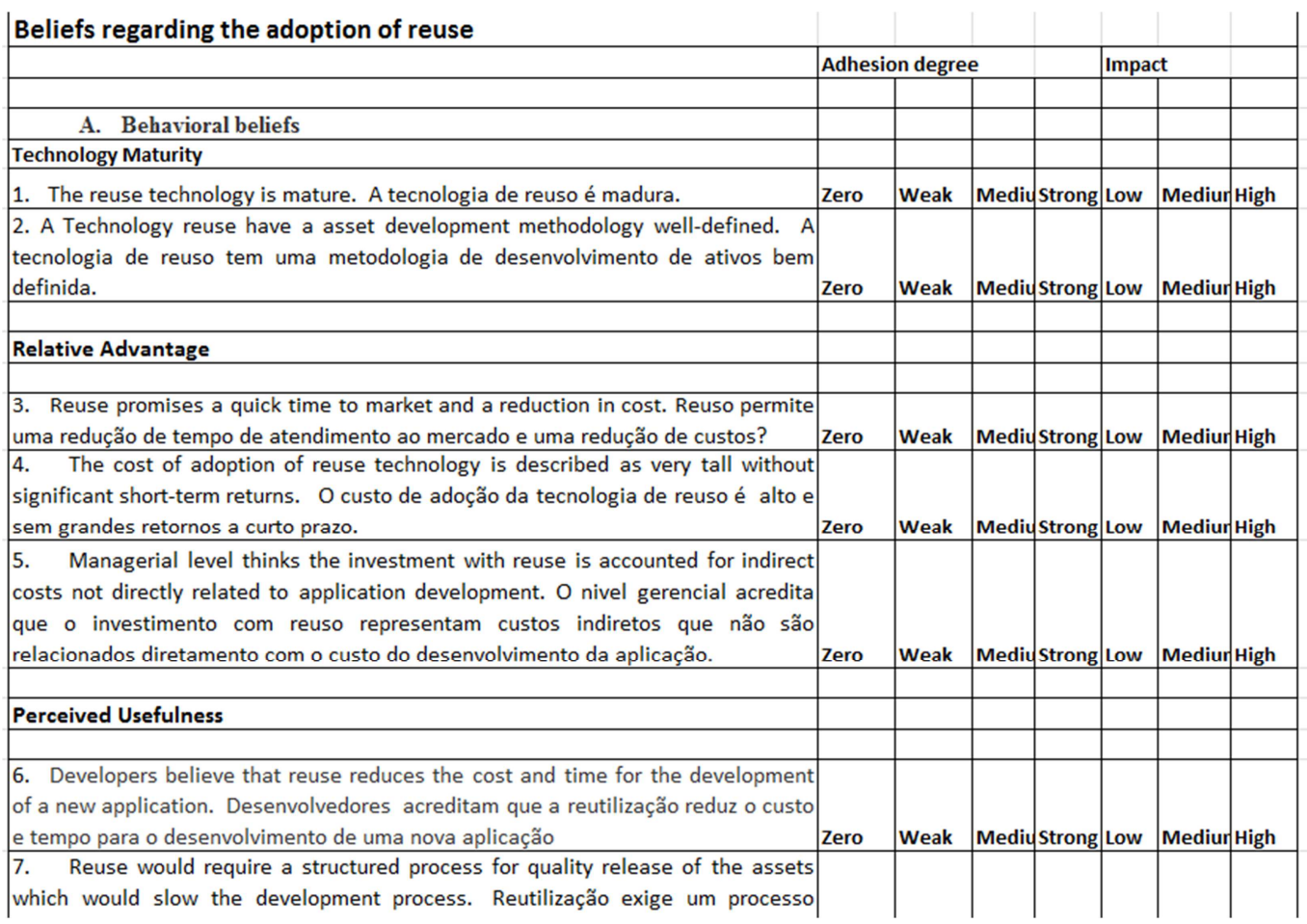

Figure 14 - Fragment of the Form to support the structured interview 


\subsection{APPLICATION PROCESS OF THE METHOD PROPOSED TO SUPPORT THE ADOPTION OF SOFTWARE REUSE TECHNOLOGY}

The method proposed in this work is summarized by the process described below for general application in a large organization that will adopt the technology of software reuse. The examples are referred to the case study with ethnography contained in Chapter 5.

\section{Process Activities:}

1. Identification of practitioners involved in the adoption process that will have their beliefs mapped. (Criteria suggested: years of work in software development, leadership, experience, if possible include all the practitioners of the group).

\section{Mapping of the group's beliefs at the beginning of the adoption process.}

\subsection{Performing semi-structured interview with the selected practitioners.}

2.1.1. Open question part. Use as Instrument questions contained in Appendix A

2.1.1.1. A "warm-up" question, which aims to connect the interviewee with the interview subject.

2.1.1.2. Questions related to the past experience of the interviewee in order to capture significant aspects of his professional life that may influence the adoption process.

2.1.1.3. At the end of the interview, questions allowing the interviewee to speak about the reuse technology, object of the adoption process.

2.1.2. Structured part. The respondents are presented with the collection of beliefs previously developed.

2.1.2.1. Instrument: Use a Form titled Beliefs Regard the Reuse Adoption in Appendix A.

2.1.2.2. For each of these beliefs, ask respondents to define their agreement on a scale of <zero, weak, medium, and strong> and impact this belief represents for the adoption process on a scale of <low, medium, high $>$. 
2.1.2.3. The interviewees should also be asked to cite other beliefs that may have been omitted from our list.

2.2. Data Analysis - The material collected from the interview represents the qualified belief system of each practitioner involved.

2.2.1. The open questions are summarized into significant aspects of the adoption process group. (e.g. pg..104 Significant results obtained with open questions)

2.2.2. The closed questions are tabulated to get an overview of the adhesion and impact of each belief for all the practitioners (e.g. pg. 106- Tabulation of the structured interview))

\section{Classification and selection of the beliefs for the re-signification process.}

3.1. The qualified beliefs are classified into four groups.

a) False Beliefs that can hinder the adoption process.

b) Conflicting Beliefs of high impact.

c) True Beliefs with high impact that can hinder the adoption process.

d) True Beliefs with high impact that can facilitate the adoption process.

Each belief of each group should be treated accordingly to support the process of technology adoption. The criteria we use for this are shown in Fig. 12 and defined on pg.71.

3.2. We recommend that the classification of beliefs is made using the Table 11 Standard Catalog of Weighted Beliefs.

4. Re-signification of beliefs. The false and conflicting beliefs are separated to be worked through the process of resignification of beliefs.

4.1. The most appropriate technique is chosen for each belief (pg. 75) and the process of re-signification to be adopted is prepared (e.g. pg. 112- Re-signification of Beliefs Identified).

4.2. The re-signification processes are applied for all practitioners, for each belief or group of belief.

5. Observation throughout the adoption process. The whole adoption process should be observed by the responsible for the conduct of this support method, so that the evolution of the beliefs of the practitioners after the process of re-signification is 
observed. Possible new beliefs that arise during the adoption process and deserve to be re-signified, and the mapped true beliefs that are abandoned by practitioners, during the practical work, should be subject to corrective action. 


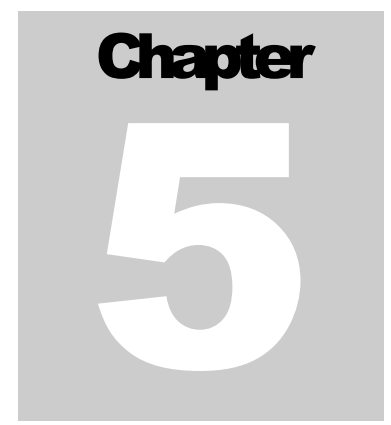

This chapter provides a description of our long-term case study with ethnography, applying the method proposed, during the adoption process of reuse technology in a large organization. It is made analysis of the practitioners' system of the belief involved in the process of adoption of the technology and using a belief re-signification process as established in the method.

\section{APPLICATION OF THE METHOD FOR THE PROCESS OF ADOPTION OF REUSE TECHNOLOGY IN A LARGE ORGANIZATION - A CASE STUDY WITH ETHNOGRAPHY}

The adoption of software reuse technology represents a significant change in the organization's software process and the way of working of the technicians involved.

We instantiate the classes of beliefs defined in our action model reasoned identifying for each class a set of beliefs as a way to support the application of the method to the adoption case study in a large organization and create a catalog of beliefs to guide the practitioners system beliefs.

The proposed method was applied in the process of reuse technology adoption in a large organization as a form of experimentation, refinement and validation of the results. To accomplish this task we used a qualitative multi-method procedure (Easterbrook et al., 2008) with a main method, a long-term case study (Runeson \& Host, 2008) conducted over 24 months of project duration, technology adoption in a large 
organization. We apply an ethnographic approach in this case study so as to be immersed in the everyday life of the project group.

Using a case study with ethnography is a consequence of the need for immersion in the organizational group culture, object of the process of adoption in order to monitor the behavior of practitioners in their own working environment, listening to their placements, observing their actions and reactions over the entire process. In this way we can see the evolution of their system of belief and the effect of the re-signification process carried out on them. Fetterman (2010) describes ethnography as "the art and science of describing a group or culture." An ethnographic study would include both structure (social structure or configuration of the group) and function (social relations among group members) (Fetterman, 2010). Ethnography enables a detailed view of the daily life of the group, their practices and behaviors (Forsey, 2010). The researcher is a participant observer and a participant listener within the group, performing a data collection of significant occurrences during the adoption process as well as analysis of the documents produced and the activities performed. In addition, the researcher conducted interviews to collect the involved practitioner's beliefs and to assess the evolution of these beliefs through the various aspects observed during the process (Forsey, 2010) (Boden et al., 2011).

\subsection{CASE STUDY CONTEXT AND DESCRIPTION}

We conducted a case study on a project of adoption of reuse technology in a large company during 24 months where we investigated the beliefs related to reuse of existing technology among those involved in the project, its effects (strength and impact) in the process of adoption and means of re-signification to them to make the process more effective. To do this we used an ethnographic approach (Passos, 2012) where we were involved throughout the project following and observing all the activities performed during the project. 
The organization has areas of software development in various locations in the country and this project of adoption was carried out in one of those areas that have around 250 practitioners involved in the process of development/evolution of software. The area of software development organization is certified ISO 9001:2008 and has an established and mature software's development and evolution process and a project management process based on PMBOK and SCRUM.

The focus of the project to adopt the reuse technology was one of the main business areas of the organization and was conducted with a description of the main business processes of the area, evaluation of the organization's software development/evolution process, proposed modifications in this process and training of practitioner involved (22 technicians). Analysis of process software environment support to the business process was also performed to identify opportunities for reuse, business component identification, specification and implementation of some of these components.

The project was carried out through a consulting contract with a research/consultancy institution, having as the first phase (one year duration), the project definition, the domain analysis of the business area involved and the survey of the main software that provide support for the business processes and the mapping of software features, identifying potential features for reuse.

Eight existing software to support the business process were analyzed and their csize was measured in function points (fp), where one $\mathrm{fp}$ is equivalent on average to 10 hours of development effort. The software are presented in Table 6. 
Table 6 - Software involved in project

\begin{tabular}{|c|l|l|}
\hline Software & Complexity(in fp) & Technology Platform \\
\hline P & 2757 & Java Open Source Tools \\
\hline C & 1719 & MS .NET \\
\hline G & 1011 & Java Open Source Tools \\
\hline S & 650 & Java Open Source Tools \\
\hline I & 382 & Java Open Source Tools \\
\hline J & 618 & Java Open Source Tools \\
\hline K & 377 & MS .NET \\
\hline L & 335 & MS.ASP \\
\hline
\end{tabular}

The organization's software development methodology was altered to incorporate the domain analysis practices. This phase is carried out, based on the steps of the figure below: 


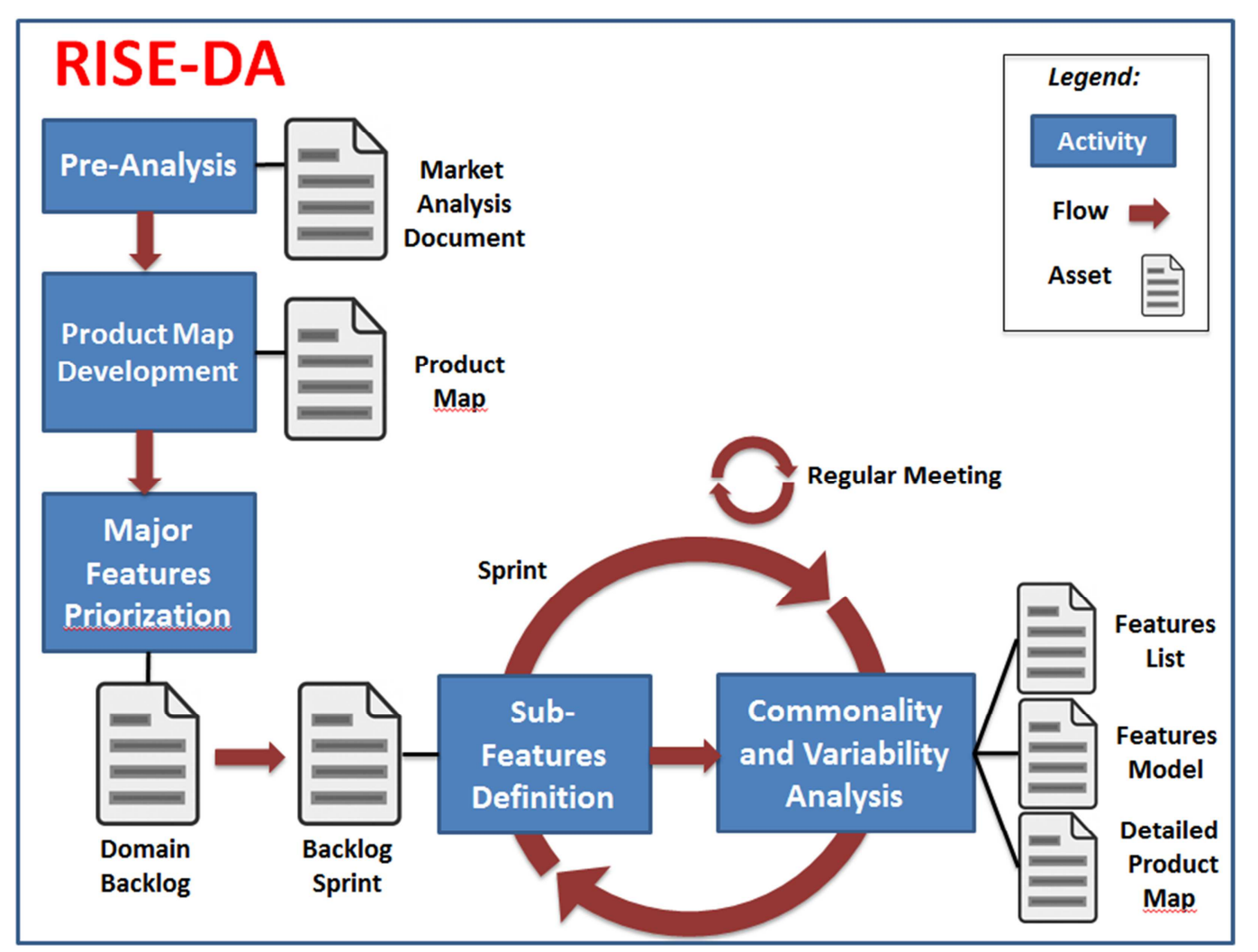

Figure 15 - Domain Analyses Process

A quantity of 136 features were identified and used to create the application map at this stage. Upon completion of this phase, adjustments were made in the organization's software development process, previously adapted.

The second phase of the project (one year duration) focused on defining the application architecture to support reuse, in accordance with the development frameworks Java and MS.NET which are used as standards for software development in the organization. The construction of reusable components adhering to this defined architecture was held. As in the previous phase, this phase was also started by a team training process, followed by adjustment of the organization's software development methodology to incorporate reuse practices according to the figure below: 


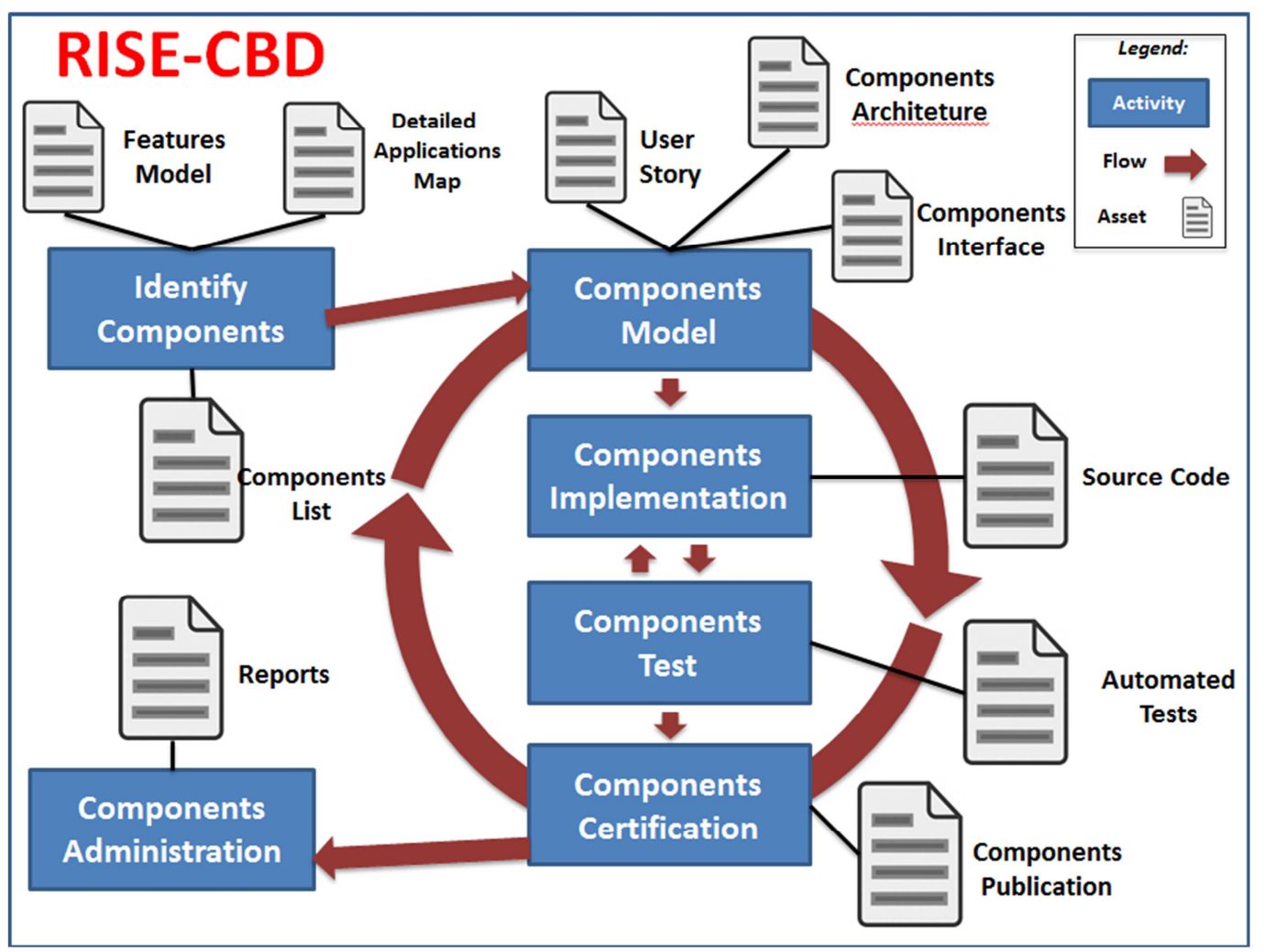

Figure 16 - Component based development

At this stage ten business components were identified. The selected components were implemented using the following environment support tools:

- Repository of components: Redmine

- Repository of source-code: SVN

- Continuous Integration: Jenkins

- Quality Control: Sonar

- IDE: Netbeans

The quality control of this phase presents the following indicators:

- Correctness - $100 \%$ of the non-compliance inspection resolved

- Maintainability

- $100 \%$ of architecture quality

- $\quad 90,9 \%$ of design quality

- $79,8 \%$ of code quality

- Tests 
- $89.5 \%$ of coverage of tests and $100 \%$ of tests performed successfully

- Performance

- Maximum answer time of 2s (two seconds) for any operation

A pilot was conducted with refactoring of software adequacy for the proposed architecture and use of components developed.

At the end of the phase, adjustments were made to previously adapted software development processes, as occurred in the previous phase.

The data collection involved semi-structured interviews, observation of meetings and project tracking, observation of the practitioners' behavior, observation of the work processes, and analysis of existing documents produced during the process.

\subsection{INTERVIEW}

We use a semi-structured interview. Open questions allow the interviewee to tell their story and experience. We began the interviews with a "warm-up" question which aimed to connect the interviewee with the interview subject. Then two questions were asked, related to the past experience of the interviewee in order to capture significant aspects of his professional life that may influence the adoption process.

In a well-structured part, the respondents were presented with the collection of beliefs previously developed. For each of these beliefs, we asked respondents to define their agreement on a scale of degree <zero, weak, medium, and strong> and what impact $<$ low, medium, high $>$ this belief represents for the adoption process. At this stage, we used the standard instrument described in item 4.2. The interviewees were also asked to cite other beliefs for each class of beliefs that may have been considered omitted and their considered significant.

Finally there were two other open questions, aimed at allowing the interviewee to speak about the reuse technology, object of the adoption process. After 
analysis of this material, we mapped the belief system of each practitioner involved. The basic questionnaire used in the interview as well as the beliefs of the evaluation instrument is presented in Appendix A.

For the interviews, we selected a sample group of technicians involved in the process, consisting of two project managers, two coordinators of development and six architects/developers/testers/process assurance peoples. All participants had more than 10 years of experience. The interviews were conducted at the beginning of the adoption project, before the formal training process, shaped to allow for identifying the profile of the group's beliefs. Each interview lasted approximately an hour and was recorded.

\subsection{OBSERVATIONS AND DOCUMENTS ANALYSIS}

The observation process was conducted by the researcher throughout the project and involved project planning meetings, the execution of project activities, the meetings of project groups, the training process for adoption, discussions of changes of software development/evolution process standards for adoption of new practices, the redefinition of architectural software, the encoding process, testing and certification of components identified, the review meetings and adjustment of the new process set after use.

To perform the observation, we were immersed throughout the project of adoption of reuse technology, living the daily life of the working group, taking part of technical meetings and management meetings of project tracking. The main focus of observation in the meetings was the practitioners, regarding the various aspects of the use of the technology. In the activities execution process, the focus of observation was the behavior involved in execution and discussion of the technical processes.

This observation process was carried out to analyse the previously identified beliefs and new beliefs, perhaps related, track this beliefs interference in the adoption process, identify which behaviours were adopted by the practitioners involved in the 
process and to verify how the interaction between the technical work process interfered in the beliefs. Informal interviews with project participants were held and field notes generated.

We had full access to the organization and all confidential material and artifacts of the project. Meeting minutes, project reports, the new software process documentation, suggested changes and artifacts generated during the various stages of adoption were analyzed. This analysis complemented the observations to certify that everything that was raised in the interviews and planning of the project were consistent with the effective behavior of the technicians.

The observation process was performed according to the observation guide presented in Appendix B and their analyses are presented in section 5.6.

\subsection{DATA ANALYSIS AND RESULTS}

We began the analysis of the data from the interviews in the first week of the project's initialization and the results were mapped into our model, allowing for the preparation of a belief re-signification plan as well as providing additional information for the observation process.

A fragment of the transcription and analysis of the open questions is presented in Table 7. 
Table 7 - Fragment of the Interview's transcription and analysis

\begin{tabular}{|l|l|}
\hline $\begin{array}{l}\text { "..my colleagues and I have reused } \\
\text { portions of code and visual } \\
\text { components for a long time ..." ("Eu e }\end{array}$ & Belief - Reuse portions of code is a \\
meus colegas fazemos reuso de \\
porções de código e componentes \\
visuais há bastante tempo...”)
\end{tabular}


". I had problems with a purchased component that did not make what the specification was saying generating rework..” (“..tive problemas com um componente comprado que não fazia aquilo que a especificação dizia gerando retrabalho..")

“.. I've used components that were not the expected and I had to waste a lot of time correcting mistakes" ( “.. já usei componentes que não faziam o eu se esperava e tive que perder muito tempo corrigindo os erros")

".. for me to participate in a project like this is important for my professional participate in a reuse project is life" (".. para mim a participação de um projeto como este e importante para minha vida profissional”)

“..participate of a reuse project is important for me as a professional because It provides a differential" ... (."participar de um projeto do reuso é importante para mim como profissional porque me fornece um diferencial...")

The significant results obtained with open questions about the group can be summarized in the following items where the majority of practitioners: 
a) Considered reuse in software development important.

b) Had positive experiences with the reuse of visual components.

c) Cited as a negative experience having used a component that did not work as specified, as a waste of time.

d) Considered participate in a reuse project important for their career.

e) Considered important to measure the degree of reuse of components and how much money was saved reusing it in a development.

f) Believed that having a structured software process is a success factor for reuse.

g) Believed that the use of quality ready components with will facilitate this work.

After applying the structured part of evaluation of the belief system they reported to have nothing more to add to the presented set of beliefs.

After analysis of the content of the interview, we mapped the vision of each interviewee before the start of the adoption process was raised as well as the characterized importance of each belief to the adoption process and the impact it would have.

The result of the semi- structured interviews about the agreement and the impact to the set of beliefs presented are shown in the Table 8 below: 
Table 8 - Tabulation of the semi-structured interviews

Tabulation of interviews

\begin{tabular}{|c|c|c|c|c|c|c|c|}
\hline & \multicolumn{4}{|c|}{ Adhesion degree } & \multicolumn{3}{|c|}{ Impact } \\
\hline & Zero & Weak & Mediuns & Strong & \begin{tabular}{|l|l} 
Low & 1 \\
\end{tabular} & Medium & High \\
\hline \multicolumn{8}{|l|}{ A. Behavioral beliefs } \\
\hline \multicolumn{8}{|l|}{ Technology Maturity } \\
\hline 1. The reuse technology is mature. & 9 & & 1 & & 2 & 1 & 7 \\
\hline $\begin{array}{l}\text { 2. The reuse technology has a well-defined development } \\
\text { methodology of assets. }\end{array}$ & 3 & 5 & 2 & & 1 & 6 & 3 \\
\hline \multicolumn{8}{|l|}{ Relative Advantage } \\
\hline $\begin{array}{l}3 . \quad \text { Reuse promises a quick time to market and a reduction in } \\
\text { cost. }\end{array}$ & & & 4 & 6 & & 4 & 6 \\
\hline $\begin{array}{l}\text { 4. The cost of adoption of reuse technology is described as very } \\
\text { high without significant short-term returns. }\end{array}$ & 3 & 1 & 3 & 3 & 2 & 4 & 4 \\
\hline $\begin{array}{l}\text { 5. Managerial levels think the investment with reuse is } \\
\text { accounted for indirect costs not directly related to application } \\
\text { development. }\end{array}$ & 3 & & 2 & 5 & 2 & 2 & 6 \\
\hline \multicolumn{8}{|l|}{ Perceived Usefulness } \\
\hline $\begin{array}{l}\text { 6. Developers believe that reuse reduces the cost and time for } \\
\text { the development of a new application. }\end{array}$ & & 1 & & 9 & & 3 & 7 \\
\hline $\begin{array}{l}\text { 7. Reuse would require a structured process for quality release } \\
\text { of the assets which would slow down the development process. }\end{array}$ & 3 & 2 & 4 & 1 & & 5 & 5 \\
\hline $\begin{array}{l}\text { 8. The benefits of reuse will depend on the range of products } \\
\text { the asset is planned to assist and the stability of the domains. }\end{array}$ & & & & 10 & & 3 & 7 \\
\hline $\begin{array}{l}\text { 9. The lack of metrics for reuse makes it difficult to identify costs } \\
\text { and benefits. }\end{array}$ & 1 & 1 & & 8 & & 2 & 8 \\
\hline $\begin{array}{l}\text { 10. Managers react to implementation reuse due to lack of } \\
\text { quantitative measures to assess the benefits and costs of their } \\
\text { utilization. }\end{array}$ & & 2 & 1 & 7 & & 3 & 7 \\
\hline Perceived Ease of Use & Zero & Weak & Mediun & Strong & Low & Medium & High \\
\hline 11. Reuse is difficult to implement in an organization. & 1 & 1 & 5 & 3 & 1 & 3 & 6 \\
\hline $\begin{array}{l}\text { 12. The use of object orientation facilitates the creation of } \\
\text { reusable assets. }\end{array}$ & 1 & & 1 & 8 & 2 & 2 & 6 \\
\hline $\begin{array}{l}\text { 13. The communication between creators and users of assets } \\
\text { facilitates the adoption process. }\end{array}$ & & & 2 & 8 & 1 & 5 & 4 \\
\hline $\begin{array}{l}\text { 14. The cost of developing a reusable asset depends on the } \\
\text { technical competence of the staff in the methodology used. }\end{array}$ & 1 & 2 & 2 & 5 & 2 & 2 & 6 \\
\hline $\begin{array}{l}\text { 15. The cost of developing a reusable asset depends on the quality } \\
\text { of the development methodology used. }\end{array}$ & 3 & 3 & 3 & 1 & 4 & 3 & 3 \\
\hline $\begin{array}{l}\text { 16. Developers believe that reuse increases the quality of a new } \\
\text { application. }\end{array}$ & 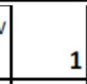 & 1 & 5 & 3 & 3 & 6 & 4 \\
\hline $\begin{array}{l}\text { 17. A systematic reuse process increases the developer's } \\
\text { productivity. }\end{array}$ & s & 1 & 1 & 1 & 2 & 2 & 8 \\
\hline
\end{tabular}




\begin{tabular}{|c|c|c|c|c|c|c|c|}
\hline Complexity & & & & & & & \\
\hline $\begin{array}{l}\text { 18. Building reusable assets and assembling them to build future } \\
\text { systems is an complex activity. }\end{array}$ & 2 & & 5 & 3 & & 5 & 5 \\
\hline $\begin{array}{l}\text { 19. Reuse technology is complex because it involves the } \\
\text { identification, construction, and maintenance of assets availability. }\end{array}$ & 1 & 1 & 3 & 5 & & 5 & 5 \\
\hline $\begin{array}{l}\text { 20. Developers believe that reuse is an opportunistic } \\
\text { "hunter/gatherer" process that depends on the cognitive abilities } \\
\text { of developers to locate the right domains and components. }\end{array}$ & 6 & 2 & 2 & & 6 & 3 & 1 \\
\hline $\begin{array}{l}\text { 21. The use of assets of limited scope or wide scope require } \\
\text { excessive effort to adapt to the new context. }\end{array}$ & 2 & & 3 & 5 & 1 & 5 & 4 \\
\hline $\begin{array}{l}\text { 22. The excess of parameterization of assets requires a high } \\
\text { investment in the testing process. } \\
\end{array}$ & & & 2 & 8 & & 3 & 7 \\
\hline Outcome expectations & Zero & Weak & Mediun & Strong & Low & Medium & High \\
\hline \begin{tabular}{|l|}
$23 . \quad$ Developers are wary of quality and performance of the \\
assets to be reused.
\end{tabular} & 1 & 3 & 2 & 4 & 3 & 2 & 5 \\
\hline $\begin{array}{l}\text { 24. The failure of reusable components to meet the future } \\
\text { needs of a domain limits the success of technology adoption. }\end{array}$ & & & 5 & 5 & & 5 & 5 \\
\hline $\begin{array}{l}\text { 25. The lack of adequate assets documentation hinders and } \\
\text { limits its use in the development process. }\end{array}$ & & & 2 & 8 & 1 & 2 & 7 \\
\hline $\begin{array}{l}\text { 26. Software developer's belief that reuse will inhibit creativity: } \\
\text { the "Not Invented Here" syndrome. }\end{array}$ & 6 & 2 & 2 & & 8 & 2 & \\
\hline $\begin{array}{l}\text { 27. The evolution of the assets may create problems with older } \\
\text { applications that use them. }\end{array}$ & & 3 & 3 & 4 & 2 & 1 & 7 \\
\hline $\begin{array}{l}\text { 28. Architecture of many levels that can be used in different } \\
\text { applications is a critical factor for success of reuse implantation. }\end{array}$ & 1 & 1 & 1 & 7 & & 1 & 9 \\
\hline $\begin{array}{l}\text { 29. A Quality Management assets approach has a significant } \\
\text { impact on the development process. }\end{array}$ & & & 1 & 9 & 1 & 1 & 8 \\
\hline $\begin{array}{l}30 . \quad \text { The quality of the assets is important to obtain the desired } \\
\text { benefits such as defect/time reduction. }\end{array}$ & & & & 10 & & & 10 \\
\hline B. Normative beliefs & & & & & & & \\
\hline & & & & & & & \\
\hline Image & & & & & & & \\
\hline $\begin{array}{l}\text { 31. To develop software with reuse is a positive differential for my } \\
\text { company and for me as a professional. }\end{array}$ & & & & 10 & & 4 & 6 \\
\hline Visibility & & & & & & & \\
\hline $\begin{array}{l}\text { 32. To participate in a project with reuse is a positive factor for my } \\
\text { work in the company. }\end{array}$ & & & 3 & 7 & & 4 & 6 \\
\hline Voluntariness of use & & & & & & & \\
\hline 33. I use the reuse technology voluntarily in my work. & & 1 & 2 & 7 & & 3 & 7 \\
\hline Social Factors & & & & & & & \\
\hline $\begin{array}{l}\text { 34. The use of the technology reuse will facilitate my interaction } \\
\text { with other technicians within and outside of my company. }\end{array}$ & 1 & & 4 & 5 & 2 & 4 & 4 \\
\hline
\end{tabular}




\begin{tabular}{|c|c|c|c|c|c|c|c|}
\hline c. Control Beliefs & & & & & & & \\
\hline Compatibility & Zero & Weak & Mediun & Strong & Low & Medium & High \\
\hline $\begin{array}{l}\text { 35. The reuse activities have incompatibility with the } \\
\text { methodology of software development organizations. }\end{array}$ & 4 & 2 & 3 & 1 & 4 & 2 & 4 \\
\hline $\begin{array}{l}\text { 36. The use of asset repository when it is not considered a } \\
\text { critical factor of success breeds dissatisfaction with the use of } \\
\text { technology reuse. }\end{array}$ & 3 & & 3 & 4 & 4 & 3 & 3 \\
\hline $\begin{array}{l}\text { 37. Elements such as the organizational structure of the reuse } \\
\text { group and their way to work hinder the deployment of technology } \\
\text { reuse. }\end{array}$ & 1 & & 3 & 6 & & 4 & 6 \\
\hline $\begin{array}{l}\text { 38. The lack of an educational and training/mentoring program } \\
\text { is a complicating factor for reuse. }\end{array}$ & & 2 & 3 & 5 & 1 & 3 & 6 \\
\hline $\begin{array}{l}\text { 39. The organization is resistant to a structure required to } \\
\text { support the reuse technology which makes the adoption process } \\
\text { very hard. }\end{array}$ & 1 & 1 & 3 & 5 & & 1 & 9 \\
\hline $\begin{array}{l}\text { 40. Managerial difficulty to allocate the necessary resources to } \\
\text { implement the necessary infrastructure is an obstacle for adoption } \\
\text { of reuse. }\end{array}$ & & & 4 & 6 & & 4 & 6 \\
\hline Facilitating Conditions & & & & & & & \\
\hline & & & & & & & \\
\hline 41. Difficulty to locate reusable assets affects deployment. & & & 3 & 7 & & 3 & 7 \\
\hline $\begin{array}{l}\text { 42. The lack of funding to allocate to staff for the development } \\
\text { of reusable assets hinders adoption. }\end{array}$ & & 2 & 1 & 7 & 1 & 2 & 7 \\
\hline $\begin{array}{l}\text { 43. The quality model usage has a strong influence on reuse } \\
\text { success. }\end{array}$ & & 1 & 3 & 6 & & 2 & 8 \\
\hline $\begin{array}{l}\text { 44. A repository of assets disintegrated from the development } \\
\text { environment significantly complicates the process of reuse. }\end{array}$ & 1 & & 4 & 5 & & 4 & 6 \\
\hline $\begin{array}{l}\text { 45. The availability of technician's talented creators of assets } \\
\text { facilitates the adoption process. }\end{array}$ & 2 & & 4 & 4 & 1 & 4 & 5 \\
\hline $\begin{array}{l}\text { 46. A pilot project success with metrics stimulates the adoption } \\
\text { of reuse in the organization. }\end{array}$ & 1 & & 3 & 6 & & 4 & 6 \\
\hline $\begin{array}{l}\text { 47. The lack of a well-organized and indexed software repository } \\
\text { with appropriate search engines is a barrier to reuse adoption. }\end{array}$ & & 1 & 4 & 5 & & 5 & 5 \\
\hline $\begin{array}{l}\text { 48. Independent reusable assets development team has an } \\
\text { influence on reuse success. }\end{array}$ & 1 & & 4 & 5 & 1 & 4 & 5 \\
\hline $\begin{array}{l}\text { 49. Lack of experience of the technicians to analyze and design } \\
\text { solutions for a range of applications of a specific domain rather } \\
\text { than only one, hinders the adoption of reuse. }\end{array}$ & & & 2 & 8 & 1 & 1 & 8 \\
\hline 50. The use of automated tools is important for reuse adoption. & 1 & 1 & 4 & 4 & 1 & 4 & 5 \\
\hline $\begin{array}{l}\text { 51. Organizations that develop software based on a product family } \\
\text { have advantages when compared to the software organizations } \\
\text { that develop isolated products. }\end{array}$ & 1 & & 2 & 7 & & 2 & 8 \\
\hline $\begin{array}{l}\text { 52. Reusing assets extracted from existing products is the best way } \\
\text { for success in reuse adoption. }\end{array}$ & 1 & & 5 & 4 & & 4 & 6 \\
\hline $\begin{array}{l}\text { 53. Configuration management is an essential element for a reuse } \\
\text { program. }\end{array}$ & & & & 10 & & 4 & 6 \\
\hline $\begin{array}{l}\text { 54. Measuring the level of reuse in software is important for each } \\
\text { adoption of reuse. }\end{array}$ & 1 & & 3 & 6 & 2 & 1 & 7 \\
\hline $\begin{array}{l}\text { 55. Measurement of the reuse levels should show return on } \\
\text { investment. }\end{array}$ & & & 1 & 9 & 1 & 1 & 8 \\
\hline $\begin{array}{l}\text { 56. The previous development of reusable assets is important for } \\
\text { the process of reuse. }\end{array}$ & & 1 & 4 & 5 & 2 & 3 & 5 \\
\hline
\end{tabular}




\begin{tabular}{|c|c|c|c|c|c|c|c|}
\hline & Zero & Weak & Mediun & nStrong & Low & Medium & High \\
\hline $\begin{array}{l}\text { 57. Reuse has to be adopted in a bottom-up approach to be } \\
\text { effective. }\end{array}$ & 3 & 1 & 3 & 3 & & 3 & 7 \\
\hline 58. The principal focus of developers are in projects not in reuse. & 1 & & 4 & 5 & & 3 & 7 \\
\hline $\begin{array}{l}\text { 59. A lack of a structured methodology to adoption is a bad factor } \\
\text { for the process. }\end{array}$ & & 1 & 2 & 7 & & 4 & 6 \\
\hline \multicolumn{8}{|l|}{ D. Self-efficacy beliefs } \\
\hline \multicolumn{8}{|l|}{ Ability and Skil } \\
\hline 60. Reuse education isn't common. & 2 & 1 & 4 & 3 & & 1 & 9 \\
\hline $\begin{array}{l}\text { 61. Developers use reuse individually or informally in a common } \\
\text { way. }\end{array}$ & & 1 & 4 & 5 & 3 & 5 & 2 \\
\hline 62. Technicians use reuse without specific training. & & & 4 & 6 & 1 & 4 & 5 \\
\hline
\end{tabular}

Analyzing Table 8, the qualified beliefs were classified into four groups that should be treated accordingly to support the process of technology adoption, according to the criteria shown in Fig. 12. Eight highly significant False Beliefs were identified and considered of high impact for the adoption process, and represents, in our view, hindering factors for the adoption process. Other beliefs that cause difficulties were identified with $25 \%$ coverage of the sample. Moreover, conflicting beliefs were identified in the sample where the respondent group was divided into extremes in the degree of adherence. We considered a conflicting belief that when at least $25 \%$ of the interviewees have a degree of adherence zero or week and at least another $25 \%$ have adherence degree medium or strong. The same applies to the degree of impact (at least 25\% low and at least $25 \%$ high).

We can summarize these results as:

a) False Beliefs that can hinder the adoption process:

1. The reuse technology isn't mature.

2. The reuse technology doesn't have a well-defined development methodology of assets.

4. The cost of adoption of reuse technology is described as very high, without significant short-term returns

9. The lack of metrics for reuse makes it difficult to identify costs and benefits. 
37. Elements such as the organizational structure of the reuse group and their way to work hinder the deployment of technology reuse.

b) True Beliefs with high impact that can facilitate the adoption process:

3. Reuse promises a quick time to market and a reduction in cost.

5. Managerial levels think the investment with reuse is accounted for as indirect costs not directly related to application development.

6. Developers believe that reuse reduces the cost and time for the development of a new application.

8. The benefits of reuse will depend on the range of products the asset is planned to assist and the stability of the domains.

16. Developers believe that reuse increases the quality of a new application.

31. To develop software with reuse is a positive differential for my company and for me as a professional.

32. To participate in a project with reuse is a positive factor for my work in the company.

33. I use the reuse technology voluntarily in my work.

46. A pilot project success with metrics stimulates the adoption of reuse in the organization.

50. The use of automated tools is important for reuse adoption.

52. Reusing assets extracted from existing products is the best way for success in reuse adoption.

c) True Beliefs with high impact that can hinder the adoption process:

11. Reuse is difficult to implement in an organization.

24. The failure of reusable components to meet the future needs of a domain limits the success of technology adoption. 
25. The lack of adequate assets documentation hinders and limits its use in the development process.

27. The evolution of the assets may create problems with older applications that use them.

40. Managerial difficulty to allocate the necessary resources to implement the necessary infrastructure is an obstacle for adoption of reuse.

49. Lack of experience of the technicians to analyze and design solutions for a range of applications of a specific domain rather than only one, hinders the adoption of reuse.

59. A lack of a structured methodology to adoption is a bad factor for the process.

d) Conflicting beliefs of high impact:

7. Reuse would require a structured process for quality release of the assets which would slow down the development process.

15. The cost of developing a reusable asset depends on the quality of the development methodology used.

35. The reuse activities have incompatibility with the methodology of software development organization.

57. Reuse has to be adopted in a bottom-up approach to be effective.

The numbers beside of each belief refer to the set of beliefs presented in the interview form.

The false and conflicting beliefs identified were separated to be worked first through the process of re-signification of beliefs. 


\subsection{RE-SIGNIFICATION OF BELIEFS}

The process of re-signification of beliefs was conducted through the use of various techniques. Two workshops, one at the beginning of the project and the other half way through presented practical cases employing reuse technology. In developing the work, those involved were encouraged to use the techniques, practices and conduct such as domain analysis activities as a means of supplementing the knowledge and encouraging reformulation of beliefs.

The work of revision and adaptation of the software process of the organization led the participants through a detailed reflective process of the technology operationalization approach. We observe how existing beliefs were discussed and adjusted/modified during the execution of the work. This led to a change of view that was confirmed in follow-up meetings.

The re-signification process has as its first focus the false beliefs as we can see below:

The belief 1 "The reuse technology isn't mature" and the belief 9 "The lack of metrics for reuse makes it difficult to identify costs and benefits" and the belief 4 "The cost of adoption of reuse technology is described as very high, without significant shortterm returns" were re-signified through examples that showed the use of technology in various large organizations, associated with reading articles with reported practical experiences.

The belief 2 "The reuse technology has a well-defined development methodology of assets" was re-signified through the presentation of the methodology and its use in a pilot of analysis and domain implementation and validation of key components.

The belief 9 "The lack of metrics for reuse makes it difficult to identify costs and benefits" was re-signified through the practical experience of defining the monitoring of the components in the repository to allow for measuring the degree of reuse and provide information to the manager. 
The belief 37 "Elements such as the organizational structure of the reuse group and their way to work hinder the deployment of technology reuse" was re-signified through the experience during the group work process in which it was to take responsibility for the parts certification process. This process was experimented in the pilot phase.

The conflicting beliefs have been clarified and re-signified through work with the entire group as described below:

The belief 35 "The reuse activities have incompatibility with the methodology of software development organizations" was re-signified during the adaptation of the organization's software process to allow for the inclusion of procedures for technology reuse as well as the restructuring of the software development environment for adequate customization of the tools used. This belief of perceived control was reformulated by the hands-on change, instantiation and execution of the process.

The belief 7 "The reuse would require a structured process for quality release of the assets which would slow down the development process" and the belief 15 "The cost of developing a reusable asset depends on the quality of the development methodology used" were re-signified by presenting the certification process of components inserted in the process of software development/evolution of the organization at the time of their adaptation to allow for introducing reuse. While running a pilot the group had the opportunity to participate in the experience of using the process.

The belief 57 "The reuse has to be adopted in a bottom-up approach to be effective" has been clarified and re-signified by developing the domain analysis pilot project, where in addition to the top-down process mapping a bottom up analysis of the existing software that supported the business processes was conducted.

The true beliefs with high impact that can hinder the adoption process were managed/treated during the adoption process so that the negative effects on the process were neutralized, as we can see in the following cases:

The beliefs 24, 25 and 27 were treated during the adaptation activity of the organization's software process to support reuse as well as for the realization of the pilot implementation of the components and the new architecture. 
The belief 11 "Reuse is difficult to implement in an organization" and the belief 59 "A lack of a structured methodology for adoption is a bad factor for the process" were subject to treatment by presenting to the group all the planning of the technology adoption project with its phases and control points.

The belief 40 "Managerial difficulty to allocate the necessary resources for implementing the necessary infrastructure is an obstacle for adoption of reuse" was transformed into an adoption project risk factor to be submitted to a project risk management process.

The belief 49 "Lack of experience of the technicians to analyze and design solutions for a range of applications of a specific domain rather than only one, hinders the adoption of reuse" was treated through the training realized at the start of each phase of the adoption process and with practical work in the domain analysis and implementation of the components in the pilot project.

The true beliefs with high impact that can facilitate the adoption process were strengthened in initial training provided in each phase as well as in the group's work meetings.

Some specific cases of individual beliefs (false and conflicting) were objects of special treatment through conversation and discussion of practical situations that stimulated the technician to perform a critical analysis and review of their initial beliefs.

\subsection{SIGNIFICANT OBSERVATIONS RECORDED DURING THE ADOPTION PROCESS}

Analyzing and condensing the data collected during the ethnographic study, we summarize the results of the case study in order to identify and understand how the system of beliefs of the practitioners was affected during the adoption process. The positive effects of the use of re-signification techniques on the beliefs of the team were observed. 
In meetings to discuss work and planning we had the opportunity to observe many times people sustaining behavior from a belief and reshaping it along the iterative process, as well as exhibiting a very different behavior than previously advocated.

In several discussion meetings and closing stages it was found that the beliefs of the practitioners, identified at the beginning, were indeed re-signified, and that made the adoption of reuse technology in the organization more effective.

We can cite some sample data condensed from observation record:

- In the reuse technology adoption project planning meetings:

○ "I am surprised by all this process to use reuse." ("Estou surpreso com todo este processo para usar reuso.")

○ "I thought that implementing reuse was much simpler" ("Pensei que para implantar reuso fosse bem mais simples")

○ "I was surprised with all this planning and I think the work process is well organized." ("Fiquei surpreso com todo este planejamento e acho que o processo de trabalho esta bem organizada.")

- After the first workshop, focused on domain analysis:

○ "I was surprised by the existence of a set of criteria to evaluate the prioritizing of the features." ("Fiquei surpreso com a existência de um conjunto de critério para avaliar a priorização das features.")

○ "I did not know the concepts of analysis of similarity and variability." ("Não conhecia os conceitos de análise de similaridade e variabilidade.”)

- "I was surprised with the various examples of success of reuse deployment." (“Surpreendi-me com os vários exemplos de sucesso de implantação de reuso.”)

○ "The practical work to find reusable components, demonstrated to me a process that I was unaware of." ("Os trabalhos práticos me mostraram um processo que desconhecia para achar componentes reusáveis.") 
- At meetings for adapting the organization's software development process to incorporate the domain analysis activities:

○ "I did not know there was an organized process for doing the domain analysis." ("Eu não sabia que havia um processo arrumado para fazer a análise de domínio.”)

○ "It will actually be possible to change the organization's software development process! Great!" ("Vai ser mesmo possível alterar o processo de desenvolvimento de software da organização! Ficou ótimo!”)

○ "Using this way of working, it is easy to identify the features that can be reused." ("Usando esta forma de trabalho fica fácil identificar as features que poderão ser reusadas.”)

○ "It's really important to create the features map as a standard process document." ("É realmente importante criar o mapa de features como documento padrão do processo.”)

○ "The main adjustment that needs to be done in the defined process is a deeper level of detail in the description of activities. It is important for the document to be as close to the reality of the organization as possible, by matching the roles of domain analysis process and the roles of the process "Implementing Software Solutions" of the Organization. It is also interesting to use examples of cases within the context of the Organization." (“O principal ajuste que precisa ser realizado no processo definido é um aprofundamento no nível de detalhamento da descrição das atividades É importante deixar o documento mais próximo à realidade da organização fazendo a correspondência entre os papéis do processo de análise de domínio e os papéis do processo "Implementar Soluções de Software" da Organização. Também é interessante o uso de casos dentro do contexto da Organização.) 
- During domain analysis using the adapted software development process of the organization:

$\circ$ "The mapping process of the value chain and business processes, and the association with existing software is interesting." ("É interessante o processo de levantamento da cadeia de valores e dos processos de negócio e a associação com os softwares existentes.")

○ "The features' identification process made from the existing software (bottom up) and then associated with business processes (top down) is a very useful and organized way of working." ("O processo de identificação das features feito a partir dos softwares existentes (bottom up) e em seguida associados com os processos de negócio (top down) é uma forma muito útil e organizada de trabalhar.")

$\circ$ "I found it very interesting the work if identifying the equivalence between applications by using the domain model." ("Achei muito interessante o trabalho de identificar as equivalências entre as aplicações através do uso do modelo de domínio.”)

$\circ$ "The configured development process has great flexibility in the order of the activities to be performed and the order can be changed at your convenience." ("O processo de desenvolvimento configurado tem grande flexibilidade na ordem das atividades a serem executadas e a ordem pode ser alterada conforme sua conveniência.")

- "The model created to communicate the functionality of a domain to interested parties is very good. With the use of the application map and the feature model it is possible to understand the features, thanks to their descriptions as well as understand the hierarchy and relationship between them." ("A Capacidade do modelo criado para comunicar as 
funcionalidades de um domínio aos interessados é muito boa. Com o uso do mapa de aplicações e do modelo de features é possível entender as features, graças às suas descrições, bem como entender a hierarquia e relacionamento entre as mesmas.")

○ "The developed models represent a unified point for understanding the domain, creating common and standardized knowledge, as the information will no longer be consulted in separate applications." ("Os modelos desenvolvidos representam um ponto unificado para o entendimento do domínio, criando um conhecimento comum e padronizado, já que as informações não serão mais consultadas em aplicações separadas.")

○ The follow-up meetings for the construction of an initial version of the domain model showed how the behavior of various technicians was undergoing changes as they performed the defined process (credibility, commitment and enthusiasm).

○ When using the brainstorming technique at the time of identifying and consolidation the main features and subfeatures, it was very important to generate a high degree of participation, involvement and responsibility with the end result.

○ The elicitation of the business process with the participation of representatives from the business area was quite informative and effective, with feedback from several participants in the meetings.

- During the phase of CBD - components-based development :

$\circ$ "The activity of preparation of the reference architecture (domain design) was very interesting and so was the means of the component identification and components' specification, following the same dynamic used in the domain analysis" 
("Foi bastante interessante a atividade de elaboração de arquitetura de referência (design de domínio) e a forma da identificação de componentes e especificação dos componentes, seguindo a mesma dinâmica usada na análise de domínio")

○ "The definition of components from artifacts created in the previous phase allows us to have a safe and well organized way of working." (“A definição de componentes a partir dos artefatos criados na fase anterior permite ter uma forma de trabalho segura e bem organizada".)

○ "I did not know there was a component modeling process. I think it is great." ("Não sabia que existia um processo de modelagem de componentes. Achei ótimo.”)

$\circ$ "The continuing inspection of the code of the components makes the process faster and safer." ("A inspeção continua do código dos componentes torna o processo mais rápido $\mathrm{e}$ seguro.”)

○ "The monitoring of the components in the repository will allow for measuring the degree of reuse and provide information to the manager." ("O acompanhamento dos componentes no repositório vai permitir medir o seu grau de reuso e fornecer informações para o gerente.”)

- The adaptation of the organization's software development process to incorporate the components of development activities, testing and certification of these components made with the group's participation was quite satisfying, as reported by the participants, which demonstrated feeling secure with the final product.

○ The workshop of this phase was conducted presenting the adapted software development process, incorporating component development activities and component 
certification. Practical case studies were presented and the participants worked using the activities and artifacts provided in this process. The experimental techniques performed were quite useful for involvement and participation of the participants and re-signification of various beliefs.

- Several suggestions for adjustments to the development process were made by the workshop groups and once analyzed and considered relevant were incorporated into the process

○ Quality attributes and metrics were selected and added to the quality model of the component development process. This caused many practitioners to express the certainty that there would be quality in the produced components. These attributes are listed in the Table 9.

Table 9 - Quality attributes for components certification

\begin{tabular}{|c|c|c|c|}
\hline $\begin{array}{c}\text { Quality } \\
\text { attribute }\end{array}$ & Metric & Method & Certification Criteria \\
\hline $\begin{array}{l}\text { Complete } \\
\text { ness }\end{array}$ & $\begin{array}{l}\% \text { Of fully implemented } \\
\text { functions/ } \\
\text { specified }\end{array}$ & $\begin{array}{ll}\begin{array}{l}\text { Inspection } \\
\text { Concordion } \\
\text { criteria }\end{array} & \begin{array}{l}\text { of the } \\
\text { acceptance }\end{array} \\
\end{array}$ & $\begin{array}{l}100 \% \text { of the criteria should have } \\
\text { implemented automated testing }\end{array}$ \\
\hline \multirow[t]{3}{*}{$\begin{array}{l}\text { Correcten } \\
\text { ess }\end{array}$} & \multirow[t]{3}{*}{ Tests approved /total tests. } & \multirow[t]{2}{*}{ Automated testing } & $\begin{array}{l}\text { A minimum of } 80 \% \text { coverage of } \\
\text { test }\end{array}$ \\
\hline & & & $\%$ of the successfully executed tests \\
\hline & & Manual testing & $\%$ of the successfully executed tests \\
\hline \multirow[t]{3}{*}{$\begin{array}{l}\text { Maintene } \\
\text { ss }\end{array}$} & \multirow{3}{*}{$\begin{array}{l}\% \text { Of effectiveness and } \\
\text { efficiency with which the } \\
\text { component can be } \\
\text { modified by the } \\
\text { development team. }\end{array}$} & \multirow[t]{3}{*}{$\begin{array}{l}\text { Metric assessment Total } \\
\text { Quality SONAR }\end{array}$} & $\begin{array}{l}\text { Minimum of } 90 \% \text { of Architecture } \\
\text { Quality }\end{array}$ \\
\hline & & & Minimum of $90 \%$ of Code Quality \\
\hline & & & Minimum of $90 \%$ of Design Quality \\
\hline $\begin{array}{l}\text { Performa } \\
\text { nce }\end{array}$ & $\begin{array}{l}\text { Restriction of time and } \\
\text { capacity that the } \\
\text { component should be able } \\
\text { to answer. (eg } 5 \mathrm{~s} \text { response } \\
\text { time for } 1000 \text { concurrent } \\
\text { users) }\end{array}$ & Performance Tests & $\begin{array}{l}100 \% \text { pre-determined values. } \\
\text { Note: Value must be determined } \\
\text { according to the needs defined by } \\
\text { the non-functional requirements of } \\
\text { the component. }\end{array}$ \\
\hline Security & $\begin{array}{l}\% \text { Coverage of non- } \\
\text { functional security } \\
\text { requirements specified. }\end{array}$ & Tests & $100 \%$ of requirements met. \\
\hline
\end{tabular}


- During the development phase of the pilot project of the component's development and re-factoring of one of the software:

- The reuse pilot project that includes the development of components for software-C was divided into 10 sprints of two weeks each. Validation and planning meetings took place at the end of each sprint.

- The practitioners were involved in the assembly of the project support environment with the installation of the tools and the same definition of integration parameters with the customization of some artifact standards.

- Practitioners showed great satisfaction with the use of automated tools to support the environment and with the integration of the uses of these tools as much as possible.

- After completion of the pilot, adjustments in the component development process were made and compared with the situation before and after the pilot. This greatly pleased the team involved.

- "The pilot was able to take advantage of the full potential of the tools, which was not observed in the past experience of the project teams, where only part of the potential of supporting tools in the process was explored." ("No Piloto foi possível tirar proveito de todo o potencial das ferramentas, coisa que não é observada nas experiências passadas das equipes de projeto, quando apenas parte do potencial das ferramentas de apoio ao processo é explorada.")

○ "The availability of the components such as RESTful web services was successful, as it was possible to integrate components with different platforms such as Java and MS .NET." (“A disponibilização dos componentes como serviços web RESTful obteve êxito, já que foi possível a integração dos 
componentes com diferentes plataformas como Java e MS .NET.")

- Significant difficulties encountered during the adoption process:

- Allocation of the time required for the technicians of the business area to participate in the process.

○ Compatibility of the technical time between emergency needs and activities of the adoption project.

- Customization and integration of some tools into the organization's software development environment.

In some cases, declared true beliefs were abandoned during the execution of activities. This was verified through behaviors that skipped meaningful activities which leads us to believe that many beliefs do not always generate consistent behavior (matching) during execution of activities. We can illustrate this with the case of technicians who had a belief in the importance of the modeling process and when implementing components by gathering two of them (Installation and Equipment) into one, to simplify the implementation, having difficulty in naming the result. In such cases, it becomes necessary to reinforce these beliefs through a process that makes the technician consider the negative aspects that failure of a process can lead to.

Another significant observation was the surprise of the technicians with the effectiveness of the technique of domain analysis for identification of components. This represents a practical case of practitioner's beliefs re-signification.

In this way we triangulated data from different qualitative sources: interviews and observations, document analysis and group meetings, project meetings which was important to corroborate findings from the case study and provide more reliable results.

The process of re-signification of beliefs occurred effectively during the whole process of adoption of reuse technology in the organization. Through observation and recording of conversations with the practitioner involved in the adoption process, we can validate the positive results of re-signification of the beliefs throughout the process.

The adoption process of reuse technology in the organization was successful and received many compliments from the practitioners involved. Practitioner particularly 
praised the way activities were developed and the form in which the project was conducted.

\subsection{VALIDITY THREATS}

"The validity of a study denotes the trustworthiness of the results, and to what extent the results are true and not biased by the researchers' subjective point of view." (Wohlin et al., 2012)

When performing the case study in a large organization during the process of adoption of reuse technology, over two years, with practitioners performing their day to day activities, we found some threats to the study validity.

According to Wohlin et al. (2012), we have four types of validity threats concerning the case study: Conclusion validity, Internal validity, Construct validity and External validity.

As threats to construct validity, we identified:

a) Potential problems concerning the interpretation of beliefs presented during the interviews, which was mitigated by clarification whenever an interviewee had a doubt.

b) After tabulating the interviews with practitioners, the mapped belief system was not presented to the group due to the technicians' time limitations. However, we do not believe that this fact has affected the selection of beliefs for the re-signification process. This statement is confirmed with the observation made during the process in the case study presented in chapter 5 .

c) The difficulty of dealing with the large volume of data in the case study with two years duration involving a complex organizational process. This threat was mitigated by the belief catalog validation with international experts. 
As threats to internal validity, we identified:

a) The possibility of management interference in the beliefs presented by practitioners. We sought to mitigate this by interviewing the technicians separately and individually, ensuring that the individual information would not be disclosed.

b) The interference of false beliefs of technicians with the power of leadership during the re-signification was treated through the presentation of concrete cases that neutralize these collocations.

c) The appearance of beliefs that do not accurately reflect the thought of the technician was treated by the process of observation and individual interaction with each practitioner.

As threats to conclusion validity, we identified:

a) Beliefs identified during individual interviews were not subject to further discussion with the interviewees after the process of re-signification due to the technicians' lack of time, being involved in operational, day to day activities. Observations throughout the ethnographic study served as the basis to identify the effectiveness of the beliefs re-signification process.

b) The observations showed that some identified beliefs were not true to some practitioners while carrying out project activities. This shows the need for constant observation during the process and repeat resignification activities when necessary.

c) Another interview with practitioners after re-signification process was not conducted. However, the observations made during the ethnographic study demonstrated the efficacy of the re-signification process used by identifying the various behavioral changes.

As threats to external validity, we identified:

a) This is a proposed method for use in a generic way, to support the process of adopting software reuse technology in large organizations. Due to the long time required for carrying out the process and the time limit for 
achieving this thesis the application could not be carried out in other organizations. We consider that this external validity threat is mitigated by the fact that the organization is mature and practitioners involved are experienced and have different profiles. A case study is certainly closer to reality than a controlled experiment. 


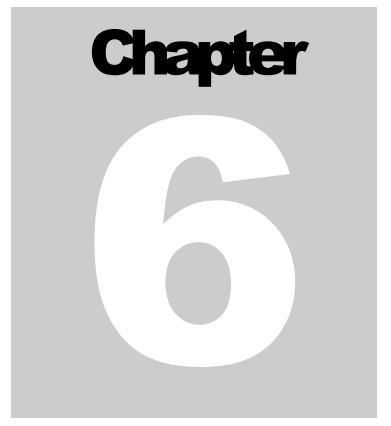

This chapter presents the validation of the set of classes of beliefs and individual beliefs regarding the adoption of reuse technology identified in each class, based on expert opinion. From this work a standard catalog reuse beliefs weighted by its impact on the process of adoption of reuse technology in a large organization is defined.

\section{A STANDARD CATALOG OF BELIEFS TO SUPPORT SOFTWARE REUSE ADOPTION BASED ON EXPERT OPINION}

The action model reasoned on beliefs classes to be used to support the adoption of reuse technology in a large organization has as a basic facilitator, the beliefs catalog for adoption of reuse software technology classified on beliefs classes. As can be seen in chapter four, this catalog has been prepared from a literature review and interviews with reuse expert in a large company.

After being used throughout our case study as described in chapter five, the catalog was (re)validated by experts. Through the validation process with experts, we aimed to refine it in order to make a general guide, valid for support reuse adoption process in any large organization.

We consider expert opinion to be the most appropriate approach for the preparation of this standard catalog of reuse beliefs. Several researches in Software Engineering have made use of expert opinion (Cooke, 1991), (Li \& Smidts, 2003). Li \& Smidts, (2003), states: "The widespread use of expert opinion stems from the fact that knowledge in many of the fields involved in probabilistic analysis and decision-making processes is generally rare and incomplete. Likewise, the experimental or statistical 
information on the basis of which predictions or decisions can be made is not easily available"

\subsection{EXPERT OPINION}

The Expert Opinion or expert judgment is a series of scientific endeavors about "the speculations, guesses, and estimates of people who are considered experts in so far as these serve as "cognitive input" in some decision process" (Cooke, 1991).

Our work use as a reference, the process presented by Li \& Smidts (2003) which consists of the following steps: Problem Statement, Selection of Experts, Elicitation of Opinions, Aggregation of Opinion, and Decision Making.

1. Problem Statement. The background and problem needs to be clearly defined and systematized.

2. Selection of Experts. A number of experts need to be identified based on a set of criteria that should include the credibility, knowledge, ability and dependability of the experts.

3. Elicitation of Opinion. This step poses the right question and ensures conditions that are conducive to an elicitation process.

4. Aggregation of Opinion. The idea is to reach an aggregated opinion or a consensus on which a decision is made. The decision process is generally based on identifying the alternatives with the least and highest values of utility.

5. Decision Making. This step makes the decision based on aggregated opinion.

For our specific case, the use of a standard format for the survey of views simplifies the phase Elicitation of Opinion. 


\subsection{BELIEF EXPERTS' VISION}

To perform the collection of experts' opinions we used the form in Appendix C. This form was run using the Google Forms cloud application.

Initially we defined our Problem Statement to make clear that we intended to gather information from experts. We were seeking to validate with the experts chosen the classes of beliefs, the classification of beliefs within each class, the agreement degree to each belief and the degree of impact that this belief has on the process of technology adoption. We also asked the experts to add other beliefs that they identified as impactful in the process of technology adoption. In this way we collected the information needed to build a catalog of weighted classified beliefs, to serve as the basis for a process of mapping the belief system of the practitioners involved in the process of adoption of reuse technology and advice on the prioritization for the process of re-signification of these beliefs.

Our problem statement was thus expressed to the experts:

"We are developing research concerning the development of a model of reasoned action based on classes of beliefs to support the adoption of software reuse technology in a large organization.

A belief is a proposition or premise that an individual holds as true, or even one formed opinion or belief. A belief generates an intention (readiness of a person to perform the behavior) that may facilitate or hinder the process of adoption of a technology. Publications were identified and selected that present beliefs of software practitioners in the use of reuse technology. These publications were analyzed and were identified the beliefs of technicians. This list of beliefs was classified and then validated by interviews with experts in reuse technology from a large company. These beliefs were used in a case study of the deployment of reuse technology in a large organization as a means of supporting the adoption process.

We request that a review be made of these beliefs. Please define for each belief, your agreement using a degree scale (zero, weak, medium, and Strong), and what impact (weak, medium, and Strong) that this belief has in the process of adoption of reuse 
technology in a large organization. The degree of concordance zero means that you agree that the belief is false and you must indicate the agreement degree to the negative belief.

If other new beliefs are identified, we ask that they be included in the form, classified and evaluated.

Beliefs are grouped into beliefs classes (A1, A2, B1, B2, C1 ...). If you think that a belief must be classified in another class, enter the new code in the field "Other belief class."

The selection of experts was performed considering the following criteria:

- Experience in the academic and business environment.

- International experience in research in the area of reuse and adoption of reuse, evidenced by their publications and experience.

The view of the experts can be very significant, with a reduced number of experts representing significant groups."It has been shown that, if the experts are dependent, then the reduction in uncertainty approaches a limiting value, thus making the use of many experts unnecessary." (Clemen \& Winkler, 1985) (Li \& Smidts, 2003).

The questionnaire in Appendix $\mathrm{C}$ was sent by email using Google forms, to 12 experts, considered candidates within the criteria set out above. The forms were returned by 5 of them, representing reliable representations of the international reuse community. The experts are well known, highly skilled and adhere to the criteria described above. All experts hold a $\mathrm{Ph}$. D. in computer science, and have actively worked in software reuse projects for several years. All of them were general chairs, program committee chairs or speakers in important software reuse conferences. The final list of experts, based on their availability and interest in the study, is presented in Table 10. 
Table 10 - List of experts that participated in the study

\begin{tabular}{|c|c|}
\hline Expert & Occupation \\
\hline Bill Frakes & Academy/Industry \\
\hline Claudia Werner & Academy \\
\hline Eduardo Almeida & Academy/Industry \\
\hline John Favaro & Academy/Industry \\
\hline Jeff Poulin & Industry \\
\hline
\end{tabular}

\subsection{RESULTS ANALYSIS AND SYNTESIS}

The aggregation of opinion was performed by tabulating the responses shown in Appendix D.

In our study, we use as a form of aggregation of the judgment of the experts a classification according to the trend of frequency of occurrence in the following classes:

- Beliefs with degree of agreement (Weak or Medium) and Impact ( Medium or Strong)

- Beliefs with degree of agreement (Weak or Medium) and Impact ( Medium or Weak)

- Beliefs with degree of agreement (Medium or Strong) and Impact ( Medium or Weak)

- Beliefs with degree of agreement (Medium or Strong) and Impact ( Medium or Strong)

- Other situations that deserve separate analysis due to disagreement between the experts

Analyzing the contents of the tabulation of opinions we classify the opinions:

A) Beliefs with degree of agreement (Weak or Medium) and Impact (Medium or Strong) 
4. The cost of adoption of reuse technology is described as very high without significant short-term returns.

5. Managerial levels think the investment with reuse is accounted for indirect costs not directly related to application development.

35. The reuse activities have incompatibility with the methodology of software development organizations.

36. The use of asset repository when it is not considered a critical factor of success breeds dissatisfaction with the use of technology reuse.

43. The quality model usage has a strong influence on reuse success.

44. A repository of assets disintegrated from the development environment significantly complicates the process of reuse.

47. The lack of a well-organized and indexed software repository with appropriate search engines is a barrier to reuse adoption.

48. Independent reusable assets development team has an influence on reuse success.

50. The use of automated tools is important for reuse adoption.

52. Reusing assets extracted from existing products is the best way for success in reuse adoption.

66. Reuse portions of code is a good practice.

\section{B) Beliefs with degree of agreement (Weak or Medium) and Impact ( Medium or Weak)}

12. The use of object orientation facilitates the creation of reusable assets.

34. The use of the technology reuse will facilitate my interaction with other technicians within and outside of my company.

39. The organization is resistant to a structure required to support the reuse technology which makes the adoption process very hard.

57. Reuse has to be adopted in a bottom-up approach to be effective.

63. To have previous reuse experience is not necessary.

68. I had troubles using third party software. 
C) Beliefs with degree of agreement (Medium or Strong) and Impact ( Medium or Weak)

59. A lack of a structured methodology to adoption is a bad factor for the process

D) Beliefs with degree of agreement (Medium or Strong) and Impact ( Medium or Strong)

All other beliefs that do not appear in the items above or in item E, are in this class.

E) Other situations that deserve separate analysis due to the disagreement between the experts. We will call information collected all these situations where we use as a reference the results of the interviews with experts described in chapter four and the results of the case study according to chapter five:

The belief " 22 . The excess of parameterization of assets requires a high investment in the testing process." was weighted by $20 \%$ of the experts as the impact being as weak and $40 \%$ of the experts consider the impact strong. In the information collected, we found that increasing the number of parameters of an asset makes the testing and certification process more laborious, generating some resistance from practitioners to realize it. Thus, we are suggesting that in the catalog the Impact is (Medium or Strong).

The belief "23. Developers are wary of quality and performance of the assets to be reused." was weighted by $40 \%$ the experts as the impact being weak and $40 \%$ of the experts consider the impact strong and another consider the degree of impact medium. In the information collected, we found that the practitioners demonstrated suspicion to use an asset that had not been developed for them and in some cases would 
even test the asset. In this way we are suggesting that in the catalog the Impact is (Medium or Strong).

The belief "26. Software developer's belief that reuse will inhibit creativity: the "Not Invented Here" syndrome." was weighted by the experts as having a weak degree of adherence by $40 \%$ of the experts, medium by $20 \%$ the experts and strong by another $40 \%$. In the information collected, we observed that $80 \%$ of the practitioners did not consider this belief to be true. In this way we are suggesting in the catalog that the degree of adherence is (Weak or Medium).

The belief " 27 . The evolution of the assets may create problems with older applications that use them." was weighted by $20 \%$ the experts with a degree of adherence being, weak or medium by $60 \%$ of the experts and strong by $40 \%$ of the experts. In the information collected, we observed that the practitioners demonstrated little concern for this belief. In this way we are suggesting in the catalog that the degree of adherence is (Weak or Medium).

The belief " 31 . To develop software with reuse is a positive differential for my company and for me as a professional." was weighted by $40 \%$ of the experts as the impact being weak and $40 \%$ of the experts consider the impact as strong and another $20 \%$ of the experts consider the degree of impact as medium. In the information collected, we found that practitioners have shown that it is quite important for them to work with reuse, which made them very motivated for the adoption of the technology. In this way we are suggesting in the catalog that the Impact is (Medium or Strong).

The belief " 32 .To participate in a project with reuse is a positive factor for my work in the company." was weighted by $60 \%$ of the experts who 
consider the impact as weak and $40 \%$ of the experts consider the impact as strong. In the information collected, we found that practitioners have shown that it is quite important for them to work with reuse within the organization and that this represented a difference for them in front of other technicians. In this way we are suggesting that in the catalog the Impact is (Medium or Strong).

The belief " 64 . To have used a structured software development process is a success factor for reuse use." to be weighted by experts as to their impact, $40 \%$ of the experts consider this weak and $20 \%$ of the experts consider the impact medium and $40 \%$ of the experts consider the degree of impact as strong. In the information collected, we found that the practitioners demonstrated the fact that the organization has a welldefined development methodology, with practitioners accustomed to working within a process, as having a strong positive impact on the adoption process. In this way we are suggesting in the catalog that the Impact is (Medium or Strong).

The belief " 65 . The use of object orientation is important for the adoption of reuse." to be weighted by experts in terms of their impact, $40 \%$ of the experts consider it Zero, $20 \%$ of the experts consider it weak and another $20 \%$ of the experts consider the impact medium and another $20 \%$ of the experts considered the degree of impact strong. In the information collected, we found that the practitioners did not consider the use of object orientation to reuse adoption important and that this fact would have no impact in the adoption process. In this way we are suggesting in the catalog that the Impact is (Weak or Medium).

Lastly, it is worth mentioning that no expert has identified the need for relocation of beliefs into the classes presented. Also they did not identify other beliefs 
impacting the process of technology adoption. One expert explicitly commented that the presented set of beliefs was quite complete.

\subsection{THE STANDARD CATALOG OF REUSE BELIEFS'}

After analysis of the results, we summarize the experts opinions in a standard catalog to guide the analysis of the practitioners' belief systems involved in the process of adoption of reuse technology. This catalog will assist the team responsible for the adoption project in establishing priorities when planning the process of re-signification of the beliefs that cause difficulties to the adoption process.

In this catalog, for consolidation purposes, we gather the degree of agreement into two classes (Weak / Medium) and (Medium / Strong) to show the trend of opinions with respect to the midpoint. We have adopted the same procedure for the impact degree of belief in the adoption process.

Regarding the beliefs with divergence between experts, we are pointing this out with $*$ and suggesting a classification based on interviews with expert described in chapter four, and the results of the work done during the ethnographic study case that is described in chapter five, according to analysis presented in the items above.

Table 11 shows our Catalog of Weighted Reuse Beliefs. 
Table 11 - Standard catalog of weighted beliefs

Catalog of weighted reuse beliefs

\begin{tabular}{|c|c|c|c|c|}
\hline & \multicolumn{2}{|c|}{ Agreement degree } & \multirow{2}{*}{$\begin{array}{l}\text { Impact } \\
\text { Weak/ } \\
\text { Medium }\end{array}$} & \multirow[b]{2}{*}{$\begin{array}{l}\text { Medium/ } \\
\text { Strong }\end{array}$} \\
\hline & $\begin{array}{l}\text { Weak/ } \\
\text { Medium }\end{array}$ & $\begin{array}{l}\text { Medium } \\
\text { /Strong }\end{array}$ & & \\
\hline \multicolumn{5}{|l|}{ A. Behavioral beliefs } \\
\hline \multicolumn{5}{|l|}{ Technology Maturity } \\
\hline 1. The reuse technology is mature. & & $x$ & & $\mathrm{x}$ \\
\hline $\begin{array}{l}\text { 2. The reuse technology has a well-defined } \\
\text { development methodology of assets. }\end{array}$ & & $x$ & & $\mathrm{x}$ \\
\hline \multicolumn{5}{|l|}{ Relative Advantage } \\
\hline $\begin{array}{l}\text { 3. Reuse promises a quick time to market and a } \\
\text { reduction in cost. }\end{array}$ & & $\mathrm{x}$ & & $\mathrm{x}$ \\
\hline $\begin{array}{l}\text { 4. The cost of adoption of reuse technology is } \\
\text { described as very high without significant short-term } \\
\text { returns. }\end{array}$ & $x$ & & & $x$ \\
\hline $\begin{array}{l}\text { 5. Managerial levels think the investment with } \\
\text { reuse is accounted for indirect costs not directly } \\
\text { related to application development. }\end{array}$ & $\mathrm{x}$ & & & $\mathrm{x}$ \\
\hline \multicolumn{5}{|l|}{ Perceived Usefulness } \\
\hline $\begin{array}{l}\text { 6. Developers believe that reuse reduces the cost } \\
\text { and time for the development of a new application. }\end{array}$ & & $x$ & & $x$ \\
\hline $\begin{array}{l}\text { 7. Reuse would require a structured process for } \\
\text { quality release of the assets which would slow down } \\
\text { the development process. }\end{array}$ & & $x$ & & $x$ \\
\hline $\begin{array}{l}\text { 8. The benefits of reuse will depend on the range of } \\
\text { products the asset is planned to assist and the } \\
\text { stability of the domains. }\end{array}$ & & $\mathrm{x}$ & & $\mathrm{x}$ \\
\hline $\begin{array}{l}\text { 9. The lack of metrics for reuse makes it difficult to } \\
\text { identify costs and benefits. }\end{array}$ & & $x$ & & $x$ \\
\hline $\begin{array}{l}\text { 10. Managers react to implementation reuse due to } \\
\text { lack of quantitative measures to assess the benefits } \\
\text { and costs of their utilization. }\end{array}$ & & $x$ & & $x$ \\
\hline
\end{tabular}




\begin{tabular}{|c|c|c|c|c|}
\hline Perceived Ease of Use & $\begin{array}{l}\text { Weak/ } \\
\text { Medium }\end{array}$ & $\begin{array}{l}\text { Medium } \\
\text { /Strong }\end{array}$ & $\begin{array}{l}\text { Weak/ } \\
\text { Medium }\end{array}$ & \begin{tabular}{|l} 
Medium/ \\
Strong
\end{tabular} \\
\hline $\begin{array}{l}\text { Reuse is difficult to implement in an } \\
\text { organization. }\end{array}$ & & $\mathrm{x}$ & & $\mathrm{x}$ \\
\hline $\begin{array}{l}\text { 12. The use of object orientation facilitates the } \\
\text { creation of reusable assets. }\end{array}$ & $x$ & & $\mathrm{x}$ & \\
\hline $\begin{array}{l}\text { 13. The communication between creators and } \\
\text { users of assets facilitates the adoption process. }\end{array}$ & & $\mathrm{x}$ & & $\mathrm{x}$ \\
\hline $\begin{array}{l}\text { 14. The cost of developing a reusable asset } \\
\text { depends on the technical competence of the staff in } \\
\text { the methodology used. }\end{array}$ & & $\mathrm{x}$ & & $\mathrm{x}$ \\
\hline $\begin{array}{l}\text { 15. The cost of developing a reusable asset depends } \\
\text { on the quality of the development methodology used. }\end{array}$ & & $\mathrm{x}$ & & $x$ \\
\hline $\begin{array}{l}\text { 16. Developers believe that reuse increases the } \\
\text { quality of a new application. }\end{array}$ & & $\mathrm{x}$ & & $\mathrm{x}$ \\
\hline $\begin{array}{l}\text { 17. A systematic reuse process increases the } \\
\text { developer's productivity. }\end{array}$ & & $\mathrm{x}$ & & $x$ \\
\hline \multicolumn{5}{|l|}{ Complexity } \\
\hline $\begin{array}{l}\text { 18. Building reusable assets and assembling them } \\
\text { to build future systems is an complex activity. }\end{array}$ & & $\mathrm{x}$ & & $\mathrm{x}$ \\
\hline $\begin{array}{l}\text { 19. Reuse technology is complex because it } \\
\text { involves the identification, construction, and } \\
\text { maintenance of assets availability. }\end{array}$ & & $x$ & & $x$ \\
\hline $\begin{array}{l}\text { 20. Developers believe that reuse is an } \\
\text { opportunistic "hunter/gatherer" process that } \\
\text { depends on the cognitive abilities of developers to } \\
\text { locate the right domains and components. }\end{array}$ & & $x$ & & $x$ \\
\hline $\begin{array}{l}\text { 21. The use of assets of limited scope or wide } \\
\text { scope require excessive effort to adapt to the new } \\
\text { context. }\end{array}$ & & $x$ & & $x$ \\
\hline $\begin{array}{l}\text { 22. The excess of parameterization of assets } \\
\text { requires a high investment in the testing process. }\end{array}$ & $x$ & & & $\mathrm{X}^{*}$ \\
\hline \multicolumn{5}{|l|}{ Outcome expectations } \\
\hline $\begin{array}{l}\text { 23. Developers are wary of quality and } \\
\text { performance of the assets to be reused. }\end{array}$ & $x$ & & & $x^{*}$ \\
\hline $\begin{array}{l}\text { 24. The failure of reusable components to meet the } \\
\text { future needs of a domain limits the success of } \\
\text { technology adoption. }\end{array}$ & & $x$ & & $x$ \\
\hline $\begin{array}{l}\text { 25. The lack of adequate assets documentation } \\
\text { hinders and limits its use in the development process. }\end{array}$ & & $x$ & & $\mathrm{x}$ \\
\hline
\end{tabular}




\begin{tabular}{|c|c|c|c|c|}
\hline $\begin{array}{l}25 . \quad \text { The lack of adequate assets documentation } \\
\text { hinders and limits its use in the development process. }\end{array}$ & & $\mathrm{x}$ & & $\mathrm{x}$ \\
\hline $\begin{array}{l}\text { 26. Software developer's belief that reuse will } \\
\text { inhibit creativity: the "Not Invented Here" syndrome. }\end{array}$ & $x^{*}$ & & $x$ & \\
\hline $\begin{array}{l}\text { 27. The evolution of the assets may create } \\
\text { problems with older applications that use them. }\end{array}$ & $x^{*}$ & & & $x$ \\
\hline $\begin{array}{l}\text { 28. Architecture of many levels that can be used in } \\
\text { different applications is a critical factor for success } \\
\text { of reuse implantation. }\end{array}$ & & $\mathrm{x}$ & & $\mathrm{x}$ \\
\hline $\begin{array}{l}\text { 29. A Quality Management assets approach has a } \\
\text { significant impact on the development process. }\end{array}$ & & $\mathrm{x}$ & & $\mathrm{x}$ \\
\hline $\begin{array}{l}\text { 30. The quality of the assets is important to obtain } \\
\text { the desired benefits such as defect/time reduction. }\end{array}$ & & $x$ & & $\mathrm{x}$ \\
\hline B. Normative beliefs & $\begin{array}{l}\text { Weak/ } \\
\text { Medium }\end{array}$ & $\begin{array}{l}\text { Medium } \\
\text { /Strong }\end{array}$ & $\begin{array}{l}\text { Weak/ } \\
\text { Medium }\end{array}$ & $\begin{array}{l}\text { Medium/ } \\
\text { Strong }\end{array}$ \\
\hline \multicolumn{5}{|l|}{ Image } \\
\hline $\begin{array}{l}\text { 31. To develop software with reuse is a positive } \\
\text { differential for my company and for me as a } \\
\text { professional. }\end{array}$ & & $\mathrm{x}$ & & $X^{*}$ \\
\hline \multicolumn{5}{|l|}{ Visibility } \\
\hline $\begin{array}{l}\text { 32.To participate in a project with reuse is a positive } \\
\text { factor for my work in the company. }\end{array}$ & & $\mathrm{x}$ & & $x^{*}$ \\
\hline \multicolumn{5}{|l|}{ Voluntariness of use } \\
\hline 33. I use the reuse technology voluntarily in my work. & & $x$ & & $x$ \\
\hline \multicolumn{5}{|l|}{ Social Factors } \\
\hline $\begin{array}{l}\text { 34. The use of the technology reuse will facilitate my } \\
\text { interaction with other technicians within and outside } \\
\text { of my company. }\end{array}$ & $\mathrm{x}$ & & $\mathrm{x}$ & \\
\hline C. Control Beliefs & & & & \\
\hline \multicolumn{5}{|l|}{ Compatibility } \\
\hline $\begin{array}{l}\text { 35. The reuse activities have incompatibility with } \\
\text { the methodology of software development } \\
\text { organizations. }\end{array}$ & $\mathrm{x}$ & & & $\mathrm{x}$ \\
\hline $\begin{array}{l}\text { 36. The use of asset repository when it is not } \\
\text { considered a critical factor of success breeds } \\
\text { dissatisfaction with the use of technology reuse. }\end{array}$ & $\mathrm{x}$ & & & $\mathrm{x}$ \\
\hline
\end{tabular}




\begin{tabular}{|c|c|c|c|c|}
\hline $\begin{array}{l}\text { 37. Elements such as the organizational structure } \\
\text { of the reuse group and their way to work hinder the } \\
\text { deployment of technology reuse. }\end{array}$ & & $\mathrm{x}$ & & $x$ \\
\hline $\begin{array}{l}\text { 38. The lack of an educational and } \\
\text { training/mentoring program is a complicating factor } \\
\text { for reuse. }\end{array}$ & & $\mathrm{x}$ & & $x$ \\
\hline $\begin{array}{l}39 . \quad \text { The organization is resistant to a structure } \\
\text { required to support the reuse technology which } \\
\text { makes the adoption process very hard. }\end{array}$ & $\mathrm{x}$ & & $\mathrm{x}$ & \\
\hline $\begin{array}{l}\text { 40. Managerial difficulty to allocate the necessary } \\
\text { resources to implement the necessary infrastructure } \\
\text { is an obstacle for adoption of reuse. }\end{array}$ & & $\mathrm{x}$ & & $\mathrm{x}$ \\
\hline Facilitating Conditions & $\begin{array}{l}\text { Weak/ } \\
\text { Medium }\end{array}$ & $\begin{array}{l}\text { Medium } \\
\text { /Strong }\end{array}$ & $\begin{array}{l}\text { Weak/ } \\
\text { Medium }\end{array}$ & $\begin{array}{l}\text { Medium/ } \\
\text { Strong }\end{array}$ \\
\hline $\begin{array}{l}\text { 41. Difficulty to locate reusable assets affects } \\
\text { deployment. }\end{array}$ & & $\mathrm{x}$ & & $\mathrm{x}$ \\
\hline $\begin{array}{l}\text { 42. The lack of funding to allocate to staff for the } \\
\text { development of reusable assets hinders adoption. }\end{array}$ & & $\mathrm{x}$ & & $\mathrm{x}$ \\
\hline $\begin{array}{l}\text { 43. The quality model usage has a strong influence } \\
\text { on reuse success. }\end{array}$ & $x$ & & & $\mathrm{x}$ \\
\hline $\begin{array}{l}\text { 44. A repository of assets disintegrated from the } \\
\text { development environment significantly complicates } \\
\text { the process of reuse. }\end{array}$ & $x$ & & & $x$ \\
\hline $\begin{array}{l}\text { 45. The availability of technician's talented } \\
\text { creators of assets facilitates the adoption process. }\end{array}$ & & $x$ & & $\mathrm{x}$ \\
\hline $\begin{array}{l}\text { 46. A pilot project success with metrics stimulates } \\
\text { the adoption of reuse in the organization. }\end{array}$ & & $\mathrm{x}$ & & $x$ \\
\hline $\begin{array}{l}\text { 47. The lack of a well-organized and indexed } \\
\text { software repository with appropriate search engines } \\
\text { is a barrier to reuse adoption. }\end{array}$ & $\mathrm{x}$ & & & $\mathrm{x}$ \\
\hline $\begin{array}{l}\text { 48. Independent reusable assets development team } \\
\text { has an influence on reuse success. }\end{array}$ & $\mathrm{x}$ & & & $x$ \\
\hline $\begin{array}{l}\text { 49. Lack of experience of the technicians to analyze } \\
\text { and design solutions for a range of applications of a } \\
\text { specific domain rather than only one, hinders the } \\
\text { adoption of reuse. }\end{array}$ & & $\mathrm{x}$ & & $x$ \\
\hline $\begin{array}{l}\text { 50. The use of automated tools is important for } \\
\text { reuse adoption. }\end{array}$ & $\mathrm{x}$ & & & $\mathrm{x}$ \\
\hline $\begin{array}{l}\text { 51. Organizations that develop software based on a } \\
\text { product family have advantages when compared to } \\
\text { the software organizations that develop isolated } \\
\text { products. }\end{array}$ & & $\mathrm{x}$ & & $x$ \\
\hline $\begin{array}{l}\text { 52. Reusing assets extracted from existing products } \\
\text { is the best way for success in reuse adoption. }\end{array}$ & $\mathrm{x}$ & & & $x$ \\
\hline
\end{tabular}




\begin{tabular}{|c|c|c|c|c|}
\hline $\begin{array}{l}\text { 52. Reusing assets extracted from existing products } \\
\text { is the best way for success in reuse adoption. }\end{array}$ & $\mathrm{x}$ & & & $x$ \\
\hline $\begin{array}{l}\text { 53. Configuration management is an essential } \\
\text { element for a reuse program. }\end{array}$ & & $\mathrm{x}$ & & $\mathrm{x}$ \\
\hline $\begin{array}{l}\text { 54. Measuring the level of reuse in software is } \\
\text { important for each adoption of reuse. }\end{array}$ & & $\mathrm{x}$ & & $\mathrm{x}$ \\
\hline $\begin{array}{l}\text { 55. Measurement of the reuse levels should show } \\
\text { return on investment. }\end{array}$ & & $\mathrm{x}$ & & $\mathrm{x}$ \\
\hline $\begin{array}{l}\text { 56. The previous development of reusable assets is } \\
\text { important for the process of reuse. }\end{array}$ & & $\mathrm{x}$ & & $\mathrm{x}$ \\
\hline $\begin{array}{l}\text { 57. Reuse has to be adopted in a bottom-up approach } \\
\text { to be effective. }\end{array}$ & $\mathrm{x}$ & & $x$ & \\
\hline $\begin{array}{l}\text { 58. The principal focus of developers are in projects } \\
\text { not in reuse. }\end{array}$ & & $x$ & & $x^{*}$ \\
\hline $\begin{array}{l}\text { 59. A lack of a structured methodology to adoption is } \\
\text { a bad factor for the process. }\end{array}$ & & $\mathrm{x}$ & $\mathrm{x}$ & \\
\hline \multicolumn{5}{|l|}{ D. Self-efficacy beliefs } \\
\hline Ability and Skil & $\begin{array}{l}\text { Weak/ } \\
\text { Medium }\end{array}$ & $\begin{array}{l}\text { Medium } \\
\text { /Strong }\end{array}$ & $\begin{array}{l}\text { Weak/ } \\
\text { Medium }\end{array}$ & \begin{tabular}{|l} 
Medium/ \\
Strong
\end{tabular} \\
\hline 60. Reuse education isn't common. & & $\mathrm{x}$ & & $\mathrm{x}$ \\
\hline $\begin{array}{l}\text { 61. Developers use reuse individually or informally in } \\
\text { a common way. }\end{array}$ & & $\mathrm{x}$ & & $\mathrm{x}$ \\
\hline 62. Technicians use reuse without specific training. & & $\mathrm{x}$ & & $\mathrm{x}$ \\
\hline \multicolumn{5}{|l|}{$\begin{array}{l}\text { Past experience- capacity to handle similar problems } \\
\text { successfully }\end{array}$} \\
\hline 63. To have previous reuse experience is not necessary. & $x$ & & $x$ & \\
\hline $\begin{array}{l}\text { 64. To have used a structured software development } \\
\text { process is a success factor for reuse use. }\end{array}$ & $x$ & & & $x^{*}$ \\
\hline $\begin{array}{l}\text { 65. The use of object orientation is important for the } \\
\text { adoption of reuse. }\end{array}$ & $\mathrm{x}$ & & $x^{*}$ & \\
\hline 66. Reuse portions of code is a good practice. & $\mathrm{x}$ & & & $\mathrm{x}$ \\
\hline $\begin{array}{l}\text { 67. The use of ready-made components has facilitated } \\
\text { my work. }\end{array}$ & & $\mathrm{x}$ & $\mathrm{x}$ & \\
\hline 68. I had troubles using third party software. & $\mathrm{x}$ & & $x$ & \\
\hline
\end{tabular}


This chapter presents the conclusion of this thesis, along with its major contributions. This chapter also addresses the limitations and validity issues of the performed work as well as the recommendations for further research.

\section{CONCLUSION AND FURTHER WORK}

The adoption process of new software technologies in organizations implements adaptations in existing processes or radical innovations that require the development of new processes in the organization. Many adoption processes of the same technology fail or significantly extrapolate the cost in some organizations and have success in other organizations. Human and organizational obstacles often outweigh the technical obstacles in this context (Sametinger, 1997).

For this reason, it is very important to observe the importance of the human factor facilitating, hindering, participating and resisting in each adoption process.

The adoption of reuse technology in a large organization significantly changes the software process of the organization as well as the modus operandi of the technicians involved. Knowing and treating these obstacles is, therefore, an important step during the adoption of reuse technology, in order to minimize the risks of failure.

In this work, we developed a systematic way to identify and treat factors that facilitate or hinder the adoption of reuse practices in large software organizations. Our approach is based on the study of the underlying belief systems of the practitioners involved in the process. 


\subsection{CONTRIBUTIONS}

The main goal of this work is to propose a method founded on an action model based on classes of beliefs that support the process of adoption of software reuse technology. This method allows for the identification and evaluation of the belief systems of practitioners involved, providing a means to deal with the beliefs that may hinder the adoption process. The proposed process of re-signification of beliefs' facilitates the treatment of the main human factors that may put at risk the adoption process in a structured manner.

The main contributions of this work can be summarized follows:

An action model reasoned on classes of beliefs to support the adoption of software technology - this model features a structured method to guide the process of mapping the systems of belief of the practitioners involved in the process of technology adoption. This is done from a standard set of classes of beliefs that seek to cover the main relevant aspects that may determine the behavior of individuals in organizations, with focus on software technology in order to reduce the risks of the process of adoption of new technologies.

A catalog of the beliefs regarding the adoption of reuse - using the class of beliefs of the model, we analyzed publications to map a set of beliefs for each class. This list of beliefs was refined by interviews conducted with experts in reuse in large companies, in order to validate and expand it. The set of beliefs was applied, and further refined and validated in a long-term ethnographic case study done during the process of adoption of reuse technology in a large company.

A method to capture, weigh and re-signify the beliefs of practitioners - a method was defined and applied to map and weight the beliefs of practitioners involved in the process of adoption of reuse technology. Criteria have been proposed to prioritize beliefs to be submitted to a re-signification process. The method of treatment of the selected beliefs was described.

A standard catalog of weighted reuse beliefs to support software reuse adoption based on expert opinion - the catalog of beliefs was submitted to validation 
and weighted by international experts according to the expert opinion technique. The result was analyzed and consolidated to form the standard weighted catalog to support the software reuse adoption process.

The case study with ethnography was undertaken and through its description we have shown the application of the process and improvements to the proposed method. Application of this method produced positive results in the adoption process of reuse technology in the large organization.

Our work emphasizes the importance of organizational aspects and human factors in software engineering. These elements are very relevant but are usually not treated in a systematic manner in software engineering. However, they can significantly compromise the results of the adoption of new technologies in the area. The proposed method systematize the way to treat the potential behavior of the practitioners involved, enabling secure and consistent planning of actions, reducing the risk of adopting new technologies and reducing the potential of financial loss to the organizations.

This is one of the first studies to use belief re-signification techniques in adopting new technologies in the field of software engineering as a way to treat beliefs of practitioners that can cause difficulties to the adoption process.

The defined research questions that express the goals of this research were:

- RQ1: What factors facilitate or hinder the adoption, acceptance, deployment and use practices of software reuse in a large organization?

The answer to this research question is presented through the Action Model reasoned on classes of beliefs to support the adoption of software technology where we presented a method to assist the process of mapping the belief system regarding the reuse of technology of software practitioners involved in the process of adoption of the technology. The second result presented the catalog of the beliefs regarding the adoption of reuse and complements the model to support the adoption of reuse in large organizations.

- RQ 2: How do you to treat these factors to facilitate the process of technology adoption? 
The answer to this research question is presented through the method to capture, weigh and re-signify the beliefs of practitioners where these beliefs are processed and properly classified so that beliefs that cause difficulties to the adoption process are treated through specific re-signification techniques, involving specific groups and technicians.

- $\quad$ RQ 3: How do you to generalize the empirical results obtained, in a model that will support the adoption practices of software reuse technologies in large organizations?

The answer to this research question is presented through the Action Model reasoned on classes of beliefs to support the adoption of software technology which is a generic model to support the adoption of reuse technology in any large organization and the standard catalog of weighted reuse beliefs to support software reuse adoption based on expert opinion that serve as a significant tool to support the processes of mapping and weighting the beliefs of the practitioners to permit activities of re-signification of beliefs.

\subsection{LIMITATIONS AND DIFFICULTIES}

Some limitations and hindering factors were identified in this work.

To develop and validate the proposed method to support the adoption of software reuse technology in a large organization, it is essential to use a long-term case study method because it can avoid typical scale-up problems observed in small experiments. Understanding and treating factors in the context of a real-life large organization is a very complex process to be handled by other experimental approaches. An ethnographic case study collect information from the variables and events that represent typical and real situations and allow observation and triangulation of information from different sources. 
We conducted an ethnography case study for two years covering the adoption process of reuse technology in a large organization. It involved seven different software to support the business process, which were developed and evolved by different project groups as recommended in reuse adoption processes. In spite of its duration, the work could yield more results if it ran through a longer period of time. The research project set up, work force time restrictions and commitments with the studied organization, made it impossible to run a more comprehensive study.

Also, we ran the study in just one organization. As it is common in in-depth qualitative studies like this, the time consumed in data collection and analysis was overwhelming. This made it impossible to apply the method in another case study in other large organization, during the time window imposed upon a doctoral dissertation.

To mitigate the risk that our model is restricted to findings in only one organization, we submitted the beliefs catalog to validation and weighting by experts, using expert opinion technique to improve the completeness and correctness of the conclusions.

An aspect that complicated the work is the large volume of data produced throughout an ethnographic case study with two years duration and involving twenty participants, working with real-world project data. The qualitative analysis of the collected data was difficult and sometimes subjective. However, the volume and nature of the collected data also greatly contributed to the positive results of this work, despite the effort and uncertainty involved in its analysis.

Despite these limitations, this work contributes to the software engineering field in augmenting its body of knowledge on the adoption of new technologies. It also facilitates the development or updating of processes related to software reuse, a result that is also important to the field. 


\subsection{FUTURE WORK}

From the results presented in this thesis, we can identify several future research opportunities that would complement this work or explore other aspects that have not been investigated yet, but are relevant for the field of software engineering technology adoption. The following points can be investigated in future:

- Application of the method to support the adoption of software reuse technology in other large organizations: Development of another empirical study using the ethnographic case study as a method to evolve and improve the instruments and method proposed.

- Application of the Action model reasoned on classes of beliefs to map the beliefs regarding the adoption of other mature software technologies: Further studies should be performed, using the classes of beliefs as the basis for mapping beliefs regarding the adoption of other software technologies, by conducting literature review and interviews with experts.

- Application of the Action Model reasoned on classes of belief to map beliefs regarding the adoption of other non-mature software technology (which will be the subject of the first new adoption processes): Further studies should be performed, using the classes of beliefs as the basis for performing the mapping of beliefs concerning the adoption of new technology. The beliefs will be identified through interviews with practitioners of the area to map the set of beliefs using as a reference the proposed classes and weighting these beliefs in a support catalog.

- Application of the action model reasoned on classes of beliefs to map the beliefs referring to the adoption of software developed in an organizational area: Further studies should be performed, to use the classes of beliefs as the basis of performing the mapping of the users' 
beliefs that may interfere in the process of adoption of software designed for end users who will significantly alter their work process. A case study should be used to validate the classes of beliefs for this purpose as well as the method of identifying and re-signifying the beliefs.

Besides these, there are certainly other directions for further research that can be performed based on the results of this thesis, making the process of adoption of software technologies in large organizations more structured and predictable.

Lastly, the results of this work show the growing importance of considering and dealing with human and organizational factors involved in developing and adopting new software technologies. This is because software technology is always embedded in processes that significantly require the participation of the human element in its enactment and execution. 


\section{BIBLIOGRAPHY}

(Adler \& Shenhar, 1990) Adler, P., Shenhar, A., Adapting your technological base: The organizational challenge, Sloan Management Review 32(1), 2537, 1990 .

(Agresti, 20110 Agresti, W., Software Reuse: Developers' Experiences and Perceptions, Journal of Software Engineering and Applications, 2011, 1, 48-58.

(Agudo-Peregrina et al., 2014) Agudo-Peregrina, A., Hernandez-Garcia A., PascualMiguel, F., Behavioral intention, use behavior and the acceptance of electronic learning systems: Differences between higher education and lifelong learning Computers in Human Behavior 34, 301-314, 2014.

(Aguirre \& Speer, 2000) Aguirre, J., Speer, N., Examining the relationship between beliefs and goals in teacher practice, Journal of Mathematical Behavior, 3(18): 327-356, 2000.

(Ahmed et al, 2007) Ahmed, F., Capretz, L., and Sheikh, S., Institutionalization of software product line: An empirical investigation of key organizational factors, Journal System Software, 80, 836-849, 2007.

(Ahmed et al, 2009) Ahmed, F., Campbell, P., Lagharid, M., Cognitive factors in software product line engineering, in Proceedings of the UK Sim 2009: 11th International Conference on Computer Modelling and Simulation, pages 352-355, Washington, DC, USA, IEEE Computer Society, 2009.

(Ahmed \& Capretz, 2010) Ahmed, F., Capretz, L., An organizational maturity model of software product line engineering, Software Quality Control, 18, $195-225,2010$.

(Ajzen \& Fishbein, 1980) Ajzen, I., Fishbein, M., Understanding attitudes and predicting social behavior, Englewood Cliffs, NJ, Prentice.Hall, 1980 .

(Ajzen, 1991) Ajzen, I., The theory of planned behavior, Organizational Behavior and Human Decision Processes, vol. 50, no. 2, pp. 179-211, 1991. 
(Ajzen \& Gilbert, 2008) Ajzen , I., Gilbert, N., Attitudes and the prediction of behavior, in W. D. Crano\& R. Prislin (Eds.), Attitudes and attitude change, pp. 289-311, New York: Psychology Press, 2008.

(Alavi et al., 2006) Alavi, M., Katworth, T., Leidner, E., An Empirical Examination of the Influence of Organizational Culture on Knowledge Management Practices, Journal of Management Information Systems, 22(3): 191-224, 2006.

(Almeida et al., 2004) Almeida, E., Alvaro, A., Lucrédio, D., Garcia, V., and Meira, S., RiSE project: towards a robust framework for software reuse. In Proceedings of the IEEE International Conference on Information Reuse and Integration, pages 48-53, Las Vegas, USA. IEEE, 2004.

(Almeida, 2007) Almeida, E., RiDE: The RiSE Process for Domain Engineering. Ph.d Thesis, Universidade Federal de Pernambuco, Brazil, 2007.

(Almeida et al., 2007) Almeida, E., Alvaro, A., Garcia, V., Mascena, J., Burégio, V., Nascimento, L., Lucrédio, D., Meira, S., C.R.U.I.S.E: Component Reuse in Software Engineering, C.E.S.A.R e-book, Brazil, 2007.

(American Psychological Association, 2013) Glossary of psychological terms, (http://www.apa.org/research/action/glossary.aspx), Apa.org.

(Argyris \& Schön, 1978) Argyris, C., Schön, D., Organizational learning: A theory of action perspective. Reading, MA: Addison Wesley, 1978.

(Argyris \& Smith, 1985) Argyris, C., Putnam, R., \& McLain Smith, D., Action science: concepts, methods, and skills for research and intervention, San Francisco, Jossey-Bass, 1985.

(Argyris \& Schön, 1996) Argyris, C., Schön, D.A., Organizational learning: Theory, method and practice, Addison-Wesley, 1996.

(Bagozzi, 2007) Bagozzi, R., The Legacy of the Technology Acceptance Model and a Proposal for a Paradigm Shift, Journal of the Association for Information Systems: Vol. 8: Iss. 4, Article 12, 2007.

(Bandura, 1986) Bandura, A., Social Foundations of Thought and Action: A Social Cognitive Theory, Prentice Hall, Englewood Cliffs, NJ, 1986.

(Bandura, 1991) Bandura, A., Social cognitive theory of self-regulationOrganizational Behavior and Human, Decision Processes, 50, 1991. 
(Bandura, 1994) Bandura, A., Self-efficacy, in V. S. Ramachaudran (Ed.), Encyclopedia of human behavior, (Vol. 4, pp. 71-81), New York: Academic Press, 1994.

(Bandura, 1997) Bandura, A., Self-efficiency: The exercise of control, New Yourk:Freeman, 1997.

(Bandura, 2012) Bandura, A., On the functional properties of perceived self-efficacy revisited, Journal of Management, 38 (1) (2012), pp. 9-44.

(Basili et al., 1995) Basili, V., Zelkowitz, M., McGarry, F., Page, J., Waligora, S., Pajerski, R., SEL's software process improvement program, IEEE Software, Nov., 1995).

(Basili et al., 1996) Basili, V., Briand, L. , Melo, W., How reuse influences productivity in object-oriented systems, Communications of the ACM, Vol. 39, No. 10, October, 1996, pp. 104-116.

(Basili et al., 1996B) Basili, V., The Role of Experimentation in Software Engineering: Past, Current, and Future," Proc. 18th Int'l Conf. Software Eng., pp. 442-449, 1996.

(Basili et al., 2006) Basili, V., Rombach, D., Selby, R., Software Engineering. Experimental Software Engineering Issues: Critical Assessment and Future Directions, International Workshop, Dagstuhl, Germany, 1992, Appeared in Lecture Notes in Computer Science, 2006.

(Basili \& Elbaum, 2006) Basili, V., Elbaum, S., Empirically driven SE research: state of the art and required maturity, in: Invited Talk, ICSE 2006, Shanghai, 2006.

(Bastos et al., 2011) Bastos, J., Neto, P., Almeida, E., Meira, S., Adopting Software Product Lines: A Systematic Mapping Study, In: 15th International Conference on Evaluation and Assessment in Software Engineering (EASE), Durham City, 2011.

(Beaudry \&. Pinsonneault, 2010) Beaudry, A., Pinsonneault, A., The other side of acceptance: Studying the direct and indirect effects of emotions on information technology use, MIS Quarterly, 34 (4) (2010), pp. 689710 .

(Benbasat and Barki, 2007) Benbasat, I., Barki, H., Quo vadis TAM? Journal of the Association for Information Systems, 8 (4), pp. 211-218, 2007. 
(Berniker \& McNabb, 2006) Berniker, E. , McNabb, D., Dialectical Inquiry: A Structured Qualitative Research Method, The Qualitative Report Volume 11 Number 4 December 2006, Nova Southeastern University.

(Bayer \& Melone, 1989) Bayer, J., Melone, N., Adoption of Software Engineering Innovations In Organizations, Software Engineering Institute, Carnegie Mellon University Pittsburgh, 1989.

(Becheikh et al., 2010) Becheikh, N. , Ziam, S., Idrissi, O., Castonguay, Y., Landry, R., How to improve knowledge transfer strategies and practices in education? Answers from a systematic literature review, Research in Higher Education Journal, p. 7, 2010.

(Blank \& Hennessy, 2012) Blank M., Hennessy, M., A reasoned action approach to hiv prevention for persons with serious mental illness, The Annals of the American Academy of Political and Social Science, 640: 173, 2012.

(Boden et al., 2011) Boden, A., Muller, C., Nett, B., Conducting a business ethnography in global software development projects of small German enterprises, Information and Software Technology 53,10121021, 2011.

(Bosch, 2001) Bosch, J., Software product lines: organizational alternatives, In Proceedings of the 23rd International Conference on Software Engineering, ICSE '01, pages 91-100, Washington, DC, USA. IEEE Computer Society, 2001.

(Bongard et al., 1993) Bongard, B., Gronquist, B., Ribot, D., Impact of Reuse on Organizations, in Proceedings Reuse'93,IEEE Computer Society Press, Los Alamitos, Calif. 1993.

(BonJour, 1985) Bonjour L., The Elements of Coherentism, In Struture of Empirical Knowledge, 87-110, Cambridge:Harvard University Press, 1985.

(Broughton et al., 2007) Broughton, S., Sinatra, G., \& Reynolds, R., The refutation text effect: Influence on learning and attention, Paper presented at the Annual Meeting of the American Educational Researchers Association, Chicago, Illinois, 2007.

(Buxton \& Malcolm, 1991) Buxton, J., Malcolm, R., Software technology transfer, Software Engineering Journal, 17-23, 1991.

(Caldiera, 1991) Caldiera, G., Domain Factory and Software Reusability, in Proceedings of the Software Engineering Symposium: New Frontiers for Software Maintenance, 1991. 
(Cambridge Dictionary, 2015)

http://dictionary.cambridge.org/pt/dicionario/britanico/belief, 2015

(Cameron, 2004) Cameron, K., A process for Changing Organizational Culture, University of Michigan Business School, 2004.

(Catal, 2009) Catal, C., Barriers to the adoption of software product line engineering, SIGSOFT Softw. Eng. Notes, 34, 1-4, 2009.

(Chi, 2008) Chi, M., Three types of conceptual change: Belief revision, mental model transformation, and categorical shift, In S. Vosniadou (Ed.), Handbook of research on conceptual change (pp. 61-82), Hillsdale, NJ: Erlbaum, 2008.

(Chrissis, 2004) Chrissis, M., Konrad, M., and Shrum, S., CMMI: Guidelines for Process Integration and Product Improvement, Addison-Wesley Professional, 2004.

(Chuttur, 2009) Chuttur, M., Overview of the Technology Acceptance Model: Origins, Developments and Future Directions, Indiana University, USA. Sprouts: Working Papers on Information Systems, 9(37), 2009.

(Chau \& Tam, 1997) Chau, P., Tam, K., Factors affecting the adoption of open systems: an exploratory study, MIS Quarterly 21 (1), 1997, pp. 124.

(Clemen \& Winkler, 1985) Clemen, R., Winkler, R., Limits for the Precision and Value of Information from Dependent Sources, Operations Research, 33(2), 427442, 1985.

(Compeau et al., 1999) Compeau, D., Higgins, C., Huff, S., Social cognitive theory and individual reactions to computing technology: a longitudinal study, MIS Quarterly, vol. 23, no. 2, pp. 145-158, 1999.

(Cooke, 1991) Cooke, R., Experts in Uncertainty: Opinion and Subjective Probability in Science, Oxford University Press, USA, 1991.

(Corbin \& Strauss, 1996) Corbin, J., Strauss, A., Basics of Qualitative Research: Techniques and Procedures for Developing Grounded Theory, USA: Sage Publications, 1996.

(Cruzes, 2007) Cruzes, D., Análise secundária de estudos experimentais em engenharia de software, Tese de Doutorado. UNICAMP, Campinas, SP, 2007. 
(Cruzes \& Dyba, 2010) Cruzes, D., Dybå, T., Synthesizing Evidence in Software Engineering Research, Proceedings of the ACM-IEEE International Symposium on Empirical Software Engineering and Measurement ESEM, 2010.

(Damanpour and Schneider, 2006) Damanpour, F., Schneider,M., Phases of adoption of innovation in organizations: Effects of environment, organization and top managers, British Journal of Management, 17 pp. 215-236, 2006.

(Davis, 1985) Davis, F., A technology acceptance model for empirically testing new end-user information systems: theory and results, Unplubished Doctoral dissertation, MIT Sloan School of Management, Campridge, 1985.

(Davis et al., 1989) Davis F., Bagozzi, R., and Warshaw, P., User acceptance of computer technology: A comparison of two theoretical models, Manage. Sci., vol. 35, pp. 982-1003, Aug. 1989.

(Davis et al., 1992) Davis, F., Bagozzi, R., Warshaw, P., Extrinsic and intrinsic motivation to use computers in the workplace, Journal of Applied Social Psychology, vol. 22, no. 14, pp. 1111-1132, 1992.

(Davis, 1991) Davis, M., STARS Framework for Reuse Processes, in Proceedings of the Fourth Annual Workshop on Institutionalizing Software Reuse. IEEE Computer Society Press, 1991.

(Deci \& Ryan, 1985) Deci, E., Ryan, R., Intrinsic motivation and self-determination in human behavior, Plenum, New York, 1985.

(Deci \& Ryan, 2014) Deci, E., Ryan, R., The importance of universal psychological needs for understanding motivation in the workplace in The oxford handbook of work engagement, motivation, and self-determination theory pp. 13-32, Oxford University Press, New York, 2014.

(Dick \& Dalmau, 1990) Dick, B., \& Dalmau, T., Values in action: Applying the ideas of Argyris and Schon, Brisbane: Interchange, 1990.

(Douglas \& Wykowski, 2011) Douglas, N., Wykowski, T., From Belief to Knowledge Achieving and Sustaining an Adaptive Culture in Organizations, USA: CRC Press, 2011.

(Easterbrook et al., 2008) Easterbrook, S., Singer J., Storey, M., Damian, D., Selecting empirical methods for software engineering research in Guide to Advanced Empirical Software Engineering, Section III, 285-311, 2008. 
(Ezran, et al., 2002) Ezran, M., Morisio, M., Tully, C., Practical Software Reuse, Springer, , pp.374, 2002.

(Feather, 1982) Feather, N., Expectations an actions: Expectancy-value models in psychology, Hillsdale, NJ:Erlbaum, 1982.

(Fetterman, 2010) Fetterman D., Ethnography: step-by-step, 3rd edition, USA, Sage, 2010.

(Fishbein \& Ajzen, 1975) Fishbein, M., Ajzen, I., Belief, Attitude, Intention, and Behavior: An Introduction to Theory and Research, Reading, Addinson-Wesley, 1975.

(Fishbein \& Ajzen, 2010) Fishbein, M., Ajzen, I., Predicting and Changing Behavior: The Reasoned Action Approach, Psychology Press, 2010.

(Fodor, 1981) Fodor, J., Representations, Cambridge, MA: MIT, 1981.

(Forsey, 2010) Forsey M., Ethnography as participant listening. Ethnography - 11(4): $558-572,2010$.

(Fowler \& Levine, 1993) Fowler, P. \& Levine, L., A Conceptual Framework for Software Technology Transition, Software Engineering Institute, Carnegie Mellon University, Pittsburgh, 1993.

(Frambach \& Schillewaert, 2002) Frambach, R., Schillewaert, N., Organizational innovation adoption: A multi-level framework of determinants and opportunities for future research Journal of Business Research, 55, pp. 163-176, 2002.

(Frakes \& Isoda, 1994) Frakes,W., Isoda, S., Success Factors of Systematic Software Reuse, IEEE Software, 11, 14-19, 1994.

(Frakes \& Fox, 1995) Frakes, W., Fox, C., Sixteens questions about software reuse, Communications of the ACM Vol. 38 Issue 6, June 1995.

(Frakes \& Kang, 2006) Frakes, W., Kang, K., Software Reuse Research, Status and Future, IEEE Transactions on Software Engineering, Vol 31, n.7, july 2006.

(Frisson, 2008) http://www.friesian.com/knowledg.htm - Copyright (c) 2007, 2008 Kelley L. Ross, Ph.D. All Rights Reserved

(Fichman \& Kemerer, 1993) Fichman, R., Kemerer, C., Adoption of Software Engineering Process Innovation: The Case of Object Orientation, Sloan Management Review, 1993. 
(Fichman \& Kemerer, 1993a) Fichman, R., Kemerer, C., Toward a theory of the adoption and diffusion of software process innovations, MIT, School of Management, Cambridge, 1993.

(Fujii, 2006) Fujii, S., Environmental concern, attitude toward frugality, and ease of behavior as exterminations of pro-environmental behavior intentions, Journal of Environmental Psychology, 26 (pp. 262-268, 2006.

(Gacek et al., 2001) Gacek, C., Knauber, P., Schmid, K., Clements, P., Successful software product line development in a small organization, In Software Product Lines: Practices and Patterns, chapter 11, Addison Wesley Longman, 2001.

(Garcia et al., 2007) Garcia, V., Lisboa, L., Meira, S., Almeida, E., Lucrécio, D., Fortes, R., Towards a Maturity model for a Reuse Incremental Adoption, in SBCARS, 2007.

(García, et al., 2011) García, A.,Pradas, S. Pealeaz,J., Miguel, F., Exploring the Attitudes and Intentions of Non-shoppers in the Acceptance of eCommerce, J.UCS, vol. 17, no. 9 (2011), 1314-1328, 2011.

(Gardner, 2006) Gardner, H., Changing Minds, Boston, Massachusetts, Harvard Business School Publishing, 2006.

(Griss, 1995) Griss M., Software Reuse: Objects and Frameworks are not Enough, Object Magazine, pp. 77-87, February 1995.

(Guzzetti, 2000) Guzzetti, B., Learning counter-intuitive science concepts: What have we learned from over a decade of research? Reading and Writing Quarterly, 16, 89-98, 2000.

(Harper \& Utiey, 2001) Harper, G., Utiey, D., Organizational culture and successful information technology implementation, Engineering Management Journal, 13 (2), pp. 11-15, 2001.

(Hassenzahl et al., 2010) Hassenzahl, M., Diefenbach, S., Göritz, A., Needs, affect, and interactive products - Facets of user experience, Interacting with Computers, Vol. 22, Issue 5, Pages 353-362, 2010.

(Hassenzahl \& Tractinsky, 2006) Hassenzahl, M., Tractinsky, N., User Experience - a research agenda [Editorial], Behavior \& Information Technology 25, 91-97, 2006.

(Hofer \& Tichy, 2007) Hofer, A. , Tichy, W., Status of Empirical Research in Software Engineering, in: Basili, V., Rombach, D., Schneider, K., 
Kitchenham, B., Pfahl, D. , Selby, R. (Eds.), Experimental Software Engineering Issues: Assessment and Future Directions, SpringerVerlag, Germany, Dagstuhl Castle, 2007 LNCS 4336, 2007.

(Hoffman \& Klepper, 2000) Hoffman, N., Keppler, R., Assimilating New Technologies: The Role of Organizational Culture, in Information Systems Managemente vol.17, Issue 3, 2000.

(Huber, 1991) Huber, G., Organizational learning: The contributing process and the literatures, Organization Science, 2(1), 88-115.

(Huisman \& Iivari, 2006) Huisman, M., Iivari, J., Deployment of systems development methodologies: perceptual congruence between IS managers and systems developers, Information \& Management, 43 (1), pp. 29-49, 2006.

(Huisman \& Iivari, 2007) IIVARI, J., HUISMAN, M. The relationship between organizational culture and the deployment of systems development methodologies, MIS Quarterly, 31(1): 35-58, 2007.

(Im et al., 2011) Im, I., Hong, S., Kang, M., An international comparison of technology adoption: Testing the UTAUT model, Information \& Management, 48 (1), pp. 1-8, 2011.

(ISO/IEC, 2003) ISO/IEC 15504-2: Software Engineering - Process Assessment Part 2: Performing An Assessment, International standard, ISO (the International Organization for Standardization) and IEC (the International Electrotechnical Commission).

(ISO/IEC, 1995) ISO/IEC 12207 Systems and Software Engineering - Software Life Cycle Processes, International standard, ISO (the International Organization for Standardization) and IEC (the International Electrotechnical Commission).

(Ivarsson \& Gorschek, 2010) Ivarsson, M., Gorschek, T., A method for evaluating rigor and industrial relevance of technology evaluations, Empirical Software Engineering, Springer Science+Business Media, 2010.

(Joanes, 2007) Joanes, C., Positive and Negative Innovations in software Engineering, Software Productivity Research, LLC, 2007.

(Joanes \& Northrop, 2010) Joanes, L. and Northrop, L., Clearing the way for software product line success, IEEE Software, 27, 22-28, 2010. 
(Kim \& Storr, 1998) Kim, Y., Storr, E., Software reuse: survey and research directions, Journal of Management Information Systems 14 (4), pp. 113, 1998.

(Knauber et al., 2000) Knauber, P., Muthig, D., Schmid, K., and Widen, T, Applying product line concepts in small and medium-sized companies, IEEE Softw., 17, 88-95, 2000.

(Kitchenham et al., 2007) Kitchenham, B., Mendes, E., Travassos, G., Cross versus within company cost estimation studies: A systematic review, Software Engineering, IEEE Transactions on, vol. 33, no. 5, pp. 316 329, May 2007.

(Kitchenham et al., 2007a) Kitchenham, B. A., Budgen, D., Brereton, P., Turner, M., Charters, S., and Linkman, S. Large-scale software engineering questions - expert opinion or empirical evidence?, IET Software, 1(5), 161, 2007.

(Kitchenham et al., 2009) Kitchenham, B., Brereton, O., Budgen, D., Turner, M., Bailey, J., Linkman, S., Systematic literature reviews in software engineering - A systematic literature review, Information and Software Technology, 51 pg. 7-15, Elsevier, 2009.

(Krueger, 1992) Krueger, C., Software Reuse, ACM Computing Surveys, Vol. 24, No. 02, June, pp. 131-183, 1992

(Ko et al., 2005) D.G. Ko, L.J. Kirsch, W.R. King Antecedents of knowledge transfer from consultants to clients in enterprise system implementations, MIS Quarterly, 29 (1) (2005), pp. 59-85

(Larsson et al., 2006) Larsson, M., Wall, A., Norström, C., Crnkovic I., Technology transfer: why some succeed and some don't, In: Proceedings of the International Workshop on Software Technology Transfer in Software Engineering (WOTTSE) at ICSE06, ACM, Shanghai, pp. 23-27, 2006.

(Lee et al., 2009) Lee, D., Rhee, Y., Dunham, R., The role of organizational and individual characteristics in technology acceptance, International Journal of Human-Computer Interaction, 25 (7), pp. 623-646, 2009.

(Lee, 2015) Lee, Y., Lee, J., Hwang, Y., Relating motivation to information and communication technology acceptance: Self-determination theory perspective, Computers in Human Behavior 51, 418-428, 2015.

(Lethbridge et al., 2005) Lethbridge, T., Sim, S., Singer, J., Studying Software Engineers: Data Collection Techniques for Software Field Studies, 
Empirical Software Engineering: An International Journal 10(3):311$341,2005$.

(Li \& Chang, 2009) Li, D., Chang, C., Initiating and institutionalizing software product line engineering: From bottom-up approach to top-down practice, In Proceedings of the 2009 33rd Annual IEEE International Computer Software and Applications Conference - Volume 01, pages 53-60, Washington, DC, USA. IEEE Computer Society, 2009.

(Li \& Smidts, 2003) Li, M. and Smidts, C., A ranking of software engineering measures based on expert opinion, IEEE Transactions on Software Engineering, 29(9), 811-824, 2003.

(Lindič et al., 2011) Lindič, J., Baloh, P., Ribière, V., Desouza, K., Deploying information technologies for organizational innovation: Lessons from case studies, International Journal of Information Management, 31 (2), pp. 183-188, 2011.

(Limayem et al., 2007) Limayem, M., Hirt, S., Cheung, C., How habit limits the predictive power of intention: the case of information systems continuance, MIS Quarterly, 31(4): 705-737, 2007.

(Livari \& Livari, 2011) Livari, J., Livari, N., The relationship between organizational culture and the deployment of agile methods, IST-5(53):509-520, 2011.

(Livari \& Huisman, 2007) Livari, J., Huisman, M., The relationship between organizational culture and the deployment of systems development methodologies, MIS Quarterly, 2007. 31(1): p. 35-58.

(Llorens et al. 2006) Llorens, J., Fuentes, J., Prieto-Díaz, R., Astudillo, H., Incremental Software Reuse, in 9th International Conference on Software Reuse, pages 386-389, Springer Berlin / Heidelberg, 2006.

(Lucredio et al., 2008) Lucredio, D., Brito, K., Alvaro, A., Garcia, V., Almeida, E., Fortes, R., Meira, S., Software reuse: The brazilian industry scenario, Journal of Systems and Software 81 pg. 996-1013, Elsevier, 2008.

(Lundy \& Cowling, 1996) Lundy, O., Cowling, A., Strategic Human Resource Management, London: Thompson, 1996.

(Lynex \& Layzell, 1998) Lynex, A., Layzell, P., Organizational considerations for software reuse, Annals of Software Engineering 5, 105-124, 1998. 
(Lytras \& Pablos, 2011) Lytras, M., Pablos, P., Software Technologies in Knowledge Society, J.UCS, vol. 17, no. 9 (2011), 1219-1221, 2011.

(Marchewka et al., 2007) Marchewka, J., Liu, C., Kostiwa , K., An application of the UTAUT model for understanding student perceptions using course management software, Communications of the IIMA, 7 (2) pp. 93-104, 2007.

(Malhotra, 1999) Malhotra, Y., Galleta, D., Extending the Technology Acceptance Model to Account for Social Influence: Theoretical Bases and Empirical Validation, in Proceedings of the $32^{\text {nd }}$ Hawai International Conference on System Sciences, IEEE, 1999.

(Mannion, 2002) Mannion, M., Organizing for software product line engineering, In Proceedings of the 10th International Workshop on Software Technology and Engineering Practice, Washington, DC, USA, IEEE Computer Society, 2002.

(McCarthy \& Wright, 2004) McCarthy, J., Wright, P., Technology as Experience, MIT Press, Cambridge, USA, 2004.

(Mili et al., 1995) Mili, H., Mili, F., Mili, A., Reusing Software: Issues and Research Directions, IEEE Transactions on Software Engineering, Vol. 21, No. 06, June, 1995, pp. 528-562.

(Merriam-webster, 2015) http://www.merriam-webster.com/dictionary/belief, 2015.

(Mishra et al., 2014) Mishra, D., Akman, I., Mishra, A., Theory of Reasoned Action application for Green Information Technology acceptance, Computers in Human Behavior Volume 36, July, Pages 29-40, 2014.

(Moore \& Benbasat, 1991) Moore, G. and Benbasat, I., Development of an Instrument to Measure the Perceptions of Adopting an Information Technology Innovation, Information Systems Research (2:3), , pp. 192-222,1991.

(Morisio et al., 2002) Morisio, M., Ezran, M., Tully, C., Success and failure factors in software reuse, IEEE Transactions on Software Engineering 28 (04), 340-357, 2002.

(Moskovitz, 2009) Moskowitz, G., Grant, H., The psychology of goals, The Guilford Press, NY, 2009.

(Moskowitz, 2012) Moskowitz, G., The Representation and Regulation of Goals, In A. Elliot, \& H. Aarts (Eds.), Goal-Directed Behavior. New York: Psychology Press/Taylor and Francis, 2012. 
(Montano \& Taplin, 1991) Montano, D., Tapli, S.,A Test of an Expanded Theory of Reasoned Action to Predict Mammography Participation. Social Science \& Medicine Journal, 32(6): 733 741, 1991.

(Muthig, 2002) Muthig, D., A Light-weight Approach Facilitating an Evolutionary Transition Towards Software product Lines. Ph.d. thesis, Universitär Kaiserlautern, 2002.

(Needle, 2004) Needle, D., Business in Context: An Introduction to Business and Its Environment, Cengage Learning Business Press, 4 edition, UK, 2004.

(Nord et al, 1987) Nord, W., Tucker, S., Implementing Routine and Radical Innovations, New Lexington Press, San Francisco, 1987.

(Northrop, 2004) Northrop, L., Software product line adoption roadmap, Technical Note CMU/SEI-2004-TR-022, SEI, 2004.

(Northrop at al., 2004) Northrop, L., Clements, P., A framework for software product line practice, version 5.0, Technical report, SEI, 2007.

(O'Rielly et al., 1991) O'Rielly, Chatman \& Caldwell, People and organizational culture: A profile comparison approach to assessing personorganization fit, Academy of Management Journal, 34, pp. 487-516, 1991.

(Oxford-Dictionaries, 2015) http://www.oxforddictionaries.com/definition/ english/, 2015.

(Partala \& Kallinen, 2012) Partala, T., Kallinen, A., Understanding the most satisfying and unsatisfying user experiences: Emotions, psychological needs, and context, Interacting with Computers, 24 (1), pp.25-34, 2012.

(Partala \& Saari, 2015) Partala,T., Saari, T., Understanding the most influential user experiences in successful and unsuccessful technology adoptions, Computers in Human Behavior 53, 381-395, 2015.

(Passos et al., 2011) Passos, C., Braun, A., Cruzes, D., Mendonça, M., Analyzing the Impact of Beliefs in Software Project Practices, ESEM, 2011.

(Passos et al., 2013) Passos, C., Cruzes, D., Mendonça, M., Applying Theory of Reasoned Action in the Context of Software Development Practices: Insights into Team Intention and Behavior, Proc. of EASE'13, Porto de Galinhas, Brazil, 2013. 
(Passos et al., 2014) Passos, C., Mendonça M., Cruzes, D., The Role of Organizational Culture in Software Development Practices: A Cross-Case Analysis of Four Software Companies, Proc. of SBES'14, Maceio, Brazil, 2014.

(Paulk et al., 1993) Paulk, M., Curtis, B., Chrissis, M., and Weber, C., Capability Maturity Model for Software (Version 1.1), Technical report, Software Engineering Institute, Carnegie Mellon University, 1993.

(Peslak, et al., 2011) Peslak, A., Ceccucci, W., Sendall, P. An empirical study of social networking behavior using theory of reasoned action, Proceedings of CONISAR'11, North Carolina, USA, November, 2011.

(Petersen et al., 2008) Petersen, K., Feldt, R., Mujtaba, S., Mattsson, M., Systematic mapping studies in software engineering, in EASE '08: Proceedings of the 12th International Conference on Evaluation and Assessment in Software Engineering, University of Bari, Italy, 2008.

(Pfleeger, 1999) Pfleeger, S., Understanding and improving technology transfer in software engineering, Journal of Systems and Software, 47, 111124, 1999.

(Pfleeger \& Menezes, 2000) Pfleeger, S., Menezes, W., Marketing technology to software practitioners, IEEE Software 17 (1), 27-33, 2000.

(Poulin, 2006) Poulin, J., The Business Case for Software Reuse: Reuse Metrics, Economic Models, Organizational Issues, and Case Studies, Tutorial Notes, Torino, Italy, June, 2006.

(Prieto-Díaz, 1991) Prieto-Díaz, R., Making software reuse work: An implementation model, ACM SIGSOFT Software Engineering Notes, 16, 61-68., 1991.

(Psychology Dictionary, 2015) http://psychologydictionary.org/

(Punter et al., 2009) Punter, T., Krikhaar, R., Bril, R., Software engineering technology innovation: turning research results into industrial success, in The Journal of Systems and Software, 1(82), 993-1003, 2009.

(Pyster \& Barnes, 1988) Pyster, A., Barnes, B., The software productivity consortium reuse program, in Digest of Papers. COMPCON Spring 88 ThirtyThird IEEE Computer Society International Conference, pages 242248, San Francisco, California, USA. IEEE Comput. Soc. Press, 1988.

(Randolph et al., 2009) Randolph, M., Pinkerton, S., Somalai, A., Kelly, J., Mcauliffe, T., Gibson, R., Hackl, K., Seriously mentally Ill women's safer sex 
behaviors and the theory of reasoned action, Journal of Health Education and Behavior, 36(5): 948-958, 2009.

(Ravasi and Schultz, 2006) Ravasi, D., Schultz, M., Responding to organizational identity threats: Exploring the role of organizational culture, Academy of Management Journal, 49(3), 433-458, 2006.

(Redwine \& Riddle, 1985) Redwine, S., Riddle, W., Software technology maturation, Proceeding ICSE '85, Proceedings of the 8th international conference on Software engineering, IEEE Computer Society Press Los Alamitos, CA, USA, 1985.

(Rine, 1997) Rine, D., Success factors for software reuse that are applicable across domains and businesses, In: ACM Symposium on Applied Computing. ACM Press, San Jose, CA, USA, pp. 182-186, 1997.

(Rine \& Sonnemann, 1998) Rine, D., Sonnemann, R., Investment in reusable software. A study on software reuse investment success factors, The Journal of Systems and Software 41, 17-32, 1998.

(Robey \& Boudreau, 1999) Robey, D., Boudreau, M., Accounting for the contradictory organizational consequences of information technology: theoretical directions and methodological implications, Information Systems Research 10 (2), pp. 167-186, 1999.

(Roberto et al., 2011) Roberto, A., Krieger, J., Katz, M., Goei, R., Jain, P., Predicting pediatricians' communication with parents about the human papillomavirus (HPV) vaccine: an application of the theory of reasoned action, Journal of Health Communication, 26(4): 303-312, 2011.

(Rogers, 2003) Rogers, E., Diffusion of innovation, New York, Free Press, 2003.

(Runeson \& Host, 2008) Runeson, P., Host, M., Guidelines for conducting and reporting case study research in software engineering in Empirical Software Engineering, 2(14):131-164, 2008.

(Ryan \& Deci, 2000) Ryan, R. and Deci, E., Self-Determination Theory and the Facilitation of Intrinsic Motivation, Social Development, and Well-Being by the American Psychological Association, Vol. 55, No. 1, 68-78, 2000.

(Sametinger, 1997) Sametinger, J., Software Engineering with Reusable Components, Springer-Verlag, pp.275,1997. 
(Schein, 2004) Schein, Organizational Culture and Leadership, Third edition, San Francisco:Jossey-Bass, 2004.

(Schwitzgebel, 2006) Schwitzgebel, E., Belief, in Zalta, Edward, The Stanford Encyclopedia of Philosophy, Stanford, CA: The Metaphysics Research Lab, 2006, http://plato.stanford.edu/entries/belief/.

(Seaman \& Basili, 1998) Seaman, C., Basili, V., Communication and Organization: An Empirical Study of Discussion in Inspection Meetings. IEEE Transactions on Software Engineering 24(7):559-572, 1998.

(Seaman, 1999) Seaman, C., Qualitative Methods in Empirical Studies of Software Engineering, IEEE Transactions on Software Engineering 25(4):557$572,1999$.

(Seaman, 2008) Seaman, C., Qualitative Methods, in Guide to Advanced Empirical Software Engineering, cap. 2, Forrest Shull, Janice Singer, and Dag I.K. Sjoberg, eds. Springer, 2008.

(Sharp, 1998) Sharp, H., Software reuse: Survey and Research Directions in Journal of Management Information Systems, vol. 14, n.4 pp. 113-147, Spring, 1998.

(Sharp et al., 2000) Sharp, H., Robinson, H., Woodman, M., Software engineering: community and culture, IEEE Software, 17(1):40-47, 2000.

(SEI, 2007) Process maturity profile of the software community, Software Engineering Institute, Carnegie Mellon University, 2007.

(Sheldon et al., 2001)Sheldon, K., Elliot, A., Kim, Y., Kasser, T., What is satisfying about satisfying events? Testing 10 candidate psychological needs, Journal of Personality and Social Psychology 80, 325-339, 2001.

(Sherif \& Vinze, 1999) Sherif, K., Vinze, A., A Qualitative Model for Barriers to software Reuse Adoption, ICIS 99 Proceedings of The $20^{\text {th }}$ International Conference on information Systems, ACM, Atlanta, 1999.

(Sherif \& Vinze, 2003) Sherif, K., Vinze, A., Barriers to adoption of software reuse A qualitative study, Information \& Management 41 9, 159-175, Elsevier, 2003.

(Sherif et al., 2006) Sherif, K., Appan, R., Lin, Z., Resources and incentives for the adoption of systematic software reuse, International Journal of Information Management, 26, 70-80, 2006. 
(Shih \& Huang, 2010) Shih, C., Huang, S., Exploring the relationship between organizational culture and software process improvement deployment, in Information \& Management 47, 271-281, Elsevier, 2010.

(Shull et al., 2004) Shull, F., Mendonça, M., Basili, V., Carver, J., Maldonado, J., Fabbri, S., Travassos, G., Oliveira, M., Knowledge-Sharing Issues in Experimental Software Engineering, Empirical Software Engineering: An International Journal, vol. 9(1), 2004.

(Shull et al., 2005) Shull, F., Cruzes, D., Basili, V., Mendonça, M., Simulating Families of Studies to Build Confidence in Defect Hypotheses, Journal of Information and Software Technology, vol. 47(15): 1019-1032, 2005.

(Sjoberg et al., 2005) Sjoberg, D., Hannay, J., Hansen, O., Kampenes, V., Karahasanovic', A. , Liborg, N., A survey of controlled experiments in software engineering, IEEE Trans. Software Eng. 31 (9)(2005) 733-753.

(Sjoberg et al., 2007) Sjoberg, D., Dyba, T., Jorgensen, M., The future of empirical methods in software engineering research, FOSE '07: Future of Software Engineering, Washington, DC, USA, 2007, pp. 358-378.

(Škerlavaj et al., 2010) Škerlavaj,M., Song,J., Lee,Y., Organizational learning culture, innovative culture and innovations in South Korean firms, Expert Systems with Applications , Vol. 37, Issue 9, September, Pages 63906403, 2010.

(Song \& Chermack, 2008) Song, J., Chermack, T., A theoretical approach to the organizational knowledge formation process: Integrating the concepts of individual learning and learning organization culture, Human Resource Development Re-view, 7(4), 424-442, 2008.

(Straub, 2009) Straub, E., Understanding technology adoption: Theory and future directions for informal learning. Review of Educational Research, 79(2), 625-649, 2009.

(Sussman and Siegal, 2003) Sussman, S., Siegal, W., Informational influence in organizations: An integrated approach to knowledge adoption, Information Systems Research, 14 (1)), pp. 47-65, 2003.

(SWEBOK, 2007) SWEBOK- Guide to the Software Engineering Body of Knowledge, Body of knowledge, Fraunhofer IESE, Robert Bosch $\mathrm{GmbH}$, University of Groningen, University of Karlskrona/Ronneby, Siemens, 2007. 
(Taylor et al., 1995a) Taylor, S., and Todd, P. Assessing IT Usage: The Role of Prior Experience, MIS Quarterly (19:2), pp. 561-570, 1995.

(Taylor et al., 1995b) S. Taylor, P. A. Todd, Understanding information technology usage: a test of competing models, Information Systems Research, vol. 6, no. 4, pp. 144-176, 1995.

(Teo \& Schaik, 2012) Teo, T., van Schaik, P., Understanding the intention to use technology by preservice teachers: An empirical test of competing theoretical models, International Journal of Human-Computer Interaction,28 (3), pp. 178-188, 2012.

(Terry, 2006) Terry, W., Learning and Memory: Basic principles, processes, and procedures, Boston: Pearson Education, Inc., 2006.

(Thompson et al., 1991) Thompson, R., Higgins, C., Howell, J., Personal computing: toward a conceptual model of utilization, MIS Quarterly, vol. 15, no. 1, pp. 124-143, 1991.

(Tippett, 2010) Tippett, C. Refutation text in science education: A review of two decades of research, International Journal of Science and Mathematics Education, 8:951-970, 2010.

(Tornatzky \& Fleischer, 1990) Tornatzky, L., Fleischer, M., The processes of technological innovation, Lexington, Lexington Books, 1990.

(Vallerand, 1997) Vallerand, R., Toward a Hierarchical Model of Intrinsic and Extrinsic Motivation, in Advances in Experimental Social Psychology (29), M. Zanna (ed.), pp. 271-360,Academic Press, New York, 1997.

(Vanlandingham et al, 1995) Vanlandingham, M., Suprasert, S., Grandjean, N., Randjean, N.Sittitrai, W., Two views of risky sexual practices among northern thai males: the health belief model and the theory of reasoned action. Journal of Health and Social Behavior, 36(2): 195-212, 1995.

(Venkatesh \& Davis, 2000) Venkatesh, V., and Davis, F., A Theoretical Extension of the Technology Acceptance Model: Four Longitudinal Field Studies, Management Science (45:2), pp. 186-204, 2000.

(Venkatesh et al., 2003) Venkatesh , V., Morris, M., Davis, G., Davis, F., User Acceptance of Information Technology: Toward a Unified View, MIS Quarterly, 27(3), 425-478, 2003.

(Venkatesh et al., 2008) Venkatesh, V., Brwon, S., Maruping, L., Bala, H., Predicting different conceptualization of system use: The competing roles of 
behavioural intention, facilitating conditions, and behavioural expectation, MIS Quarterly, 32 (3), pp. 483-502, 2008.

(Venkatesh et al., 2012) Venkatesh, V., Thong, J., Xu, J., Consumer acceptance and use of information technology: Extending the unified theory of acceptance and use of technology, MIS Quarterly, 36 (1), pp. 157$178,2012$.

(Venkatesh \& Bala, 2008) Venkatesh, V., Bala, H., Technology acceptance model 3 and a research agenda on interventions, Decision Sciences, 39 (2), pp. 273-315, 2008.

(Xu \&Quaddus, 2012) Xu, J., Quaddus, M., Examining a model of knowledge management systems adoption and diffusion: A Partial Least Square approach Knowledge-Based Systems, 27, pp. 18-28, 2012.

(Wernick \& Hall, 2004) Wernick, P., Hall, T., Can Thomas Kuhn's paradigms help us understand software engineering, European Journal of Information Systems, 13 (3): 235-243, 2004.

(Wohlin et al., 2012) Wohlinf, C., Runeson, P., Höst, M., Ohlsson, M., Regnell, B., Wesslén, A., Experimentation in Software Engineering, SprinVerlag, Berlin, 2012.

(Yoo et al., 2011) Yoo, M., Vonderembse, T., Ragu-Nathan, Knowledge quality: Antecedents and consequence in project teams, Journal of Knowledge Management, 15 (2), pp. 329-343, 2011.

(Zelkowitz, 1996) Zelkowitz, M., Software Engineering Technology Infusion within NASA, Institute for Advanced Computer Studies and Department of Computer Science University of Maryland, College Park, 1996.

(Zelkowitz et al., 1998) Zelkowitz, M., Wallace, D., Binkley, D., Understanding the Culture in Software Engineering Technology Transfer, tech. report, Univ. of Maryland, 1998.

(Zhao et al., 2015) Zhao, J., Ordóñez de Pablos, P., Tennyson, R., Organizational Innovation and IT Governance in Emerging Economies, IGIGlobal, 2015. 
APPENDIX 


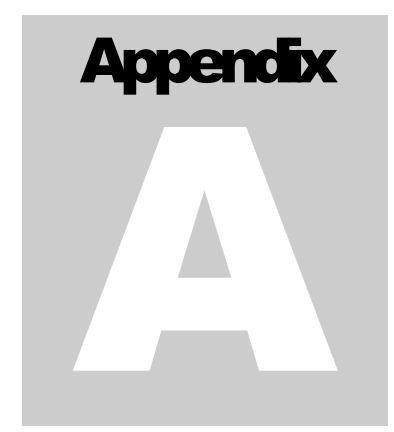

This appendix presents the questionnaire used for the interviews in the open part and a fragment of the form used in the structured part.

INTERVIEW BASIC QUESTIONNAIRE

\section{Open Questions}

\section{Warm up}

OQ1. What do you think of the use of reuse in software development? (O que você pensa do uso de reutilização no desenvolvimento de software?)

\section{Past Experience}

OQ2. How have you used reuse in your software development work? (Como você usou reuso no seu trabalho de desenvolvimento de software?)

OQ3. Provide positive experiences you've had with reuse. And negative. (Cite experiências positivas que você teve com reuso. E negativas?)

\section{Other Questions}

OQ4. What does it mean for you to participate in this project of reuse technology adoption? (O que significa para você participar de um projeto de adoção da tecnologia de reuso?)

OQ5. How do you think that reuse can be measured in an organization? (Como você acha que o reuso pode ser medido em uma organização?) 


\section{After the structured part of the interview}

OQ5. Introduce other important aspects regarding the adoption of reuse that were not treated. (Apresente outros aspectos importantes referentes à adoção do reuso que não foram tratados.)

\section{Fragment of the form used in the structured interview part about beliefs regarding} the adoption of reuse

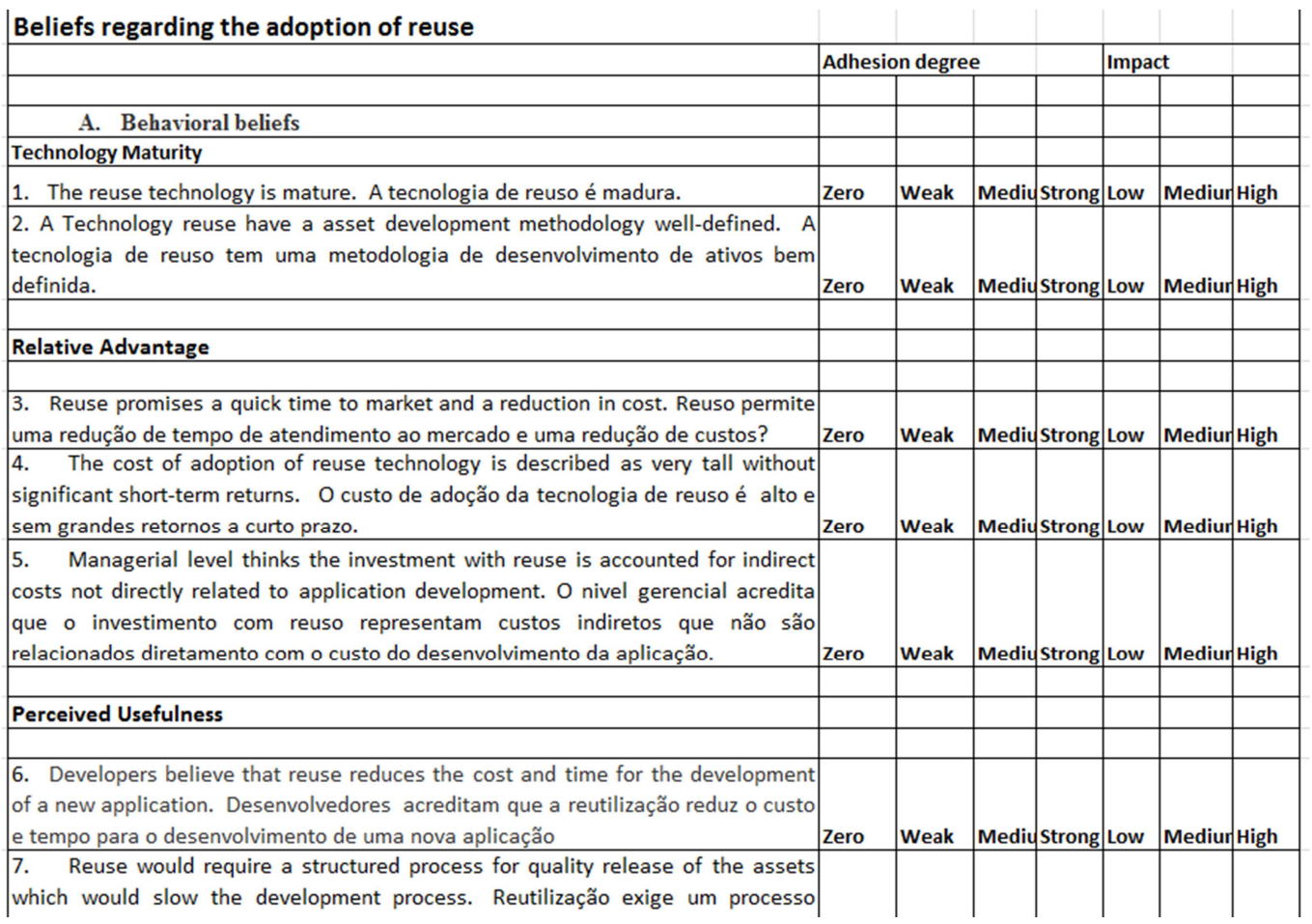




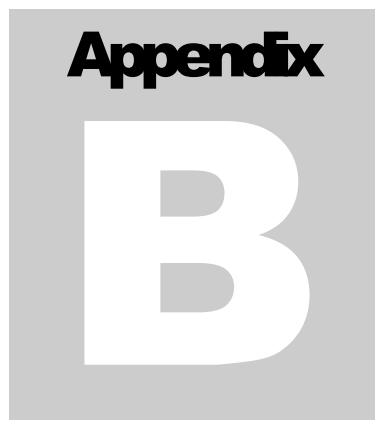

This appendix presents the instrument that established specific goals for our observation tasks as a way to guide the researchers' work.

\section{OBSERVATION INSTRUMENT}

\section{Specific goals to be observed and registered}

- The mapped beliefs of practitioners and the behavior and speeches of these practitioners during the process.

- Practices adopted by members of the project group.

- Evolution of beliefs after the re-signification activities.

- Degree of involvement of practitioners in the adoption process.

- Activities carried out within the organization's software development process.

- Use of tools to support the process.

- Metrics collection form during the process.

- Events and significant exceptions that may occur.

- Difficulties encountered during the project.

- Interactions between project members. 


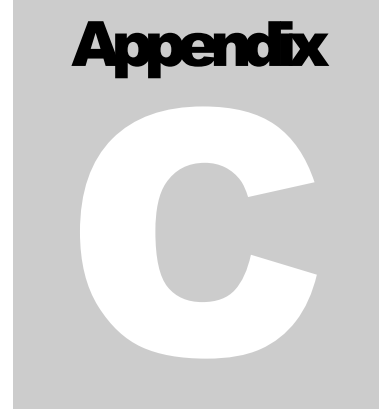

This appendix presents the questionnaire used for the Expert Opinion by Google Form.

EXPERT OPNIONS OF THE CLASSES OF BELIEFS AND BELIEFS 


\section{Beliefs regarding the adoption of reuse - Vision of researchers}

* Required

\section{Instructions}

We are developing research concerning the development of a model of reasoned action based on classes of beliefs to support the adoption of software reuse technology in a large organization.

A belief is a proposition or premise that an individual holds as true, or even one formed opinion or belief. A belief generates an intention (readiness of a person to perform the behavior) that may facilitate or hinder the process of adoption of a technology.

Publications were identified and selected that present beliefs of software practitioners in the use of reuse technology. These publications were analyzed and were identified the beliefs of technicians. This list of beliefs was classified and then validated by interviews with experts in reuse technology from a large company. These beliefs were used in a case study of the deployment of reuse technology in a large organization as a means of supporting the adoption process.

We request that a review be made of these beliefs. Please define for each belief, your agreement using a degree scale (zero, weak, medium, and Strong), and what impact (weak, medium, and Strong) that this belief has in the process of adoption of reuse technology in a large organization. The degree of concordance zero means that you agree that the belief is false and you must indicate the agreement degree to the negative belief.

If other new beliefs are identified, we ask that they be included in the form, classified and evaluated.

Beliefs are grouped into beliefs classes (A1, A2, B1, B2, C1,...). If you think that a belief must be classified in another class, enter the new code in the field "Other belief class."

Thank you for your participation in this research work.

\section{Research Identification ( Name)}

\section{A. Behavioral beliefs}

People have beliefs about the positive or negative consequences that can occur if performing a behavior. (Fishbein \& Ajzen, 2010)

\section{Belief's Class A1 - Technology Maturity}


Level of popularization and dissemination on a large scale by the technical community (Redwine \& Riddle, 1985)

Belief 1. The reuse technology is mature.

\begin{tabular}{lcccc} 
& Zero & Week & Medium & Strong \\
\hline $\begin{array}{l}\text { Agreement } \\
\text { degree }\end{array}$ & $\bigcirc$ & $\bigcirc$ & $\bigcirc$ & $\bigcirc$ \\
\hline Impact & $\bigcirc$ & $\bigcirc$ & $\bigcirc$ & $\bigcirc$ \\
\hline
\end{tabular}

Other Belief's Class

Belief 2. The reuse technology has a well-defined development methodology of assets. *

\begin{tabular}{lcccc} 
& Zero & Week & Medium & Strong \\
\hline $\begin{array}{l}\text { Agreement } \\
\text { degree }\end{array}$ & $\bigcirc$ & $\bigcirc$ & $\bigcirc$ & $\bigcirc$ \\
\hline Impact & $\bigcirc$ & $\bigcirc$ & $\bigcirc$ & $\bigcirc$ \\
\hline
\end{tabular}

Other Belief's Class

\section{Belief's Class A2 - Relative Advantage}

The degree to which using an innovation is perceived as being better than using its precursor. (Moore \& Benbasat, 1991)

Belief 3. Reuse promises a quick time to market and a reduction in cost.

\begin{tabular}{lcccc} 
& Zero & Week & Medium & Strong \\
\hline $\begin{array}{l}\text { Agreement } \\
\text { degree }\end{array}$ & $\bigcirc$ & $\bigcirc$ & $\bigcirc$ & $\bigcirc$ \\
\hline Impact & $\bigcirc$ & $\bigcirc$ & $\bigcirc$ & $\bigcirc$ \\
\hline
\end{tabular}

\section{Other Belief's Class}

Belief 4. The cost of adoption of reuse technology is described as very high without significant short-term returns. *

\begin{tabular}{lcccc} 
& Zero & Week & Medium & Strong \\
\hline $\begin{array}{l}\text { Agreement } \\
\text { degree }\end{array}$ & 0 & 0 & 0 & $\bigcirc$ \\
\hline
\end{tabular}




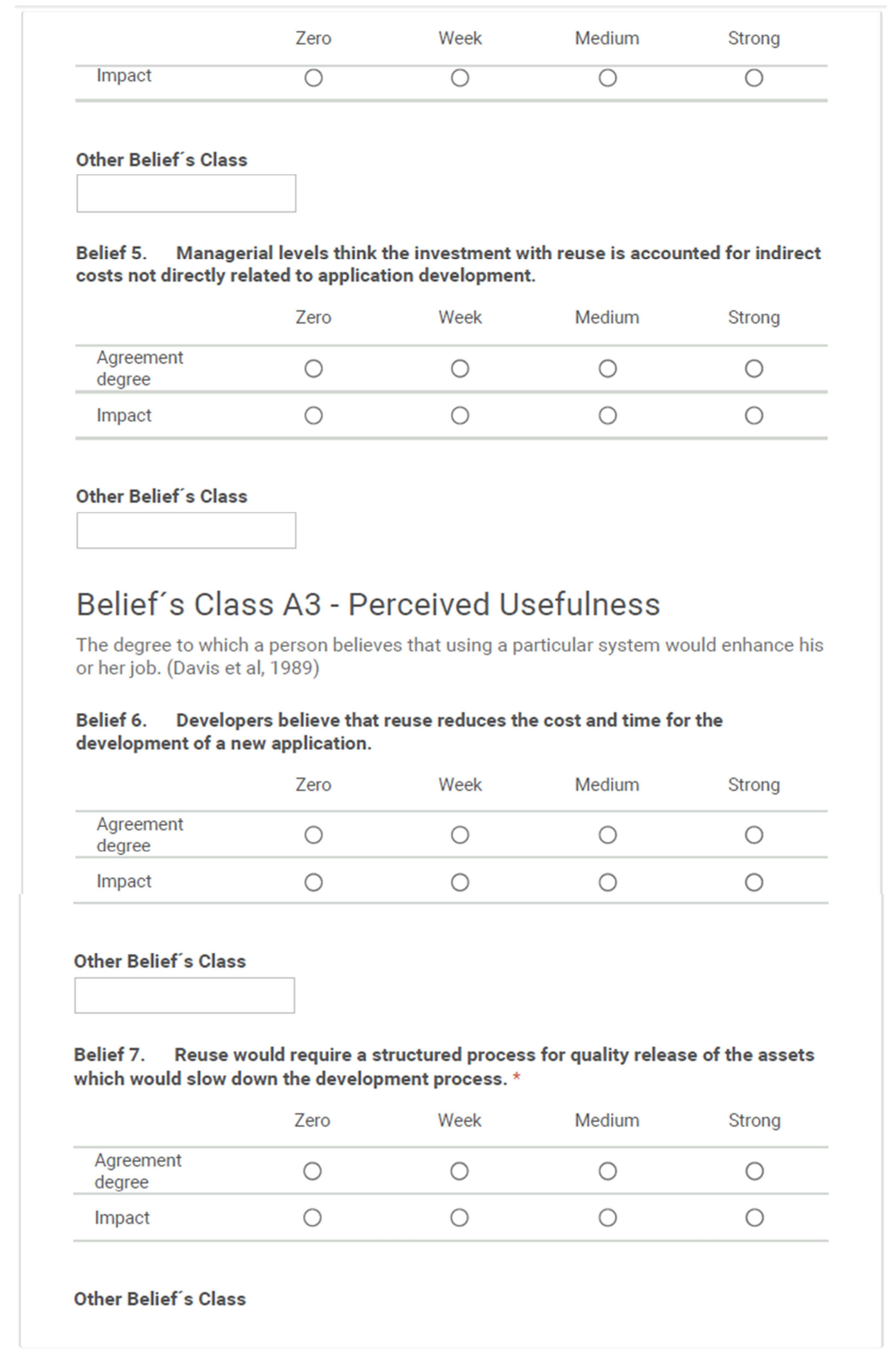


Belief 8. The benefits of reuse will depend on the range of products the asset is planned to assist and the stability of the domains.

\begin{tabular}{lcccc} 
& Zero & Week & Medium & Strong \\
\hline $\begin{array}{l}\text { Agreement } \\
\text { degree }\end{array}$ & $\bigcirc$ & $\bigcirc$ & $\bigcirc$ & $\bigcirc$ \\
\hline Impact & $\bigcirc$ & $\bigcirc$ & $\bigcirc$ & $\bigcirc$ \\
\hline
\end{tabular}

Other Belief's Class

Belief 9. The lack of metrics for reuse makes it difficult to identify costs and benefits.

\begin{tabular}{lcccc} 
& Zero & Week & Medium & Strong \\
\hline $\begin{array}{l}\text { Agreement } \\
\text { degree }\end{array}$ & $\bigcirc$ & $\bigcirc$ & $\bigcirc$ & $\bigcirc$ \\
\hline Impact & $\bigcirc$ & $\bigcirc$ & $\bigcirc$ & $\bigcirc$ \\
\hline
\end{tabular}

Other Belief's Class

Belief 10. Managers react to implementation reuse due to lack of quantitative measures to assess the benefits and costs of their utilization.

\begin{tabular}{lcccc} 
& Zero & Week & Medium & Strong \\
\hline $\begin{array}{l}\text { Agreement } \\
\text { degree }\end{array}$ & $\bigcirc$ & $\bigcirc$ & $\bigcirc$ & $\bigcirc$ \\
\hline Impact & $\bigcirc$ & $\bigcirc$ & $\bigcirc$ & $\bigcirc$ \\
\hline
\end{tabular}

Other Belief's Class

\section{Belief's Class A4 - Perceived Ease of Use}

The degree to which a person believes that using a system would be free of effort. (Davis et al, 1989)

Belief 11. Reuse is difficult to implement in one organization. *

\begin{tabular}{lcccc} 
& Zero & Week & Medium & Strong \\
\hline $\begin{array}{l}\text { Agreement } \\
\text { degree }\end{array}$ & $\bigcirc$ & $\bigcirc$ & $\bigcirc$ & $\bigcirc$
\end{tabular}




\begin{tabular}{ccccc} 
& Zero & Week & Medium & Strong \\
\hline Impact & $\bigcirc$ & $\bigcirc$ & 0 & $\bigcirc$ \\
\hline
\end{tabular}

Other Belief's Class

Belief 12. The use of object orientation facilitates the creation of reusable assets.

\begin{tabular}{lcccc} 
& Zero & Week & Medium & Strong \\
\hline $\begin{array}{l}\text { Agreement } \\
\text { degree }\end{array}$ & $\bigcirc$ & $\bigcirc$ & $\bigcirc$ & $\bigcirc$ \\
\hline Impact & $\bigcirc$ & $\bigcirc$ & $\bigcirc$ & $\bigcirc$ \\
\hline
\end{tabular}

Other Belief's Class

Belief 13. The communication between creators and users of assets facilitates the adoption process.

\begin{tabular}{lcccc} 
& Zero & Week & Medium & Strong \\
\hline $\begin{array}{l}\text { Agreement } \\
\text { degree }\end{array}$ & $\bigcirc$ & $\bigcirc$ & $\bigcirc$ & $\bigcirc$ \\
\hline Impact & $\bigcirc$ & $\bigcirc$ & $\bigcirc$ & $\bigcirc$
\end{tabular}

Other Belief's Class

Belief 14. The cost of developing a reusable asset depends on the technical competence of the staff in the methodology used.

\begin{tabular}{lcccc} 
& Zero & Week & Medium & Strong \\
\hline $\begin{array}{l}\text { Agreement } \\
\text { degree }\end{array}$ & $\bigcirc$ & $\bigcirc$ & $\bigcirc$ & $\bigcirc$ \\
\hline Impact & $\bigcirc$ & $\bigcirc$ & $\bigcirc$ & $\bigcirc$ \\
\hline
\end{tabular}

Other Belief's Class

Belief 15. The cost of developing a reusable asset depends on the quality of the development methodology used.

$\begin{array}{llll}\text { Zero } & \text { Week } & \text { Medium } & \text { Strong }\end{array}$




\begin{tabular}{lcccc} 
& Zero & Week & Medium & Strong \\
\hline $\begin{array}{l}\text { Agreement } \\
\text { degree }\end{array}$ & $\bigcirc$ & $\bigcirc$ & $\bigcirc$ & $\bigcirc$ \\
\hline Impact & $\bigcirc$ & $\bigcirc$ & $\bigcirc$ & $\bigcirc$ \\
\hline
\end{tabular}

Other Belief's Class

Belief 16. Developers believe that reuse increases the quality of a new application.

\begin{tabular}{lcccc} 
& Zero & Week & Medium & Strong \\
\hline $\begin{array}{l}\text { Agreement } \\
\text { degree }\end{array}$ & $\bigcirc$ & $\bigcirc$ & $\bigcirc$ & $\bigcirc$ \\
\hline Impact & $\bigcirc$ & $\bigcirc$ & $\bigcirc$ & $\bigcirc$ \\
\hline
\end{tabular}

\section{Other Belief's Class}

Belief 17. A systematic reuse process increases the developer's productivity.

\begin{tabular}{lcccc} 
& Zero & Week & Medium & Strong \\
\hline $\begin{array}{l}\text { Agreement } \\
\text { degree }\end{array}$ & $\bigcirc$ & $\bigcirc$ & $\bigcirc$ & $\bigcirc$ \\
\hline Impact & $\bigcirc$ & $\bigcirc$ & $\bigcirc$ & $\bigcirc$
\end{tabular}

\section{Other Belief's Class}

\section{Belief's Class A5 - Complexity}

The degree to which a system is perceived as relatively difficult understand. (Thompson et al, 1991)

Belief 18. Building reusable assets and assembling them to build future systems is a complex activity.

\begin{tabular}{lcccc} 
& Zero & Week & Medium & Strong \\
\hline $\begin{array}{l}\text { Agreement } \\
\text { degree }\end{array}$ & $\bigcirc$ & $\bigcirc$ & $\bigcirc$ & $\bigcirc$ \\
\hline Impact & $\bigcirc$ & $\bigcirc$ & $\bigcirc$ & $\bigcirc$ \\
\hline
\end{tabular}

Other Belief's Class 
Belief 19. Reuse technology is complex because it involves the identification, construction, and maintenance of assets availability.

\begin{tabular}{lcccc} 
& Zero & Week & Medium & Strong \\
\hline $\begin{array}{l}\text { Agreement } \\
\text { degree }\end{array}$ & 0 & $\bigcirc$ & 0 & $\bigcirc$ \\
\hline Impact & 0 & 0 & 0 & $\bigcirc$ \\
\hline
\end{tabular}

Other Belief's Class

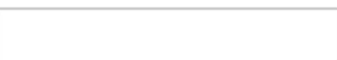

Belief 20. Developers believe that reuse is an opportunistic "hunter/gatherer" process that depends on the cognitive abilities of developers to locate the right domains and components.

\begin{tabular}{lcccc} 
& Zero & Week & Medium & Strong \\
\hline $\begin{array}{l}\text { Agreement } \\
\text { degree }\end{array}$ & $\bigcirc$ & $\bigcirc$ & $\bigcirc$ & $\bigcirc$ \\
\hline Impact & $\bigcirc$ & $\bigcirc$ & $\bigcirc$ & $\bigcirc$ \\
\hline
\end{tabular}

\section{Other Belief's Class}

Belief 21. The use of assets of limited scope or wide scope require excessive effort to adapt to the new context.

\begin{tabular}{lcccc} 
& Zero & Week & Medium & Strong \\
\hline $\begin{array}{l}\text { Agreement } \\
\text { degree }\end{array}$ & $\bigcirc$ & $\bigcirc$ & $\bigcirc$ & $\bigcirc$ \\
\hline Impact & $\bigcirc$ & $\bigcirc$ & $\bigcirc$ & $\bigcirc$ \\
\hline
\end{tabular}

Other Belief's Class

Belief 22. The excess of parameterization of assets requires a high investment in the testing process.

\begin{tabular}{lcccc} 
& Zero & Week & Medium & Strong \\
\hline $\begin{array}{l}\text { Agreement } \\
\text { degree }\end{array}$ & $\bigcirc$ & $\bigcirc$ & $\bigcirc$ & $\bigcirc$ \\
\hline Impact & $\bigcirc$ & $\bigcirc$ & $\bigcirc$ & $\bigcirc$ \\
\hline
\end{tabular}




\section{Belief's Class A6 - Outcome expectations}

Relate to the consequences of the behavior. (Compeau et al., 1995)

Belief 23. Developers suspect of the quality and performance of the assets to be reused.

\begin{tabular}{lcccc} 
& Zero & Week & Medium & Strong \\
\hline $\begin{array}{l}\text { Agreement } \\
\text { degree }\end{array}$ & $\bigcirc$ & $\bigcirc$ & $\bigcirc$ & $\bigcirc$ \\
\hline Impact & $\bigcirc$ & $\bigcirc$ & $\bigcirc$ & $\bigcirc$ \\
\hline
\end{tabular}

\section{Other Belief's Class}

Belief 24. The failure of reusable components to meet the future needs of a domain limits the success of technology adoption.

\begin{tabular}{lcccc} 
& Zero & Week & Medium & Strong \\
\hline $\begin{array}{l}\text { Agreement } \\
\text { degree }\end{array}$ & $\bigcirc$ & $\bigcirc$ & $\bigcirc$ & $\bigcirc$ \\
\hline Impact & $\bigcirc$ & $\bigcirc$ & $\bigcirc$ & $\bigcirc$ \\
\hline
\end{tabular}

\section{Other Belief's Class}

Belief 25. The lack of adequate assets documentation hinders and limits its use in the development process.

\begin{tabular}{lcccc} 
& Zero & Week & Medium & Strong \\
\hline $\begin{array}{l}\text { Agreement } \\
\text { degree }\end{array}$ & $\bigcirc$ & $\bigcirc$ & $\bigcirc$ & $\bigcirc$ \\
\hline Impact & $\bigcirc$ & $\bigcirc$ & $\bigcirc$ & $\bigcirc$
\end{tabular}

Other Belief's Class

Belief 26. Software developer's belief that reuse will inhibit creativity: the "Not Invented Here" syndrome. 


\begin{tabular}{lcccc} 
& Zero & Week & Medium & Strong \\
\hline $\begin{array}{l}\text { Agreement } \\
\text { degree }\end{array}$ & 0 & 0 & 0 & 0 \\
\hline Impact & 0 & 0 & 0 & 0 \\
\hline
\end{tabular}

Other Belief's Class

Belief 27. The evolution of the assets may create problems with older applications that use them.

\begin{tabular}{lcccc} 
& Zero & Week & Medium & Strong \\
\hline $\begin{array}{l}\text { Agreement } \\
\text { degree }\end{array}$ & $\bigcirc$ & $\bigcirc$ & $\bigcirc$ & $\bigcirc$ \\
\hline Impact & $\bigcirc$ & $\bigcirc$ & $\bigcirc$ & $\bigcirc$
\end{tabular}

Other Belief's Class

Belief 28. Architecture of many levels that can be used in different applications is a critical factor for success of reuse implantation.

\begin{tabular}{lcccc} 
& Zero & Week & Medium & Strong \\
\hline $\begin{array}{l}\text { Agreement } \\
\text { degree }\end{array}$ & $\bigcirc$ & $\bigcirc$ & 0 & $\bigcirc$ \\
\hline Impact & 0 & 0 & 0 & 0
\end{tabular}

Other Belief's Class

Belief 29. A Quality Management assets approach has a significant impact on the development process.

\begin{tabular}{lcccc} 
& Zero & Week & Medium & Strong \\
\hline $\begin{array}{l}\text { Agreement } \\
\text { degree }\end{array}$ & $\bigcirc$ & $\bigcirc$ & $\bigcirc$ & $\bigcirc$ \\
\hline Impact & 0 & $\bigcirc$ & $\bigcirc$ & $\bigcirc$
\end{tabular}

Other Belief's Class 
Belief 30. The quality of the assets is important to obtain the desired benefits such as defect/time reduction .

\begin{tabular}{lcccc} 
& Zero & Week & Medium & Strong \\
\hline $\begin{array}{l}\text { Agreement } \\
\text { degree }\end{array}$ & $\bigcirc$ & $\bigcirc$ & $\bigcirc$ & $\bigcirc$ \\
\hline Impact & $\bigcirc$ & $\bigcirc$ & $\bigcirc$ & $\bigcirc$
\end{tabular}

Other Belief's Class

\section{B. Normative beliefs}

People form about individuals or groups important in their lives will approve or disapprove the realization of the behavior. (Fishbein \& Ajzen, 2010)

\section{Belief's Class B1 - Image}

The degree to which use of an innovation is perceived to enhance one's image or status in one's social system. (Moore \& Benbasat,1991)

Belief 31. To develop software with reuse is a positive differential for my company and for me as a professional.

\begin{tabular}{lcccc} 
& Zero & Week & Medium & Strong \\
\hline $\begin{array}{l}\text { Agreement } \\
\text { degree }\end{array}$ & $\bigcirc$ & $\bigcirc$ & $\bigcirc$ & $\bigcirc$ \\
\hline Impact & $\bigcirc$ & $\bigcirc$ & $\bigcirc$ & $\bigcirc$ \\
\hline
\end{tabular}

Other Belief's Class

\section{Belief's Class B2 - Visibility}

The degree to which one can see others using the system in the organization (Moore \& Benbasat, 1991)

Belief 32. Participate in a project with reuse is a positive factor for my work in the company.

\begin{tabular}{lcccc} 
& Zero & Week & Medium & Strong \\
\hline $\begin{array}{l}\text { Agreement } \\
\text { degree }\end{array}$ & $\bigcirc$ & $\bigcirc$ & $\bigcirc$ & $\bigcirc$ \\
\hline Impact & $\bigcirc$ & $\bigcirc$ & $\bigcirc$ & $\bigcirc$ \\
\hline
\end{tabular}




\section{Belief's Class B3 - Voluntariness of use}

The use of the innovation is perceived as being voluntary or of free will (Moore \& Benbasat, 1991)

Belief 33. I use the reuse technology voluntarily in my work.

\begin{tabular}{lcccc} 
& Zero & Week & Medium & Strong \\
\hline $\begin{array}{l}\text { Agreement } \\
\text { degree }\end{array}$ & $\bigcirc$ & $\bigcirc$ & $\bigcirc$ & $\bigcirc$ \\
\hline Impact & $\bigcirc$ & $\bigcirc$ & $\bigcirc$ & $\bigcirc$ \\
\hline
\end{tabular}

Other Belief's Class

\section{Belief's Class B4 - Social Factors}

The individual's internalization of the reference group's subjective culture, and specific interpersonal agreements that the individual has made with others, in specific social situations. (Thompson et al., 1991)

Belief 34. The use of the technology reuse will facilitate my interaction with other technicians within and outside of my company.

\begin{tabular}{lcccc} 
& Zero & Week & Medium & Strong \\
\hline $\begin{array}{l}\text { Agreement } \\
\text { degree }\end{array}$ & $\bigcirc$ & $\bigcirc$ & $\bigcirc$ & $\bigcirc$ \\
\hline Impact & $\bigcirc$ & $\bigcirc$ & $\bigcirc$ & $\bigcirc$
\end{tabular}

Other Belief's Class

\section{Control Beliefs}

People form about the personal and environmental factors that can help or hinder their attempts to perform the behavior. (Fishbein \& Ajzen, 2010)

\section{Belief's Class C1 - Compatibility}

The degree to which an innovation is perceived as being consistent with the existing values, needs, and past experiences of potential adopters. (Moore \& Benbasat, 1991)

Belief 35. The reuse activities have incompatibility with the methodology of software development organizations. 


\begin{tabular}{lcccc} 
& Zero & Week & Medium & Strong \\
\hline $\begin{array}{l}\text { Agreement } \\
\text { degree }\end{array}$ & $\bigcirc$ & $\bigcirc$ & $\bigcirc$ & $\bigcirc$ \\
\hline Impact & $\bigcirc$ & $\bigcirc$ & $\bigcirc$ & $\bigcirc$ \\
\hline
\end{tabular}

Other Belief's Class

Belief 36. The use of asset repository when it is not considered a critical factor of success generates dissatisfaction with the use of technology reuse.

\begin{tabular}{lcccc} 
& Zero & Week & Medium & Strong \\
\hline $\begin{array}{l}\text { Agreement } \\
\text { degree }\end{array}$ & $\bigcirc$ & $\bigcirc$ & $\bigcirc$ & $\bigcirc$ \\
\hline Impact & $\bigcirc$ & $\bigcirc$ & $\bigcirc$ & $\bigcirc$ \\
\hline
\end{tabular}

\section{Other Belief's Class}

Belief 37. Elements such as the organizational structure of the reuse group and their way to work hinder the deployment of technology reuse.

\begin{tabular}{lcccc} 
& Zero & Week & Medium & Strong \\
\hline $\begin{array}{l}\text { Agreement } \\
\text { degree }\end{array}$ & $\bigcirc$ & $\bigcirc$ & $\bigcirc$ & $\bigcirc$ \\
\hline Impact & $\bigcirc$ & $\bigcirc$ & $\bigcirc$ & $\bigcirc$ \\
\hline
\end{tabular}

\section{Other Belief's Class}

Belief 38. The lack of an educational and training/mentoring program is a complicating factor for reuse.

\begin{tabular}{lcccc} 
& Zero & Week & Medium & Strong \\
\hline $\begin{array}{l}\text { Agreement } \\
\text { degree }\end{array}$ & $\bigcirc$ & $\bigcirc$ & $\bigcirc$ & $\bigcirc$ \\
\hline Impact & $\bigcirc$ & $\bigcirc$ & $\bigcirc$ & $\bigcirc$ \\
\hline
\end{tabular}

\section{Other Belief's Class}


Belief 39. The organization is resistant to a structure required to support the reuse technology which makes the adoption process very hard.

\begin{tabular}{lcccc} 
& Zero & Week & Medium & Strong \\
\hline $\begin{array}{l}\text { Agreement } \\
\text { degree }\end{array}$ & $\bigcirc$ & $\bigcirc$ & $\bigcirc$ & $\bigcirc$ \\
\hline Impact & $\bigcirc$ & $\bigcirc$ & $\bigcirc$ & $\bigcirc$
\end{tabular}

Other Belief's Class

Belief 40. Managerial difficulty to allocate the necessary resources to implement the necessary infrastructure is an obstacle for adoption of reuse.

\begin{tabular}{lcccc} 
& Zero & Week & Medium & Strong \\
\hline $\begin{array}{l}\text { Agreement } \\
\text { degree }\end{array}$ & $\bigcirc$ & $\bigcirc$ & $\bigcirc$ & $\bigcirc$ \\
\hline Impact & $\bigcirc$ & $\bigcirc$ & $\bigcirc$ & $\bigcirc$
\end{tabular}

Other Belief's Class

\section{Belief's Class C2 - Facilitating Conditions}

Objective factors in the environment that observers agree make an act easy to accomplish. (Thompson et al., 1991)

Belief 41. Difficulty to locate reusable assets affects deployment.

\begin{tabular}{lcccc} 
& Zero & Week & Medium & Strong \\
\hline $\begin{array}{l}\text { Agreement } \\
\text { degree }\end{array}$ & $\bigcirc$ & $\bigcirc$ & $\bigcirc$ & $\bigcirc$ \\
\hline Impact & $\bigcirc$ & $\bigcirc$ & $\bigcirc$ & $\bigcirc$ \\
\hline
\end{tabular}

Other Belief's Class

Belief 42. The lack of funding to allocate to staff for the development of reusable assets hinders adoption.

\begin{tabular}{lcccc} 
& Zero & Week & Medium & Strong \\
\hline $\begin{array}{l}\text { Agreement } \\
\text { degree }\end{array}$ & $\bigcirc$ & $\bigcirc$ & $\bigcirc$ & $\bigcirc$ \\
\hline Impact & $\bigcirc$ & $\bigcirc$ & $\bigcirc$ & $\bigcirc$
\end{tabular}


Other Belief's Class

Belief 43. The quality model usage has a strong influence on reuse success.

\begin{tabular}{lcccc} 
& Zero & Week & Medium & Strong \\
\hline $\begin{array}{l}\text { Agreement } \\
\text { degree }\end{array}$ & $\bigcirc$ & $\bigcirc$ & $\bigcirc$ & $\bigcirc$ \\
\hline Impact & $\bigcirc$ & $\bigcirc$ & $\bigcirc$ & $\bigcirc$
\end{tabular}

Other Belief's Class

Belief 44. A repository of assets disintegrated from the development environment significantly complicates the process of reuse.

\begin{tabular}{lcccc} 
& Zero & Week & Medium & Strong \\
\hline $\begin{array}{l}\text { Agreement } \\
\text { degree }\end{array}$ & $\bigcirc$ & $\bigcirc$ & $\bigcirc$ & $\bigcirc$ \\
\hline Impact & $\bigcirc$ & $\bigcirc$ & $\bigcirc$ & $\bigcirc$
\end{tabular}

Other Belief's Class

Belief 45. The availability of technician's talented creators of assets facilitates the adoption process.

\begin{tabular}{lcccc} 
& Zero & Week & Medium & Strong \\
\hline $\begin{array}{l}\text { Agreement } \\
\text { degree }\end{array}$ & $\bigcirc$ & $\bigcirc$ & $\bigcirc$ & $\bigcirc$ \\
\hline Impact & $\bigcirc$ & $\bigcirc$ & $\bigcirc$ & $\bigcirc$ \\
\hline
\end{tabular}

Other Belief's Class

Belief 46. A pilot project success with metrics stimulates the adoption of reuse in the organization.

\begin{tabular}{lcccc} 
& Zero & Week & Medium & Strong \\
\hline $\begin{array}{l}\text { Agreement } \\
\text { degree }\end{array}$ & $\bigcirc$ & $\bigcirc$ & $\bigcirc$ & $\bigcirc$ \\
\hline Impact & $\bigcirc$ & $\bigcirc$ & $\bigcirc$ & $\bigcirc$ \\
\hline
\end{tabular}


Other Belief's Class

Belief 47. The lack of a well-organized and indexed software repository with appropriate search engines is a barrier to reuse adoption.

\begin{tabular}{lcccc} 
& Zero & Week & Medium & Strong \\
\hline $\begin{array}{l}\text { Agreement } \\
\text { degree }\end{array}$ & $\bigcirc$ & $\bigcirc$ & $\bigcirc$ & $\bigcirc$ \\
\hline Impact & $\bigcirc$ & $\bigcirc$ & $\bigcirc$ & $\bigcirc$ \\
\hline
\end{tabular}

Other Belief's Class

Belief 48. A independent reusable assets development team has an influence on reuse success.

\begin{tabular}{lcccc} 
& Zero & Week & Medium & Strong \\
\hline $\begin{array}{l}\text { Agreement } \\
\text { degree }\end{array}$ & $\bigcirc$ & $\bigcirc$ & $\bigcirc$ & $\bigcirc$ \\
\hline Impact & $\bigcirc$ & $\bigcirc$ & $\bigcirc$ & $\bigcirc$ \\
\hline
\end{tabular}

Other Belief's Class

Belief 49. Lack of experience of the technicians to analyze and design solutions for a range of applications of a specific domain rather than only one, hinders the adoption of reuse.

\begin{tabular}{lcccc} 
& Zero & Week & Medium & Strong \\
\hline $\begin{array}{l}\text { Agreement } \\
\text { degree }\end{array}$ & $\bigcirc$ & $\bigcirc$ & $\bigcirc$ & $\bigcirc$ \\
\hline Impact & $\bigcirc$ & $\bigcirc$ & $\bigcirc$ & $\bigcirc$ \\
\hline
\end{tabular}

Other Belief's Class

Belief 50. The use of automated tools is important for reuse adoption.

\begin{tabular}{lcccc} 
& Zero & Week & Medium & Strong \\
\hline $\begin{array}{l}\text { Agreement } \\
\text { degree }\end{array}$ & $\bigcirc$ & $\bigcirc$ & $\bigcirc$ & $\bigcirc$ \\
\hline Impact & $\bigcirc$ & $\bigcirc$ & $\bigcirc$ & $\bigcirc$
\end{tabular}


Belief 51. Organizations that develop software based on a product family have advantages when compared to the software organizations that develop isolated products.

\begin{tabular}{lcccc} 
& Zero & Week & Medium & Strong \\
\hline $\begin{array}{l}\text { Agreement } \\
\text { degree }\end{array}$ & $\bigcirc$ & $\bigcirc$ & $\bigcirc$ & $\bigcirc$ \\
\hline Impact & $\bigcirc$ & $\bigcirc$ & $\bigcirc$ & $\bigcirc$
\end{tabular}

\section{Other Belief's Class}

Belief 52. Reusing assets extracted from existing products is the best way for success in reuse adoption.

\begin{tabular}{lcccc} 
& Zero & Week & Medium & Strong \\
\hline $\begin{array}{l}\text { Agreement } \\
\text { degree }\end{array}$ & $\bigcirc$ & $\bigcirc$ & $\bigcirc$ & $\bigcirc$ \\
\hline Impact & $\bigcirc$ & $\bigcirc$ & $\bigcirc$ & $\bigcirc$
\end{tabular}

\section{Other Belief's Class}

Belief 53. Configuration management is an essential element for a reuse program.

\begin{tabular}{lcccc} 
& Zero & Week & Medium & Strong \\
\hline $\begin{array}{l}\text { Agreement } \\
\text { degree }\end{array}$ & $\bigcirc$ & $\bigcirc$ & $\bigcirc$ & $\bigcirc$ \\
\hline Impact & $\bigcirc$ & $\bigcirc$ & $\bigcirc$ & $\bigcirc$ \\
\hline
\end{tabular}

Other Belief's Class

Belief 54. Measuring the level of reuse in software is important for each adoption of reuse.

\begin{tabular}{lcccc} 
& Zero & Week & Medium & Strong \\
\hline $\begin{array}{l}\text { Agreement } \\
\text { degree }\end{array}$ & $\bigcirc$ & $\bigcirc$ & $\bigcirc$ & $\bigcirc$ \\
\hline Impact & $\bigcirc$ & $\bigcirc$ & $\bigcirc$ & $\bigcirc$
\end{tabular}


Other Belief's Class

Belief 55. Measurement of the reuse levels should show return on investment.

\begin{tabular}{lcccc} 
& Zero & Week & Medium & Strong \\
\hline $\begin{array}{l}\text { Agreement } \\
\text { degree }\end{array}$ & $\bigcirc$ & $\bigcirc$ & $\bigcirc$ & $\bigcirc$ \\
\hline Impact & $\bigcirc$ & $\bigcirc$ & $\bigcirc$ & $\bigcirc$
\end{tabular}

Other Belief's Class

Belief 56. The previous development of reusable assets is important for the reuse process.

\begin{tabular}{lcccc} 
& Zero & Week & Medium & Strong \\
\hline $\begin{array}{l}\text { Agreement } \\
\text { degree }\end{array}$ & $\bigcirc$ & $\bigcirc$ & $\bigcirc$ & $\bigcirc$ \\
\hline Impact & $\bigcirc$ & $\bigcirc$ & $\bigcirc$ & $\bigcirc$
\end{tabular}

Other Belief's Class

Belief 57. Reuse has to be adopted in a bottom-up approach to be effective.

\begin{tabular}{lcccc} 
& Zero & Week & Medium & Strong \\
\hline $\begin{array}{l}\text { Agreement } \\
\text { degree }\end{array}$ & $\bigcirc$ & 0 & 0 & $\bigcirc$ \\
\hline Impact & 0 & 0 & 0 & $\bigcirc$
\end{tabular}

Other Belief's Class

Belief 58. The principal focus of developers is in projects not in reuse.

\begin{tabular}{lcccc} 
& Zero & Week & Medium & Strong \\
\hline $\begin{array}{l}\text { Agreement } \\
\text { degree }\end{array}$ & $\bigcirc$ & $\bigcirc$ & $\bigcirc$ & $\bigcirc$ \\
\hline Impact & $\bigcirc$ & $\bigcirc$ & $\bigcirc$ & $\bigcirc$ \\
\hline
\end{tabular}

Other Belief's Class 
Belief 59. A lack of a structured methodology to adoption is a bad factor for the process.

\begin{tabular}{lcccc} 
& Zero & Week & Medium & Strong \\
\hline $\begin{array}{l}\text { Agreement } \\
\text { degree }\end{array}$ & $\bigcirc$ & $\bigcirc$ & $\bigcirc$ & $\bigcirc$ \\
\hline Impact & $\bigcirc$ & $\bigcirc$ & 0 & $\bigcirc$ \\
\hline
\end{tabular}

Other Belief's Class

\section{Self-efficacy beliefs}

The ability of people to produce certain levels of performance. (Bandura, 1991).

\section{Belief's Class D1 - Ability and Skill}

Judgment of one's ability to use a technology to accomplish a particular job or task. (Compeau et al., 1995)

Belief 60 . Reuse education isn't common.

\begin{tabular}{lcccc} 
& Zero & Week & Medium & Strong \\
\hline $\begin{array}{l}\text { Agreement } \\
\text { degree }\end{array}$ & $\bigcirc$ & $\bigcirc$ & $\bigcirc$ & $\bigcirc$ \\
\hline Impact & $\bigcirc$ & $\bigcirc$ & $\bigcirc$ & $\bigcirc$ \\
\hline
\end{tabular}

Other Belief's Class

Belief 61. Developers use reuse individually or informally in a common way.

\begin{tabular}{lcccc} 
& Zero & Week & Medium & Strong \\
\hline $\begin{array}{l}\text { Agreement } \\
\text { degree }\end{array}$ & $\bigcirc$ & $\bigcirc$ & $\bigcirc$ & $\bigcirc$ \\
\hline Impact & $\bigcirc$ & $\bigcirc$ & $\bigcirc$ & $\bigcirc$ \\
\hline
\end{tabular}

Other Belief's Class

Belief 62. Technicians use reuse without specific training. 


\begin{tabular}{lcccc} 
& Zero & Week & Medium & Strong \\
\hline $\begin{array}{l}\text { Agreement } \\
\text { degree }\end{array}$ & $\bigcirc$ & $\bigcirc$ & $\bigcirc$ & $\bigcirc$ \\
\hline Impact & $\bigcirc$ & $\bigcirc$ & $\bigcirc$ & $\bigcirc$ \\
\hline
\end{tabular}

Other Belief'sclass

\section{Belief's Class D2 - Past experience}

Capacity to handle similar problems successfully

Belief 63 . To have previous reuse experience is not necessary.

\begin{tabular}{lcccc} 
& Zero & Week & Medium & Strong \\
\hline $\begin{array}{l}\text { Agreement } \\
\text { degree }\end{array}$ & $\bigcirc$ & $\bigcirc$ & $\bigcirc$ & $\bigcirc$ \\
\hline Impact & $\bigcirc$ & $\bigcirc$ & $\bigcirc$ & $\bigcirc$
\end{tabular}

Other Belief's Class

Belief 64. To have used a structured software development process is a success factor for reuse use.

\begin{tabular}{lcccc} 
& Zero & Week & Medium & Strong \\
\hline $\begin{array}{l}\text { Agreement } \\
\text { degree }\end{array}$ & 0 & 0 & $\bigcirc$ & $\bigcirc$ \\
\hline Impact & 0 & $\bigcirc$ & $\bigcirc$ & $\bigcirc$ \\
\hline
\end{tabular}

Other Belief's Class

Belief 65 . The use of object orientation is important for the adoption of reuse.

\begin{tabular}{lcccc} 
& Zero & Week & Medium & Strong \\
\hline $\begin{array}{l}\text { Agreement } \\
\text { degree }\end{array}$ & $\bigcirc$ & $\bigcirc$ & $\bigcirc$ & $\bigcirc$ \\
\hline Impact & $\bigcirc$ & $\bigcirc$ & $\bigcirc$ & $\bigcirc$
\end{tabular}

Other Belief's Class 
Belief 66. Reuse portions of code is a good practice.

\begin{tabular}{lcccc} 
& Zero & Week & Medium & Strong \\
\hline $\begin{array}{l}\text { Agreement } \\
\text { degree }\end{array}$ & $\bigcirc$ & $\bigcirc$ & $\bigcirc$ & $\bigcirc$ \\
\hline Impact & $\bigcirc$ & $\bigcirc$ & $\bigcirc$ & $\bigcirc$ \\
\hline
\end{tabular}

Other Belief's Class

Belief 67 . The use of ready-made components has facilitated my work.

\begin{tabular}{lcccc} 
& Zero & Week & Medium & Strong \\
\hline $\begin{array}{l}\text { Agreement } \\
\text { degree }\end{array}$ & $\bigcirc$ & $\bigcirc$ & $\bigcirc$ & $\bigcirc$ \\
\hline Impact & $\bigcirc$ & $\bigcirc$ & $\bigcirc$ & $\bigcirc$ \\
\hline
\end{tabular}

Other Belief's Class

Belief 68 . I had troubles using third party software.

\begin{tabular}{lcccc} 
& Zero & Week & Medium & Strong \\
\hline $\begin{array}{l}\text { Agreement } \\
\text { degree }\end{array}$ & $\bigcirc$ & $\bigcirc$ & $\bigcirc$ & $\bigcirc$ \\
\hline Impact & $\bigcirc$ & $\bigcirc$ & $\bigcirc$ & $\bigcirc$ \\
\hline
\end{tabular}

\section{Other Belief's Class}

Others Beliefs Sugested

Belief - Belief's Class - Agreement degree - Impact

Submit

Never submit passwords through Google Forms. 


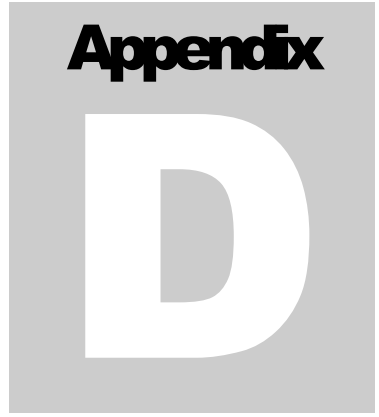

This appendix presents the tabulation of the answers of the questionnaire sent to the experts by Google form.

\section{TABULATION OF THE EXPERT OPINION}


Tabulation of Research interviews

\begin{tabular}{|c|c|c|c|c|c|c|c|c|}
\hline & \multicolumn{3}{|c|}{ Agreement degree } & & \multicolumn{2}{|c|}{ Impact } & & \\
\hline & Zero & Weak & Medium & Strong & Zero & Weak & Medium & Strong \\
\hline \multicolumn{9}{|l|}{ A. Behavioral beliefs } \\
\hline \multicolumn{9}{|l|}{ Technology Maturity } \\
\hline 1. The reuse technology is mature. & & & 3 & 2 & & & 1 & 4 \\
\hline $\begin{array}{l}\text { 2. The reuse technology has a well-defined } \\
\text { development methodology of assets. }\end{array}$ & & & 4 & 1 & & & 1 & 4 \\
\hline \multicolumn{9}{|l|}{ Relative Advantage } \\
\hline $\begin{array}{l}\text { 3. Reuse promises a quick time to market and a } \\
\text { reduction in cost. }\end{array}$ & & & 3 & 2 & & & & 3 \\
\hline $\begin{array}{l}\text { 4. The cost of adoption of reuse technology is } \\
\text { described as very high without significant short- } \\
\text { term returns. }\end{array}$ & & 2 & 2 & 1 & & 1 & 2 & 2 \\
\hline $\begin{array}{l}\text { 5. Managerial levels think the investment with } \\
\text { reuse is accounted for indirect costs not directly } \\
\text { related to application development. }\end{array}$ & & 2 & 2 & 1 & 1 & & 3 & 1 \\
\hline \multicolumn{9}{|l|}{ Perceived Usefulness } \\
\hline $\begin{array}{l}\text { cost and time for the development of a new } \\
\text { application. }\end{array}$ & & & 1 & 4 & & & 3 & 2 \\
\hline $\begin{array}{l}\text { 7. Reuse would require a structured process for } \\
\text { quality release of the assets which would slow } \\
\text { down the development process. }\end{array}$ & 1 & 1 & 2 & 1 & 1 & & 2 & 2 \\
\hline $\begin{array}{l}\text { 8. The benefits of reuse will depend on the } \\
\text { range of products the asset is planned to assist } \\
\text { and the stability of the domains. }\end{array}$ & & & & 5 & & & & 5 \\
\hline $\begin{array}{l}\text { 9. The lack of metrics for reuse makes it } \\
\text { difficult to identify costs and benefits. }\end{array}$ & 1 & & 2 & 2 & & 1 & 1 & 3 \\
\hline $\begin{array}{l}\text { 10. Managers react to implementation reuse } \\
\text { due to lack of quantitative measures to assess the } \\
\text { benefits and costs of their utilization. }\end{array}$ & 1 & & 2 & 2 & 1 & & 2 & 2 \\
\hline
\end{tabular}




\begin{tabular}{|c|c|c|c|c|c|c|c|}
\hline Perceived Ease of Use & Zero Weak & Mediuns & Strong & Zero & Weak & Medium & Strong \\
\hline $\begin{array}{l}\text { Reuse is difficult to implement in an } \\
\text { organization. }\end{array}$ & & 3 & 2 & & & 2 & 3 \\
\hline $\begin{array}{l}\text { 12. The use of object orientation facilitates the } \\
\text { creation of reusable assets. }\end{array}$ & 2 & 3 & & & 4 & & 1 \\
\hline $\begin{array}{l}\text { 13. The communication between creators and } \\
\text { users of assets facilitates the adoption process. }\end{array}$ & & 2 & 3 & 1 & 1 & & 3 \\
\hline $\begin{array}{l}\text { 14. The cost of developing a reusable asset } \\
\text { depends on the technical competence of the staff } \\
\text { in the methodology used. }\end{array}$ & & 1 & 4 & & 1 & 1 & 3 \\
\hline $\begin{array}{l}\text { 15. The cost of developing a reusable asset } \\
\text { depends on the quality of the development } \\
\text { methodology used. }\end{array}$ & & 1. & 4 & & & 3 & 2 \\
\hline $\begin{array}{l}\text { 16. Developers believe that reuse increases the } \\
\text { quality of a new application. }\end{array}$ & 1 & 2 & 2 & & & 3 & 2 \\
\hline $\begin{array}{l}\text { 17. A systematic reuse process increases the } \\
\text { developer's productivity. }\end{array}$ & & 2 & 3 & & & 1 & 4 \\
\hline \multicolumn{8}{|l|}{ Complexity } \\
\hline $\begin{array}{l}\text { 18. Buldong reusable assets and assembling } \\
\text { them to build future systems is an complex } \\
\text { totivitu. }\end{array}$ & 1 & 1 & 3 & & & 2 & 3 \\
\hline $\begin{array}{l}\text { 19. Reuse technology is complex because it } \\
\text { involves the identification, construction, and } \\
\text { maintenance of assets availability. }\end{array}$ & 1 & 2 & 2 & & & 2 & 3 \\
\hline $\begin{array}{l}\text { 20. Developers believe that reuse is an } \\
\text { opportunistic "hunter/gatherer" process that } \\
\text { depends on the cognitive abilities of developers to } \\
\text { locate the right domains and components. }\end{array}$ & 1 & 3 & 1 & & & 3 & 2 \\
\hline $\begin{array}{l}21 . \quad \text { The use of assets of limited scope or wide } \\
\text { scope require excessive effort to adapt to the new } \\
\text { context. }\end{array}$ & & 5 & & & 1 & 3 & 1 \\
\hline $\begin{array}{l}\text { 22. The excess of parameterization of assets } \\
\text { requires a high investment in the testing process. }\end{array}$ & 2 & 2 & 1 & & 3 & & 2 \\
\hline \multicolumn{8}{|l|}{ Outcome expectations } \\
\hline $\begin{array}{l}\text { 23. Developers are wary of quality and } \\
\text { performance of the assets to be reused. }\end{array}$ & 2 & 2 & 1 & & 2 & 1 & 2 \\
\hline $\begin{array}{l}\text { 24. The failure of reusable components to meet } \\
\text { the future needs of a domain limits the success of } \\
\text { technology adoption. }\end{array}$ & 1 & & 4 & 1 & & 1 & 3 \\
\hline $\begin{array}{l}\text { 25. The lack of adequate assets documentation } \\
\text { hinders and limits its use in the development } \\
\text { process. }\end{array}$ & 1 & 2 & 2 & & 2 & 2 & 1 \\
\hline $\begin{array}{l}\text { 26. Software developer's belief that reuse will } \\
\text { inhibit creativity: the "Not Invented Here" } \\
\text { svndrome. }\end{array}$ & 2 & 1 & 2 & & 2 & 2 & 1 \\
\hline $\begin{array}{l}\text { 27. The evolution of the assets may create } \\
\text { problems with older applications that use them. }\end{array}$ & 1 & 3 & 1 & 1 & & 3 & 1 \\
\hline
\end{tabular}




\begin{tabular}{|c|c|c|c|c|c|c|c|c|}
\hline $\begin{array}{l}\text { 28. Architecture of many levels that can be used } \\
\text { in different applications is a critical factor for } \\
\text { success of reuse implantation. }\end{array}$ & & & 3 & 2 & & 1 & 2 & 2 \\
\hline $\begin{array}{l}\text { 29. A Quality Management assets approach has } \\
\text { a significant impact on the development process. }\end{array}$ & & 1 & 2 & 2 & & 1 & 2 & 2 \\
\hline $\begin{array}{l}30 . \quad \text { The quality of the assets is important to } \\
\text { obtain the desired benefits such as defect/time } \\
\text { reduction. }\end{array}$ & & & 2 & 3 & & & & 5 \\
\hline B. Normative beliefs & Zero & Weak & Medium & Strong & Zero & Weak & Medium & Strong \\
\hline Image & & & & & & & & \\
\hline $\begin{array}{l}\text { differential for my company and for me as a } \\
\text { professional. }\end{array}$ & & 1 & 2 & 2 & & 2 & 1 & 2 \\
\hline Visibility & & & & & & & & \\
\hline $\begin{array}{l}\text { 32.To participate in a project with reuse is a } \\
\text { positive factor for my work in the company. }\end{array}$ & & 1 & 1 & 3 & & 3 & & 2 \\
\hline Voluntariness of use & & & & & & & & \\
\hline $\begin{array}{l}\text { 33. I use the reuse technology voluntarily in my } \\
\text { work. }\end{array}$ & & 1 & 2 & 2 & & 1 & 1 & 3 \\
\hline Social Factors & & & & & & & & \\
\hline $\begin{array}{l}\text { 34. The use of the technology reuse will facilitate } \\
\text { my interaction with other technicians within and } \\
\text { outside of my company. }\end{array}$ & & 3 & 1 & 1 & 1 & 2 & & 2 \\
\hline C. Control Beliefs & & & & & & & & \\
\hline Compatibility & & & & & & & & \\
\hline $\begin{array}{l}35 . \quad \text { The reuse activities have incompatibility } \\
\text { with the methodology of software development } \\
\text { organizations. }\end{array}$ & 1 & 2 & 2 & & 1 & 1 & 1 & 2 \\
\hline $\begin{array}{l}\text { 36. The use of asset repository when it is not } \\
\text { considered a critical factor of success breeds } \\
\text { dissatisfaction with the use of technology reuse. }\end{array}$ & & 3 & 1 & 1 & 1 & 1 & 2 & 1 \\
\hline $\begin{array}{l}\text { 37. Elements such as the organizational } \\
\text { structure of the reuse group and their way to work } \\
\text { hinder the deployment of technology reuse. }\end{array}$ & & 1 & 2 & 2 & & 1 & 3 & 1 \\
\hline $\begin{array}{l}\text { 38. The lack of an educational and } \\
\text { training/mentoring program is a complicating } \\
\text { factor for reuse. }\end{array}$ & & 2 & 1 & 2 & & 2 & & 3 \\
\hline $\begin{array}{l}\text { 39. The organization is resistant to a structure } \\
\text { required to support the reuse technology which } \\
\text { makes the adoption process very hard. }\end{array}$ & & 2 & 3 & & & 2 & 2 & 1 \\
\hline $\begin{array}{l}40 . \quad \text { Managerial difficulty to allocate the } \\
\text { necessary resources to implement the necessary } \\
\text { infrastructure is an obstacle for adoption of } \\
\text { reuse. }\end{array}$ & & 1 & 2 & 2 & & 1 & 2 & 2 \\
\hline
\end{tabular}




\begin{tabular}{|c|c|c|c|c|c|c|c|c|}
\hline Facilitating Conditions & Zero & Weak & Medium & Strong & Zero & Weak & Medium & Strong \\
\hline $\begin{array}{l}41 . \quad \text { Difficulty to locate reusable assets affects } \\
\text { deployment. }\end{array}$ & & & 2 & 3 & & & 1 & \\
\hline $\begin{array}{l}\text { 42. The lack of funding to allocate to staff for } \\
\text { the development of reusable assets hinders } \\
\text { adoption. }\end{array}$ & & & 2 & 3 & & 1 & 1 & 3 \\
\hline $\begin{array}{l}\text { 43. The quality model usage has a strong } \\
\text { influence on reuse success. }\end{array}$ & & 2 & 3 & & 1 & 1 & 1 & 2 \\
\hline $\begin{array}{l}\text { 44. A repository of assets disintegrated from } \\
\text { the development environment significantly } \\
\text { complicates the process of reuse. }\end{array}$ & & 1 & 4 & & & 2 & 2 & 1 \\
\hline creators of assets facilitates the adoption & & & 2 & 3 & & & 2 & 3 \\
\hline $\begin{array}{l}46 . \quad \text { A pilot project success with metrics } \\
\text { stimulates the adoption of reuse in the } \\
\text { organization }\end{array}$ & & & 2 & 3 & & 1 & 4 & \\
\hline $\begin{array}{l}\text { 47. The lack of a well-organized and indexed } \\
\text { software repository with appropriate search } \\
\text { engines is a barrier to reuse adoption. }\end{array}$ & & 3 & 1 & 1 & & 2 & 2 & 1 \\
\hline $\begin{array}{l}\text { 48. Independent reusable assets development } \\
\text { team has an influence on reuse success. }\end{array}$ & & 3 & 1 & 1 & 1 & 1 & 2 & 1 \\
\hline $\begin{array}{l}49 \text {. Lack of experience of the technicians to } \\
\text { analyze and design solutions for a range of } \\
\text { applications of a specific domain rather than only } \\
\text { one, hinders the adoption of reuse. }\end{array}$ & & 1 & 2 & 2 & & 2 & & 3 \\
\hline $\begin{array}{l}\text { 50. The use of automated tools is important for } \\
\text { reuse adoption. }\end{array}$ & 1 & 1 & 3 & & 2 & & 1 & 2 \\
\hline $\begin{array}{l}\text { 51. Organizations that develop software based on } \\
\text { a product family have advantages when compared } \\
\text { to the software organizations that develop } \\
\text { isolated products. }\end{array}$ & & & 1 & 4 & 1 & & 1 & \\
\hline $\begin{array}{l}\text { 52. Reusing assets extracted from existing } \\
\text { products is the best way for success in reuse } \\
\text { adoption. }\end{array}$ & & 1 & 4 & & & & 4 & 1 \\
\hline $\begin{array}{l}\text { 53. Configuration management is an essential } \\
\text { element for a reuse program. }\end{array}$ & & & & 5 & & & 1 & \\
\hline $\begin{array}{l}\text { 54. Measuring the level of reuse in software is } \\
\text { important for each adoption of reuse. }\end{array}$ & & & 2 & 3 & & 1 & 1 & 3 \\
\hline $\begin{array}{l}\text { 55. Measurement of the reuse levels should show } \\
\text { return on investment. }\end{array}$ & & 1 & & 4 & & & 2 & 3 \\
\hline $\begin{array}{l}\text { 56. The previous development of reusable assets } \\
\text { is important for the process of reuse. }\end{array}$ & & 1 & 2 & 2 & & 1 & 2 & 2 \\
\hline $\begin{array}{l}\text { 57. Reuse has to be adopted in a bottom-up } \\
\text { approach to be effective. }\end{array}$ & & 3 & 2 & & 1 & 2 & 2 & \\
\hline $\begin{array}{l}\text { 58. The principal focus of developers are in } \\
\text { projects not in reuse. }\end{array}$ & & 1 & & 4 & & 2 & 1 & 4 \\
\hline $\begin{array}{l}\text { 59. A lack of a structured method } \\
\text { adoption is a bad factor for the process. }\end{array}$ & & 1 & & 1 & & 3 & & \\
\hline
\end{tabular}




\begin{tabular}{|c|c|c|c|c|c|c|c|c|}
\hline D. Self-efficacy beliefs & Zero & Weak & Mediun & Strong & Zero & Weak & Medium & Strong \\
\hline Ability and Skil & & & & & & & & \\
\hline 60. Reuse education isn't common. & & & 2 & 3 & & 2 & 1 & 2 \\
\hline $\begin{array}{l}\text { 61. Developers use reuse individually or } \\
\text { informally in a common way. }\end{array}$ & & 1 & 1 & 3 & & & 3 & 2 \\
\hline $\begin{array}{l}\text { 62. Technicians use reuse without specific } \\
\text { training. }\end{array}$ & & 1 & 2 & 2 & & & 2 & 3 \\
\hline $\begin{array}{l}\text { Past experience- capacity to handle similar } \\
\text { problems successfully }\end{array}$ & & & & & & & & \\
\hline $\begin{array}{l}\text { 63. To have previous reuse experience is not } \\
\text { necessary. }\end{array}$ & & 3 & 1 & 1 & & 2 & 2 & 1 \\
\hline $\begin{array}{l}\text { 64. To have used a structured software } \\
\text { development process is a success factor for reuse }\end{array}$ & & 1 & 3 & 1 & & 2 & 1 & 2 \\
\hline $\begin{array}{l}\text { 65. The use of object orientation is important for the } \\
\text { adoption of reuse. }\end{array}$ & & 4 & 1 & & 2 & 1 & 1 & 1 \\
\hline 66. Reuse portions of code is a good practice. & 1 & 3 & 1 & & & 1 & 1 & 3 \\
\hline $\begin{array}{l}\text { 67. The use of ready-made components has } \\
\text { facilitated my work. }\end{array}$ & & & 3 & 2 & & 1 & & 4 \\
\hline 68. I had troubles using third party software. & & 3 & 1 & 1 & & 2 & 2 & 1 \\
\hline
\end{tabular}

